KfK 4648

November 1989

\title{
Engineering Components Grow like Trees
}

C. Mattheck

Institut für Material- und Festkörperforschung

\section{Kernforschungszentrum Karlsruhe}





\section{KERNFORSCHUNGSZENTRUM KARLSRUHE}

Institut für Material- und Festkörperforschung

KfK 4648

\section{ENGINEERING COMPONENTS \\ GROW LIKE TREES}

C. MATTHECK

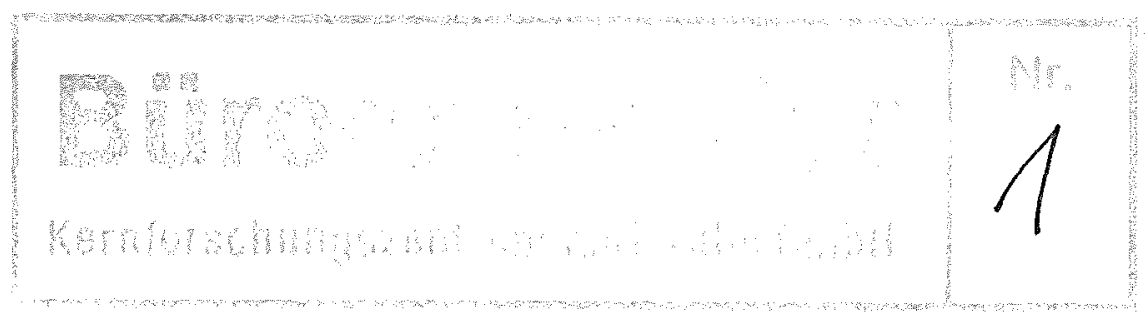

KERNFORSCHUNGSZENTRUM KARLSRUHE GMBH, KARLSRUHE 


\section{ENGINEERING COMPONENTS GROW LIKE TREES}

\section{Summary}

Biological structures consist of mechanical load carriers, which are highly optimized in terms of mechanical strength and minimum weight. It is demonstrated on some selected examples that a constant Mises-stress at the surface of the biological component can be accepted as a significant biological design rule. However, a general proof of this hypothesis seems to be impossible. It is discussed how ready-grown biological designs can be transferred to engineering applications. A new method of structural shape optimization was developed because biological 'components' do not always exist exactly in a shape ready to be copied for engineering use. The method is based on the computer-simulation of tree growth which is performed by use of the 'volumetric swelling' option or alternatively by stress-controlled thermal expansion in the FEM-code ABAQUS. A number of examples show that the growth of biological structures can be computer-simulated very well and incidentally the 'natural' loading case can be defined precisely. Technical applications show that the method is very efficient in structural shape optimization of 2D and 3D engineering structures. It is compared with other methods of structural optimization found in the literature.

\section{BAUTEILE WACHSEN WIE BÄUME}

\section{Zusammenfassung}

Biologische Strukturen bestehen aus Kraftträgern, die hochgradig gewichtsund festigkeitsoptimiert sind. An ausgewäh1ten Beispielen wurde gezeigt, daß eine konstante v. Mises-Spannung an der Oberfläche der biologischen 'Komponente' durchaus als wesentliches Konstruktionsmerkmal akzeptiert werden kann, wenngleich ein allgemeiner Beweis dieser Hypothese wegen der Vielfalt biologischer Konstruktionen woh1 unmöglich sein dürfte. Es wird diskutiert, wie biologische Konstruktionen durch einfaches Kopieren in den Maschinenbau überführt werden können. Da allerdings nicht immer eine fertige, gewachsene 'Vorlage' unter entsprechender Betriebsbelastung in der Natur vorliegt, wurde eine neue Methode der Gestaltoptimierung entwicke1t, die auf biologischem Wachstum basiert und ziem1ich genau das Wachstum der Bäume mit der Option 'volumetrisches Schwellen' oder alternativ mit spannungsgesteuerter Wärmeausdehnung im FEM-Code ABAQUS simuliert. Eine Reihe von Beispielen zeigt, dafi das Wachstum biologischer Strukturen sehr gut vorausgesagt werden kann und dabei auch Aussagen iber die natürliche Belastung gemacht werden können. Technische Anwendungen zeigen, daß die Methode sehr effektiv zweiund dreidimensionale Maschinenbauteile gestaltoptimieren kann. Das Verfahren wird mit anderen Methoden zur Gestaltoptimierung vergleichend bewertet. 



\section{PREFACE}

The method of structural shape optimization described in this report is the computer simulation of a procedure of biological self-optimization developed and improved in millions of years by evolution.

The fate of this development is characterized by compromise-less selective brutality leading not only to perfectly optimized biological constructions but also to an effective mechanism which models the design of them:

\section{THE MECHANISM OF ADAPTIVE GROWTH}

\section{i. INTRODUCTOOÁ}

Looking at biological load carriers found in animals or plants one does not need much fantasy to believe that they are functionally optimized in a general sense. This means that they are highly adapted to all boundary and loading conditions defined by their environment. In the hard competition for energy and living space only the most economically working construction is able to survive.

Especially for mechanical components the word 'optimum' means:

- sufficient strength for all relevant loading cases,

- $\quad$ minimum weight.

On account of bending stresses and small defects present frequently, the failure of a component often starts at its surface. It, therefore, has to be stated that a good mechanical design is characterized by a homogeneous stress distribution at its surface. Only in this case there is no point at which failure more probably occurs than at another point subjected to lower stresses. Because of the possibility of three-dimensional stress states this hypothesis of constant surface stress has to be specified to the requirement of a constant Mises-stress at the surface of a mechanically optimized structure. (The Mises stress has been used because it gives good results in practical growth prediction as it will be shown later.)

It is, of course, clear that this requirement cannot always be satisfied in biological structures with respect to all possible load cases which can be imagined. Therefore, it has to be expected that the optimized design is a compromise well adapted to the most important load cases and, to a lesser degree to the less important load cases. 
Example: If a tree is loaded by wind mainly in a certain direction, its stem will ovalize in that direction producing increased bending stiffness. In the direction perpendicular to the main wind activities the stem will not build up so much wood. If the wind blew in that direction (where the stem is weak), the tree would, evidently, be less well adapted to that load case.

This simple example is to illustrate that biological components are a compromise design best adapted to the most important (e.g. most dangerous) load cases. For this most important load case the biological load carrier is expected to grow into a state of constant Mises-stress at its surface. The structure will at least try to avoid any localized stress peaks (notch

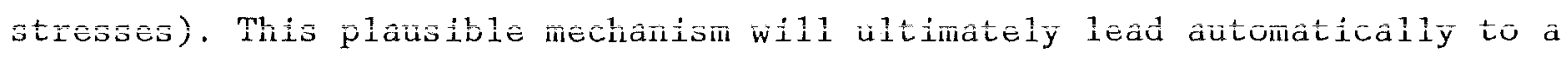
constant stress state at the surface of the biological load carrier and to a minimum weight design which will be illustrated by a number of examples in the next chapter.

The reader who wants to know more details on the biological background should read in [3] on the mechanics of trees.

Furthermore, a very good overview on adaptive growth in bony structures in the sense of a qualitative description is given by Currey [22].

In this report only some selected biological examples are described just to give an idea on the biomechanical background of the optimization method. 


\section{EXAMPLES OF A CONSTANT STRESS STATE IN BIOLOGICAL STRUCTURES}

\subsection{TREE STEMS}

In [1] it is discussed qualitatively that trees have to grow into a slender shape because of the competition for light in tree groups. On the other hand, the tree has to be thick enough to withstand breakage due to wind loading. Whilst Alexander [1] discussed only the thickness of the tree butt in [2] a similar relation was derived in order to predict the relation between the tree radius and the height where this radius has actually been measured. In [3] it was stated that all the applicable equations are expected to depend oni the shape of the trec crown. Only for a crown localized at the very top of an otherwise leafless tree the force of the wind can be modelled by a single force acting laterally at the tree top and causing a linear bending moment distribution downward along the stem. In that case, the requirement of constant surface stress along the stem would lead to the equation

$$
\mathrm{h} \sim \mathrm{D}^{3}
$$

which was found experimentally in some cases [2]. Of course, for other types of trees as Sitka spruce-like trees with crowns distributed nearly all over the stem length a different relation has to be expected to hold.

However, in a qualitative way the adaption of the tree stem diameter to wind loading is evident to everybody. The butt of the tree where highest bending moments are acting is thickest and the very top of the tree has a thickness tending toward zero as does the bending moment (Figure 1). The same holds for the branches, which are thickest near the stem, again where the highest bending moments due to wind loading and in this case also due to gravity are acting. The next question is how the joint between the branch and stem is optimized to avoid notch stresses caused by localized redirectioning of the force flow.

\subsection{BRANCH-STEM JOINTS}

Figure 2 shows a Finite-Element calculation using a simplified plane-strain model $[4,5]$. The upper side of the branch is most exposed to the danger of failure. Therefore, the main tensile stresses along its contour in the range of the joint are plotted. The load applied consists in downward bending of the branch and bending of the stem with different bending moments. It is amazing that the stress distribution is not much effected by the bending of 
the stem. In all cases a nearly constant normalized stress without any notch stresses can be seen which indicates a perfect shape optimization of the joint. Similarly designed joints may be seen also in bony structures as for example in deer antlers [6].

\subsection{RED DEER ANTLERS}

In Figure 3 some antler spikes are shown with the FEM-structures related and again the tensile stresses along the upper contour line of the spike joint. Similar to the branch joints the antler design is very well shape optimized with respect to bending loads and, as branches have been, the spikes are not optimum designed for axial tension. These results indicate that shape adaption has to focus on the most important load case. It is interesting that the antler spikes are best adapted to a lateral single load acting at the end of the spike and less adapted to distributed loads acting along the spike. This is also plausible in the sense of a design resistant to the worst load case.

\subsection{THE BAUD CURVE - A BIOLOGICAL DESIGN RULE}

Already in 1934 an example of empirical shape optimization has been published [7] with the transition contour line of a beam with narrowing cross-section recommended for tensile and bending loads, respectively. The method used [7] was more or less empirical because a celluloid strip was filed by hand and the stress state was checked continuously with respect to its local homogeneity. Finally, a state of homogeneously distributed stresses could be verified by optical methods. Two different contour lines were found corresponding to tensile and bending loads, respectively (Figure 4). Whilst Baud [7] carried out his investigations for rectangular beam joints only, it was shown in [5] that slanted joints of beams, hollow beams and other variations of the original 'Baud-curve' do not disturb very much the shape optimized state of the design. The main requirement is that the transition contour line is at least partially described by a Baud-curve or consists of two mirrored Baud-curves. A number of examples are shown in Figure 5. With this knowledge it is more than plausible to look into the nature for designs characterized by original [7] or modified [5] Baud-curve contour 1ines. Going back to Figures 2 and 3 it can easily be checked that branch joints as well as antler joints obey the law of a modified Baud-curve design $[5,6]$. 
What other behaviour should be expected? If it is true that biological structures grow into a shape without notch stresses and the Baud-curve [7] and their variations [5] are such curves, it is plausible enough that the contours are at least very similar to each other. Of course, it is impossible to prove the validity of this 'Baud-curve' hypothesis in a general way for a11 joints grown in nature. However, in Figure 6 it is shown for a number of examples that the modified Baud-curves can be found in a wide variety of biological specimens. Even the larger bones of different mammals are characterized by this design. In Figure 7 a plot of the Mises-stresses acting in a human tibia under physiological loading shows an excellent constant stress behaviour of this design. Although the Baud-curve actually seems to

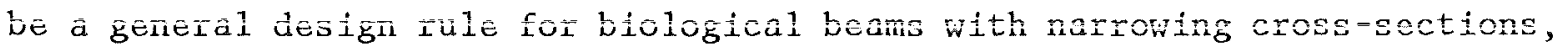
the reader should be careful not to make a mistake when very short beams are considered. There is at least one other design law for the case of pure bending which will be the subject of the next chapter.

\subsection{THE LOGARITHMIC SPIRAL - ANOTHER BIOLOGICAL DESIGN RULE}

Short beams loaded by pure bending and clamped at the opposite end are exposed to steep gradients of bending moment if a single lateral force is acting at the free end of the beam. This gradient of the bending moment is the reason why a Baud-curve design cannot be expected for short beams. In [8] it was stated that some biological structures growing into a curved beam design are characterized by the logarithmic spiral which could be verified here (Figure 8). A1though this statement in [8] was a great success and a welcomed first step, nothing has been said in [8] about the mechanical reasons for the formation of this shape. Therefore, the design of a tiger claw as one typical design characterized by the logarithmic spiral was analysed by FEM-calculations [9]. The result is shown in a self-explaining way in Figure 9. The isolines of constant Mises-stresses run very closely paralle1 to the border of the claw. (Because of the uni-axial force flow the Mises stress is practically identic with the main normal stresses on the tensile side of bending.) It should be noted that the FEM-model was three-dimensional regarding the 'profile' of the claw (Figure 9). However, no effort was made to simulate the effect of the internal material of the U-shaped cross-section, which is expected to carry some part of the load, too. On the other hand, the horny part of the claw seems to do the main job because of the load-adapted fibre orientation in this part. It should be admitted that near the clamping of the claw reality is probably not simulated very well. However, looking at the stress distribution in the part of the claw situated 
between its tip and $3 / 4$ of its length from the tip, one should observe a stress distribution very close to reality. This example is another proof of the validity of constant stress hypothesis in living structures.

\subsection{RESTORATION OF DISTURBED STATES OF CONSTANT STRESS IN BIOLOGICAL STRUCTURES}

\subsubsection{WOUND HEALIN.G IN TREES}

In preceding chapters it was argued that trees always try to grow into a state of constant siress. In ohiner words, the tree is feeing weî if it incosporates with a constant stress distribution at its surface. If by accident or on purpose the tree is wounded and in this way some notch stresses are caused at the border of the wound (notch), it is plausible that the tree will hurry to restore its original state of homogeneous stresses. This procedure is called wound healing and it is fastest at places where highest stress peaks are found. In Figure 10 the normal way of wound healing is shown for branch holes. The notch stresses due to redirectioning of the force flow are highest beside the hole, and indeed at these places wound healing is fastest $[10,11]$. This example will be computer-simulated later-on when the computer-aided shape optimization is introduced. More details on normal healing are given in $[3,10]$, where also notches are considered with special notchstress distributions related to more sophisticated notch shapes (triangular, etc.).

In [11] another proof of the stress stimulation of wound healing is given for a London plane (Platanus acerifolia) whose branch holes healed at a certain angle with respect to the vertical stem because the flow of forces was slanted in the same way as the main stress trajectories indicate in Figure 11. All this suggests that wound healing in trees is the restoration of the state of constant surface stress.

\subsubsection{REDUCTION OF CONTACT STRESSES BY ADAPTIVE GROWTH}

It has been qualitatively discussed that wound healing in trees reduces the notch stresses beside a wound (notch) and restores the state of constant stress which is believed to be the most general design rule [3] in biological load carriers. However, this ideal state cannot be disturbed by wounding only, but also by applying a mechanical contact load as the stone in Figure $12 \mathrm{a}$ does. As in the case of wound healing, the tree reacts by adaptive growth 
in order to reduce the localized stress peak. This adaptive growth leads to an increase in the contacting area and in this way it reduces the contact stress because the contact force is not altered [12]. The stress-reducing effect of this 'overgrowth' is calculated by FEM [12] and a summary is given in Figure 12b. The stress reduction is evident. In Figure 13 another example is shown where the same mechanism was acting successfully.

\subsubsection{FORGOTTEN TREES ATTACHED TO STAKES}

When a tree is attached to stakes in order to limit movements under wind loading and this support is forgotten, the tree adapts to the new situation (Figure 14). It is obvious that increased stresses have to be expected at the place where the stakes are attached to the tree because at those points the effective cross-section of the whole construction 'jumps' from the stake-tree composite to the stem alone. Although the shape of the adapted tree in Figure 14 looks a little curious, there is no doubt that the tree has grown into this optimized shape in order to restore the state of constant stress along the whole stem. If these stakes are removed the tree feels

'irritated' again by the presence of a new notch just below the increased girth. This notch has been unactivated before by the presence of the stakes. The tree will grow with the time into its 'normal shape' as any other unsupported tree. That means it will adapt to its new unsupported situation.

\subsubsection{BONY PLUGS BELOW THE SHAFT TIP OF HIP ENDOPROSTHESES}

The force flow running downward from the hip joint through the stem of a hip endoprosthesis is redirected at the deepest point out of the stem into the bony surrounding. This may lead to local stress peaks and, therefore, to an increase in wall thickness of the cortical bone just below the prosthesis stem and a diminution of the proximal cortical bone, which is to reduce these notch stresses (Figure 15). It is obvious that this example is equivalent to the adaptive tree growth in Figure 14 except that the tree stem was externally supported by stakes whilst the bone is supported (or better unloaded) internally by the stem of the prosthesis. The common behaviour is that both biological 'composite' structures react by growth to restore a fair distribution of internal stresses disturbed by these supporting effects. 


\subsection{FINAL REMARKS ON THE CONSTANT STRESS DESIGN RULE}

A number of different biological structures have been introduced to the reader in order to give him a 'taste' of the general validity of the hypothesis of constant surface stress. However, a general proof seems to be impossible to the author's knowledge. On the other hand, this proof is perhaps not really necessary. Without doubt, a good mechanical design has to satisfy the requirement that no part of it is exposed to higher stresses and by that way prone to the danger of failure than any other part. Only in this way pre-defined points of failure can be avoided which are characteristic of most misconstructions. In this sense, the present findings regarding a consiani surface-siress hypothesis for bioiogicaì siructures are just what every engineer would have expected from an optimized structure grown into its own perfection in a process of evolution extending over thousands of years. Knowing now that biological components are mechanically optimized, it is an obvious step to copy these living designs. This method is known by the name 'bionics' and has been very successful in the past. However, it is limited to constructions which are readily available in nature and should be known to the designer who looks for them.

Another more general way would be to improve a first design proposal by systematic optimization. This will be considered in the next chapters. 
Many attempts of structural optimization are reported in the literature and it would take a lot of time to review all of them. Therefore, this chapter will be restricted giving just an impression of what other authors are doing.

There are two works which should be mentioned, because they come very close to the method proposed in this paper. Umetanu and Hirai [13] in 1975 also tried to copy biological growth for structural optimization purposes. Huiskes et al. [14] rediscovered that method or even developed it independently without hâving knowledge of [13]. Doth procedures consist in an elastir FEM-run whereby according to a distribution of stress components or elastic energy densities [14] the surface of the design proposal is shifted normal to the initial surface. This will lead to an improved design which may be subjected to another elastic analysis and so on. In both references $[13,14]$ some modifications are discussed which are not related very much to the present paper and, therefore, they are not outlined here. As the reader will see later-on, the papers are close to the present method. However, they still have some disadvantages.

In both papers $[13,14]$ growth is proceeding in a direction normal to the surface of the design proposal. This means that the normal vector has to be known and, hence, to be computed. This alone is very difficult for the case of 2D- and 3D-structures. Although it might help to cover the contour line of 2D-structures with 'soft' beams and the surface of 3D-structures with 'soft' she11 elements which calculate their own normal vectors by themselves in most FEM-codes, the attachement of these additional elements means a non-negligible effort and frustration to the engineer who has to do it. This problem does not occur in our method proposed later-on and is one of the improvements with respect to $[13,14]$. Another disadvantage of $[13,14]$ is that the 'growth step' has to be programmed individually in a second program in addition to the FEM-code. Additional users of these methods have to buy new 'growth'-programs or write them themselves. None of these two possibilities makes these methods more attractive.

Jancu and Schnack [15] try to obtain a homogeneous state of Mises-stresses on the surface of the structure considered which is perhaps the best criterion of structural shape optimization. By use of small perturbations of the contour line of the design proposal it is tried to reduce the maximum Mises-stress and to increase the minimum Mises-stress in order to get a more homogeneous Mises-stress distribution. This method also requires compatible 
software packages in addition to the FEM-program. Although the method is successfully verified on a number of $2 \mathrm{D}$-examples, its effective application to 3D-structures seems to be difficult. The only 3D-example [15] known to the author which was treated with this method was not very convincing. After a number of 24 iterations the stress magnification factor was reduced from 3.36 to on $1 y 2.70$, whilst with the method presented in this paper the maximum Mises-stress in a 3D-structure was reduced down to $50 \%$ in one cycle only. However, in the literature not many other papers have been found where shape optimization of a 3D-problem is even reported. A method, which is frequently reported, is called 'decomposition method'. In [16] it is used for shape optimization. Eschenauer et a1. [23] are able to report a large number of successíui exampies. They dỉa not focus on sỉape optimization aione as cione in this paper.

The decomposition methods admitted there have also a number of disadvantages, because the procedure consists in a decomposition of the main structure into a number of substructures which are optimized more easily. By the way the 'shape functions' (splines) describing the varied contour line are of a simpler type. However, one disadvantage is that the choice of the shape functions influences the optimized shape. Because the selection of these shape functions is an 'individual decision', it has little to do with the physics of the problem. Other weak points of the method admitted in [16] are, for example, the decreasing convergency of the method with increasing coupling of the subsystems and the fact that the sum of a11 the 'suboptimums' is in general not the global optimum. It is very doubtful to the author whether the method can be managed with reasonable effort in case of 3D-structures with a number of interacting notches.

Other methods of shape optimization have been published. However, the interested reader will find a more general review for example in [17].

In this paper a new type of shape optimization will be described which seems to be useful, especially for practical applications. 


\section{COMPUTER AIDED SHAPE OPTIMIZATION (CAO) BASED ON BIOLOGICAL GROWTH}

In the preceding chapter a number of optimization methods have been reviewed. All of them seem to be able to optimize frame works or some of them also 2D-structures, with some effort. However, to the author's knowledge, none of them has shown to be appropriate for optimizing 3D-shapes with reasonable effort. A more effective method was, therefore, looked for which should work well in both 2D- and 3D-shape optimization with acceptable effort and which would not require much individual and problem-specific programming and 'adjustment' beyond the FEM-mesh generation, which is admitted to be indispensible if the FEM is used.

As we have seen that biological structures self-optimize in a perfect way, the suggestion is not far-fetched that the mechanism of biological growth itself could be simulated as a procedure of optimization. Furthermore, it can be expected that the biological structures optimize themselves in an effective way. In other words, not only the product of biological optimization is optimum, but also the way to achieve it.

Let us have a look at what happens if a tree is growing (Figure 16). Only the outermost growth ring adapts by reactive growth to external loading. This mechanism of tree growth can be computer simulated by the following steps $[4,19,20,21]$ :

1. Generate a design proposa1 (FEM-mesh) of your mechanical component to be optimized.

(If this is a bad misconstruction you will need more computer time!)

2. Cover its surface with a thin layer of finite elements having the same thickness everywhere and having a Young's modulus which is very sma11 compared to the rest of the structure below this layer. This surface layer is equivalent to the outermost growth ring in trees.

3. Perform an elastic FEM-run from which you will get the distribution of the Mises-stresses in the structure and, by the way, also in the soft surface layer.

4. Using the option of 'volumetric swelling' in ABAQUS [18], the soft surface is allowed to swell now according to the law for the volumetric strain rate:

$$
\dot{\varepsilon}_{V}=k\left(\sigma_{M}-\sigma_{\text {reference }}\right)
$$


where $\mathrm{k}=$ constant. (If no swelling option is available in your FEM-program, this step can also be performed by heating up the surface layer, with the temperature distribution set forma1ly equal to the Mises-stress distribution calculated in step 3. In this case the heat expansion coefficient in the soft surface layer has to be non-zero whilst the stiffer material below has a zero coefficient of thermal expansion.)

5. The incremental displacements due to swelling or thermal expansion calculated in step 4 are now scaled up by a 'reasonable' factor in order to get visible displacements which are added to the nodal point coordinates of the undeformed mesh.

6. Now the disturbed mesh is corrected in order to restore everywhere the same thickness of the thin soft surface layer.

7. This improved mesh will be the input for another elastic run starting again at point 3 of the procedure.

8. The optimization has to be stopped if design limitations derived from functional reasons are reached or if all notch stresses have completely disappeared which would be the ideal case.

9. Fina1ly an optional elastic run can be performed in which the Young's modulus of the surface layer should have the same value as the basic material below. This run allows to assess the stress reduction by shape optimization in comparison to the design proposal.

The procedure described here is sketched schematically in Figure 17. One important advantage of the method seems to be that no additional effort has to be made for 3D-shape optimization beyond the 3D-mesh generation. The success and efficiency of this CAO-method will be demonstrated below by a number of examples. 


\section{APPLICATION OF THE NEW CAO-METHOD TO BIOLOGICAL AND ENGINEERING STRUCTURES}

In order to facilitate understanding of the examples, the non-optimized structure is arranged on one page together with the optimized design, and the related stress distributions are plotted. This will illustrate in a very condensed way the success of the optimization. A text description is also given. Thus, the examples are arranged in a self-explaining way (Figures 18-36) and there is no need for further text description in this chapter.

\section{COMCLUSIONS}

The main results of this study can be summarized in the following statements.

- Biological load carriers self-optimize by growth, during that process they always try to adapt a state of constant stress at their surfaces. This is the optimum mechanical state with minimized danger of failure and fairly distributed stresses, where no point of the surface is loaded higher than another.

- If this optimum state is disturbed in trees (or bones) they try to restore the optimum state by attachment of more material (e.g. faster growth) at overloaded points.

- In trees on1y the outermost growth ring adapts to mechanica1 loading by reactive growth.

- This behaviour can easily be computer-simulated by use of the option of 'volumetric swelling' or by stress-controlled thermal expansion in the FEM-code ABAQUS [18].

- Design proposals of engineering components can be improved by growth as a tree would grow if it had the shape of the design proposal.

- The surface of a design proposal of the structure to be optimized has to be covered with a soft surface layer which is allowed to swe11 according to the distribution of Mises-stresses taken from an earlier elastic calculation. The related swelling law (growth law) is

$$
\dot{\varepsilon}_{V}=k\left(\sigma_{M}-\sigma_{\text {reference }}\right)
$$

This procedure can be repeated, if necessary. 
- The procedure of optimization is either completed if an entirely homogeneous stress state is reached or if further growth is limited by dimensional restrictions derived from functional reasons.

- The method works well for $2 \mathrm{D}$ - and 3D-structures. It is appropriate to reduce notch stresses even in complex structures with many interacting notches.

- If the 3D-structures consume much computer time even one growth cycle can lead to a striking reduction of notch stresses.

- The new CAO method is a very helpful tool in practical design improvement. Furthermore, it is a powerful method for the 'design of notches without notch stresses' successfully tested on a large number of 2D- and 3D-examples.

- CAO can also be used for studies in biological structures in order to predict growth or to characterize the type of natural loading which is related to the special shape of the grown structure. The question to be answered in this case is: Which external (natural) loading stimulates the design proposal to grow into the shape of the real biological structure?

\section{Advantages of CAO}

- CAO as a shape optimization method is as generally applicable as the FEM itself.

- You need an FEM-program and nothing e1se.

- No problem-specific modifications of the method are necessary. Just generate your FEM-mesh with the important soft surface layer.

- CAO works well for 2D- and 3D-structures even if there are many interacting notches.

- Even a cheap one-cycle-optimization can result in significant notch stress reduction. 


\section{Acknowledgements}

The author would like to thank a11 who helped doing the numerical work, especially Mrs. Susanne Burkhardt, Mrs. Dagmar Erb, and Mrs. Heidemarie Huber-Betzer. The engineering consultant, Mr. H. Moldenhauer, has kindly supported us in handling the 'swelling option' in ABAQUS and contributed much experience by numerous numerical examples. Furthermore, the author is grateful to Dr. Lothar Harzheim as well as to the students Gabriele Korseska, Manfred Prinz, Gerhard Rausch, Stefan Reuß, Uwe Vorberg, Frank Walther who all performed FEM-studies of different biological structures.

Furthermore, the author is gratefu1 to the management of the Kar1sruhe Nuclear Research Centre, especially to Dr. Helmut Hermann who trusted in our ideas and promoted and encouraged us from the early beginning until successful application of the method.

Because the method was started by studies on tree growth the author also has to thank the professional hunters and guides Andreas Arzt (BC), Peter Clausen (SWA), Walther Ernst (BC), Dan Liberty (USA) and Curt Rounseve11 (USA). They guided me around the forests and helped me to find many exotically grown trees which were the design teachers for all of us.

Without the active help of all these colleagues, friends and promoters, the CAO-method would never have been developed in such a short time. 


\section{Literature}

[1] R. McN. Alexander

Size and Shape

Sidgwick \& Jackson, London 1968

[2] B. Wilson, R. Archer

Tree Design: Some biological solutions to mechanical problems Bioscience 29 (1979) 293-298

[3] C. Mattheck

Warum sie wachsen, wie sie wachsen - die Mechanik der Bäume Report KfK 4486 of the Karlsxuhe Nuclear Research Center 1988 (English translation 'Why they grow, how they grow - the mechanics of trees' to appear in Aboricultural Journal, 1990)

[4] C. Mattheck

Eine intelligente CAO-Methode auf der Basis biologischen Wachstums zur Streckung der Rißinitiierungsphase technischer Bauteile 21. Vortragsveranstaltung des DVM-Arbeitskreises 'Bruchvorgänge' 27./28.2.1989 in Bad Nauheim, S. 135-144

[5] C. Mattheck, H. Huber-Betzer, D. Erb Internal Report of the Karlsruhe Nuclear Research Center 1988

[6] G. Rausch Internal Report of the Karlsruhe Nuclear Research Center 1989

[7] R. Baud Beiträge zur Kenntnis der Spannungsverteilung in prismatischen und keilförmigen Konstruktionselementen mit Querschnittsübergängen Report 29, Schweiz. Verband für Materialprüfung in der Technik (Bericht 83 der Eidgen. Mat. Prüf.-Anstalt, Zürich 1934)

[8] D'Arcy Thompson

On growth and form

University Press, Cambridge 1942

[9] S. Reuß

Internal Report of the Karlsruhe Nuclear Research Center 1989 
[10] C. Mattheck, H. Huber-Betzer, K. Keilen

Die Kerbspannungen am Astloch als Ursache der Wundheilung bei Bäumen

to appear 1989 in 'Allgemeine Deutsche Jagd- und Forstzeitung'

[11] C. Mattheck, G. Korseska

Woundhealing in a London Plane (platanus acerifolia) -

a proof of its mechanical stimulation

Arboricultura1 Journa1, 13 (1989) 211-218

[12] C. Mattheck, H. Huber-Betzer, K. Keilen

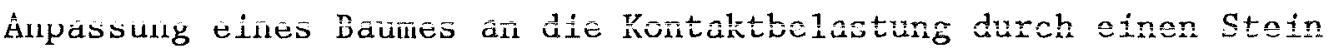

Report KfK 4526 of the Karlsruhe Nuclear Research Center 1989

[13] Y. Umetani, S. Hirai

An adaptive shape optimization method for structural material

using the growing-reforming procedure

Proc. of 1975 Joint ISME-ASME

Applied Mechanics Western Conference, 359-365

[14] R. Huiskes, H. Weinans, H. Grootenboer, M. Dalstra,

B. Fudala, T. Sloof

Adaptive bone remodelling theory applied to prosthetic

design analysis

J. Biomechanics 20 (1987) 1135-1150

[15] G. Jancu, E. Schnack

Control of the von Mises stress with dynamic programming

Proc. of the GAMM-Meeting, Oct. 5-7 1988 in Siegen

Lecture Notes in Engineering 42 (1989) 154-161

[16] M. Bremicker

Dekompositionsstrategie in Anwendung auf Probleme der Gestaltoptimierung

VDI - Fortschrittsberichte Reihe 1 Nr. 173, 1989

[17] E. Atrek, R. Gallagher, K. Ragsde11, 0. Zienkiewicz

New directions in optimum structural design

Chichester: John Wiley \& Sons 1984 
[18] D. Hibbitt, B. Karlsson, S. Sorensen

ABAQUS -Us er-Manual

Providence, Rhode Island 1987

[19] C. Mattheck, H. Moldenhauer

Intelligent CAD-Method based on biological growth

Accepted for publication 1989 by

Fatigue \& Fracture of Engineering Materials \& Structures

[20] C. Mattheck

Design and growth rules for biological structures and their application to engincering

accepted for publication 1989 by

Fatigue \& Fracture of Engineering Materials \& Structures

[21] C. Mattheck, S. Burkhardt

A new method of structural shape optimization based on biologica1 growth

Accepted for publication 1989 by Int. J. Fatigue

[22] J. D. Currey

The mechanical adaptions of bone

Univ. Press, Princeton, 1984

[23] H. Eschenauer, P. U. Post, M. Bremicker

Einsatz der Optimierungsprozedur SAPOP zur Auslegung von Bauteilkomponenten

Bauingenieur 63 (1988) 515-526 


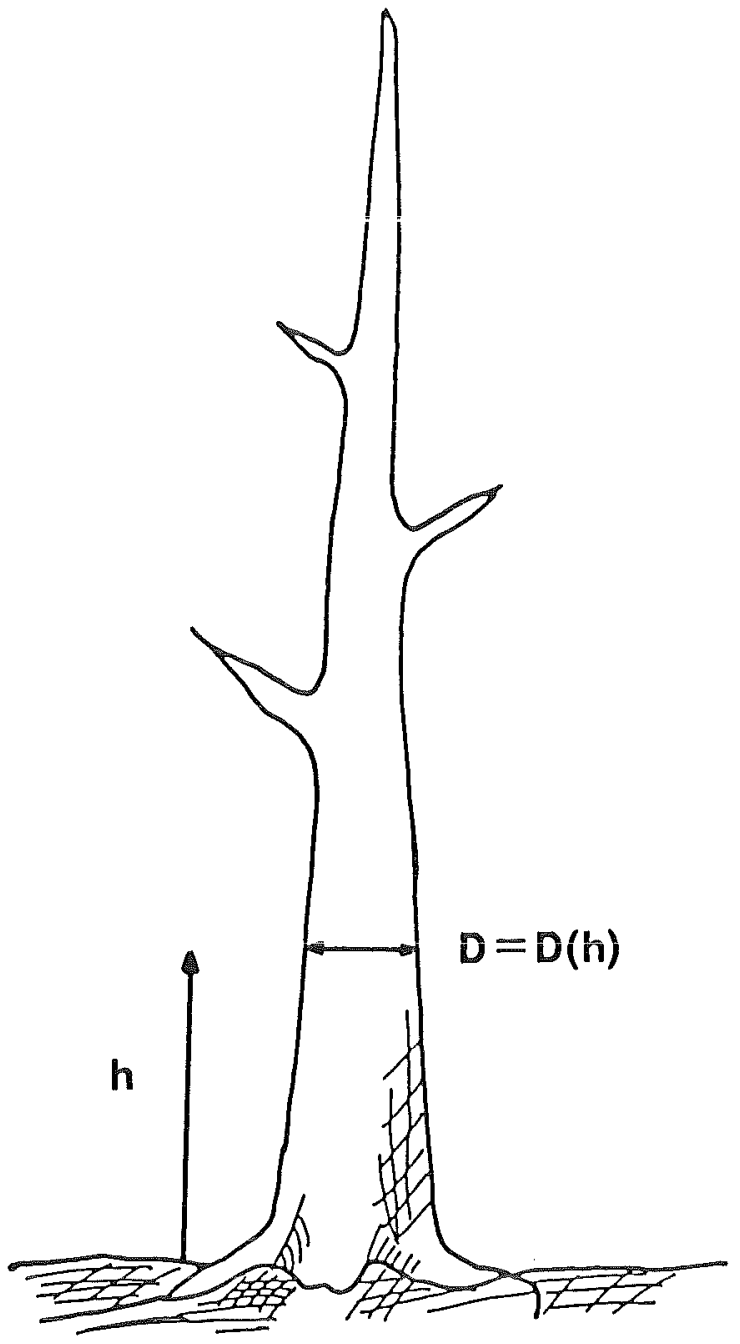

Fig.1 Thickness of tree stems varies along the stem according to the variation of the bending moment due to wind loading 

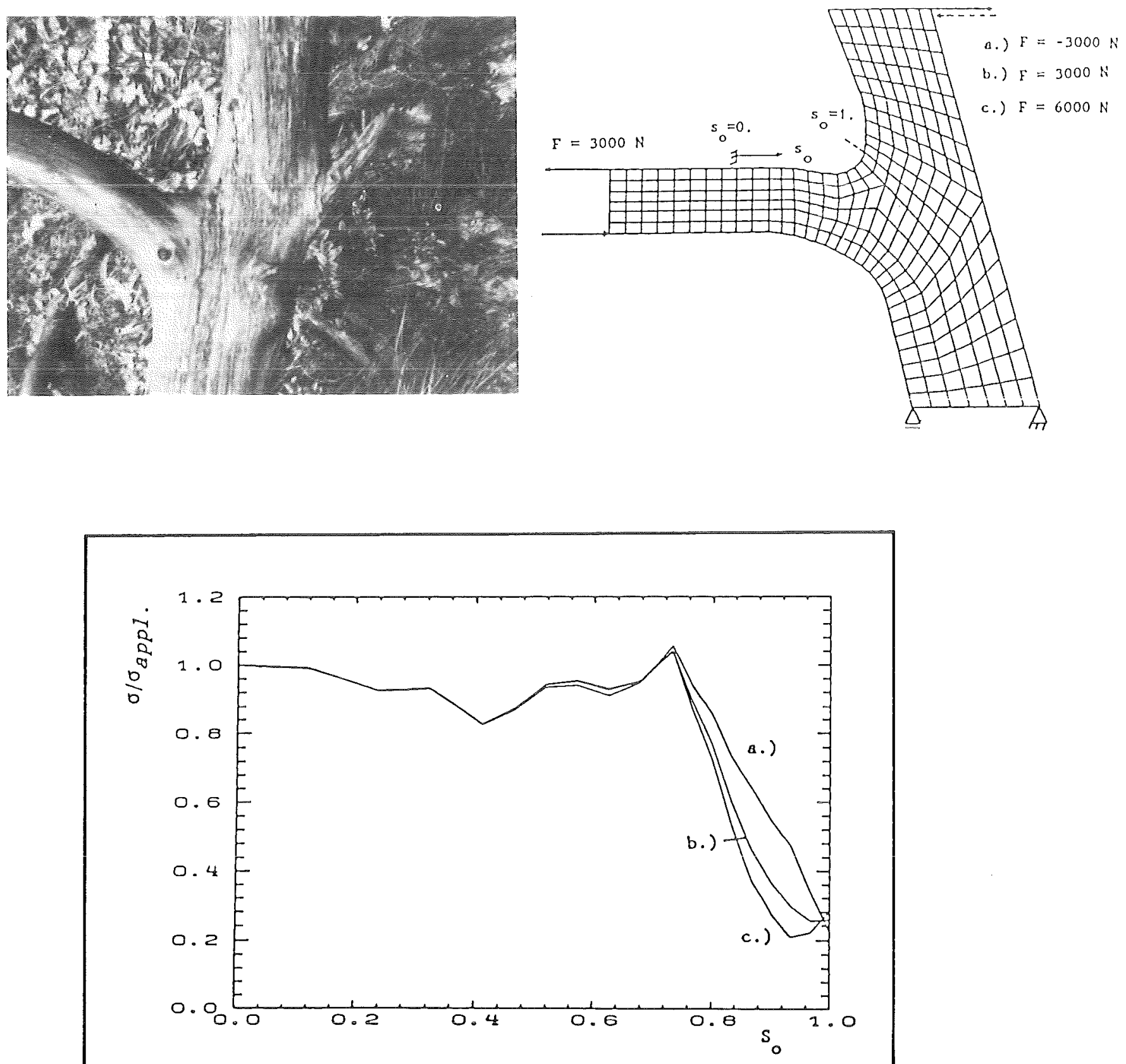

Fig.2 FEM-analysis of a branch stem joint shows excellent shape optimization for bending loads by growth because any notch stress peaks are avoided 

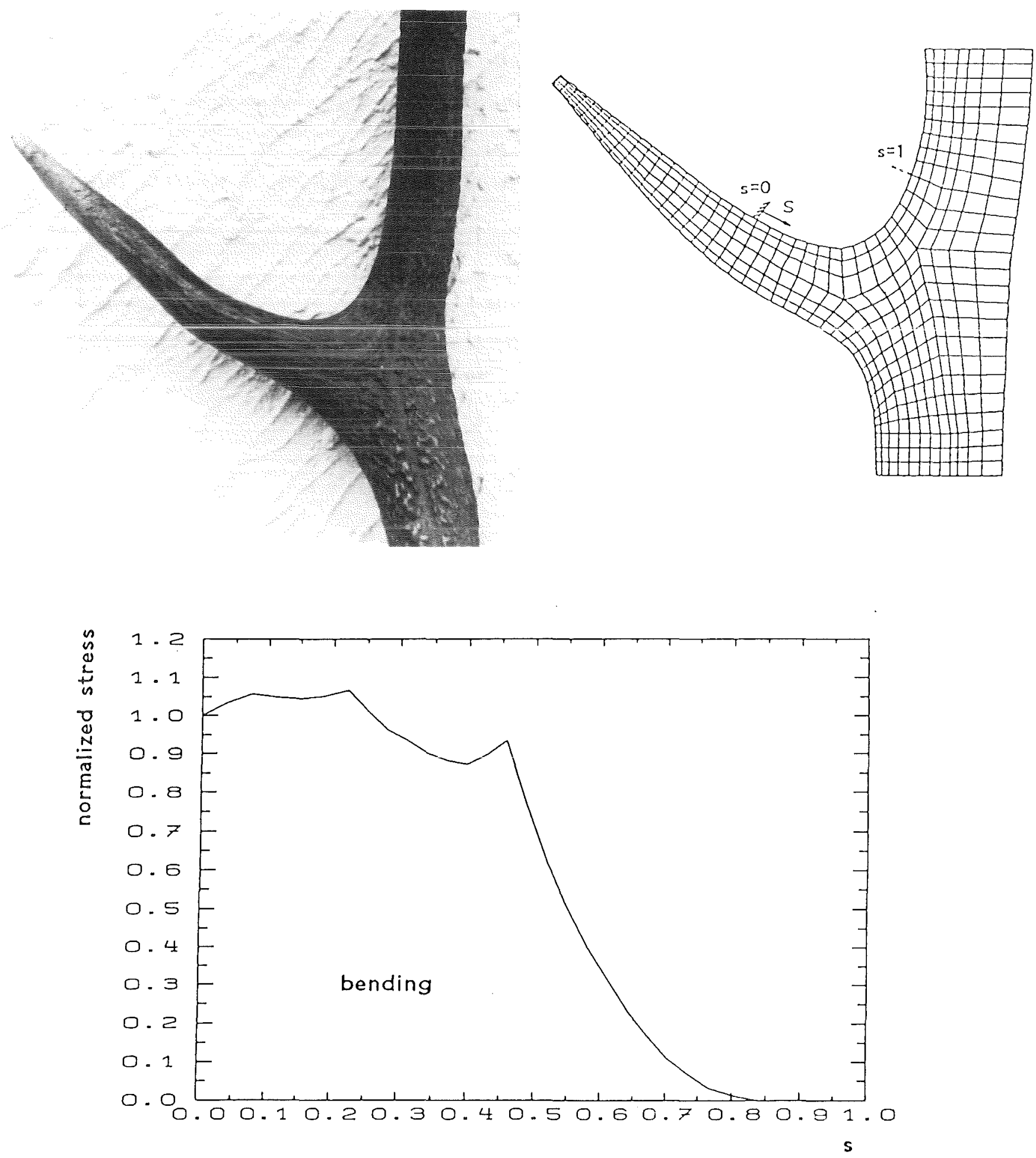

Fig.3 FEM-analysis of a red deer antler joint showing excellent shape optimization with respect to bending loads 


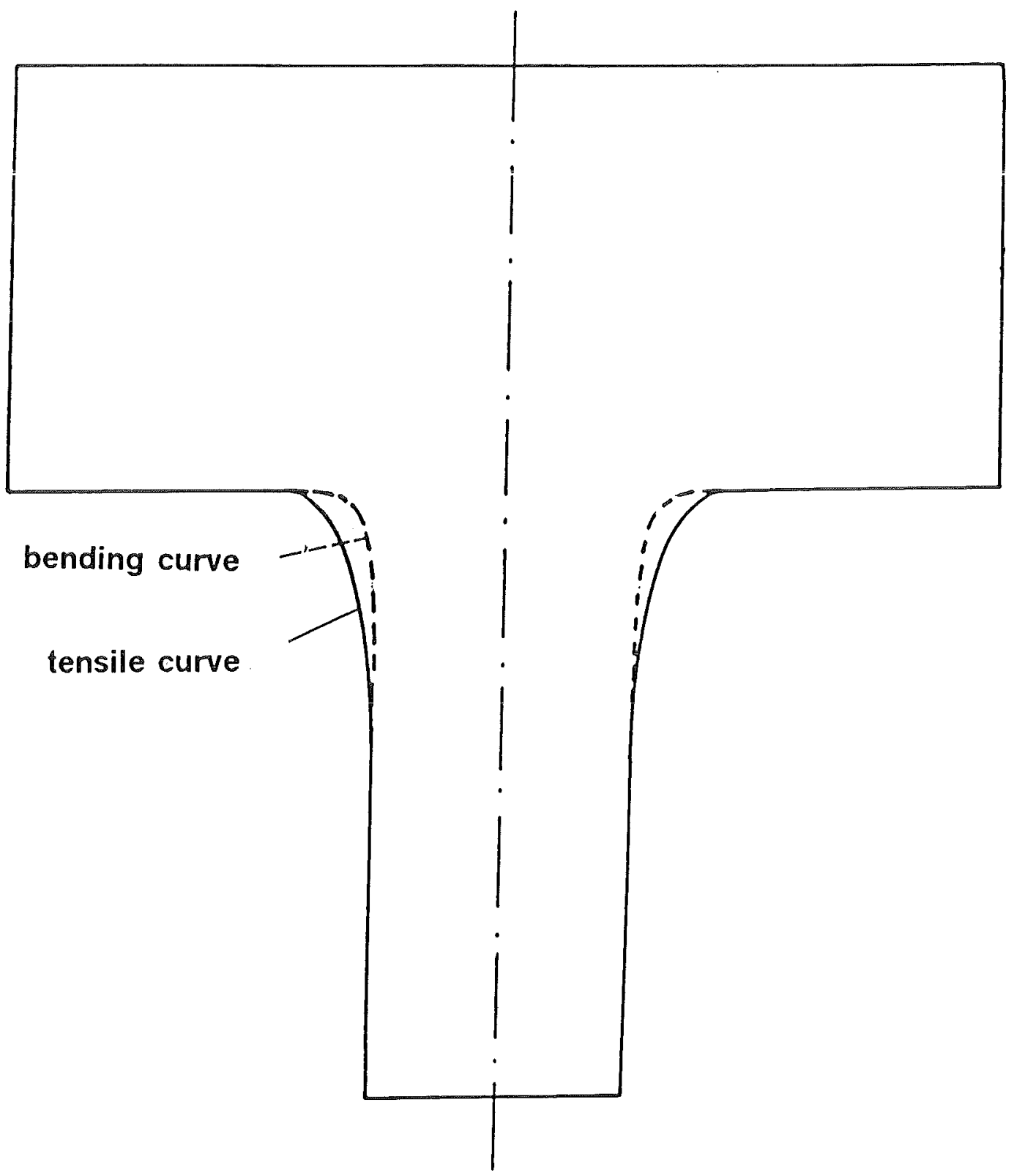

Fig.4 The original Baud curves [7] for tension and bending loads are notches without notch stresses 


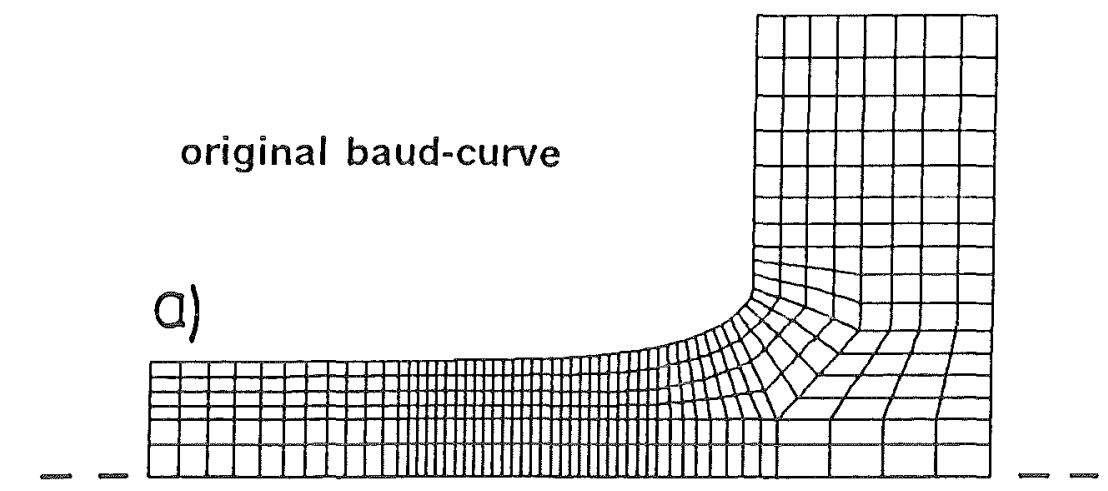

modifications

b)
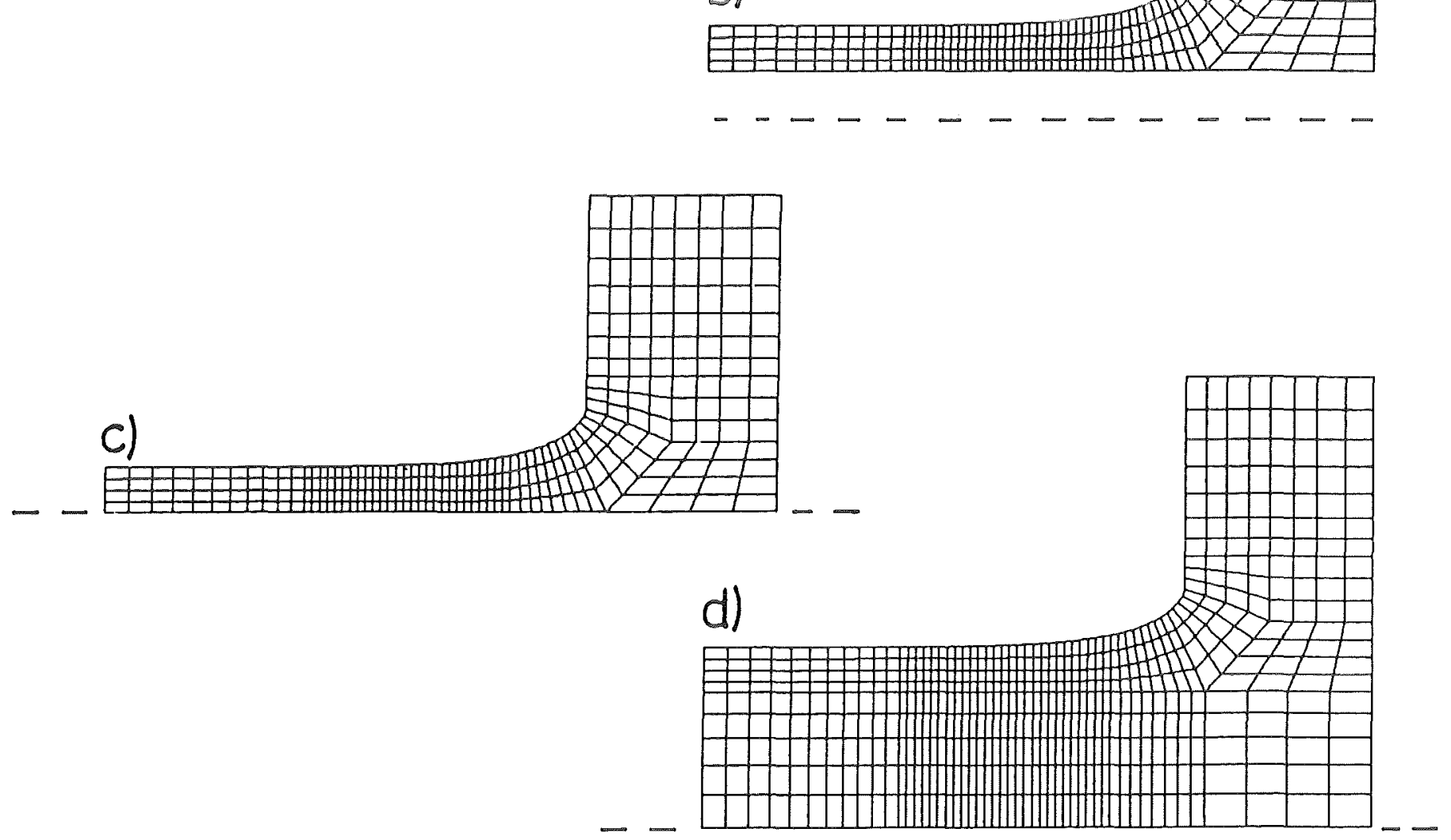

Fig.5 Modified Baud curves after [5] 

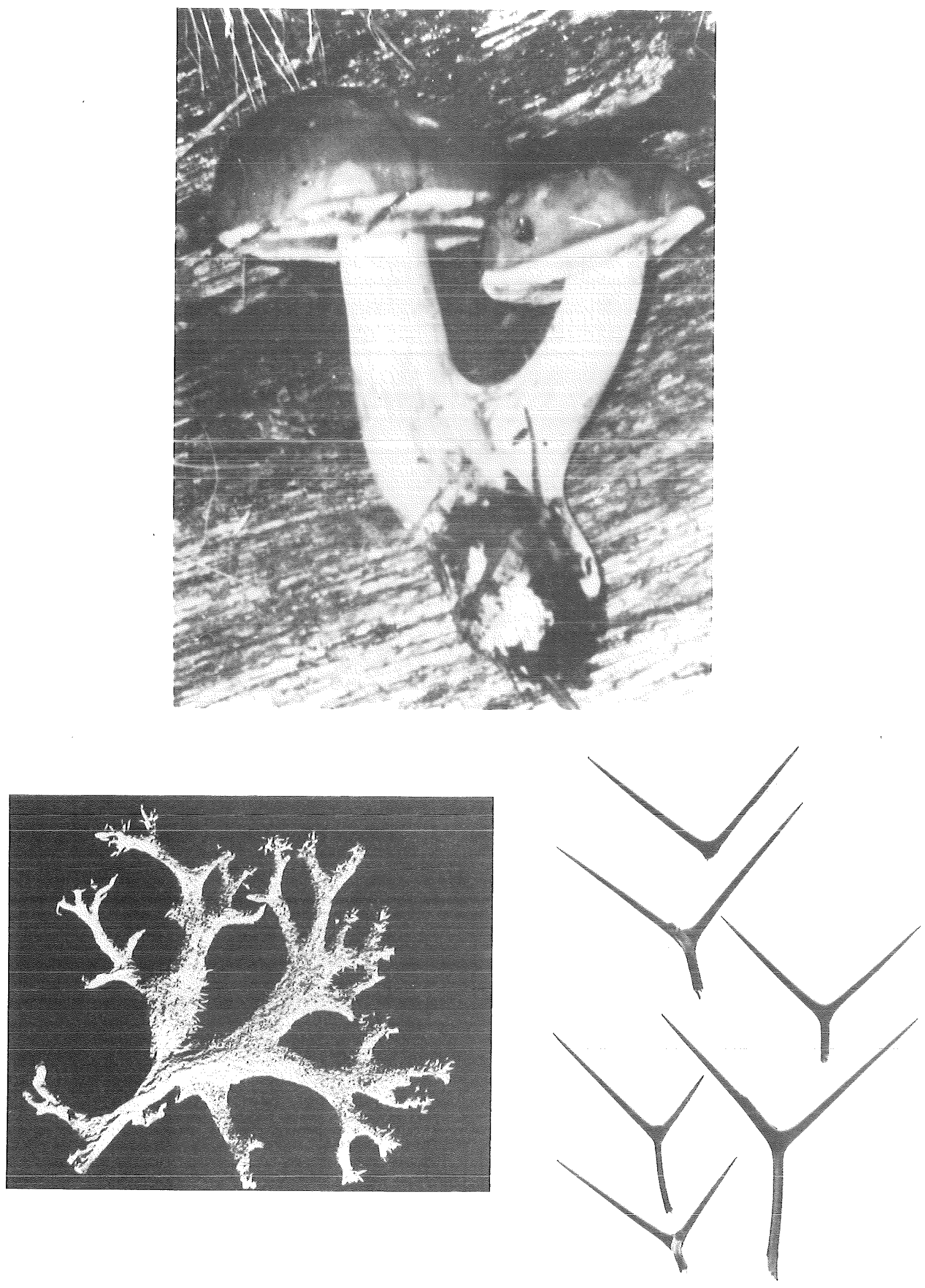

Fig.6 Examples illustrating the existance of the Baud curve in different biological structures 

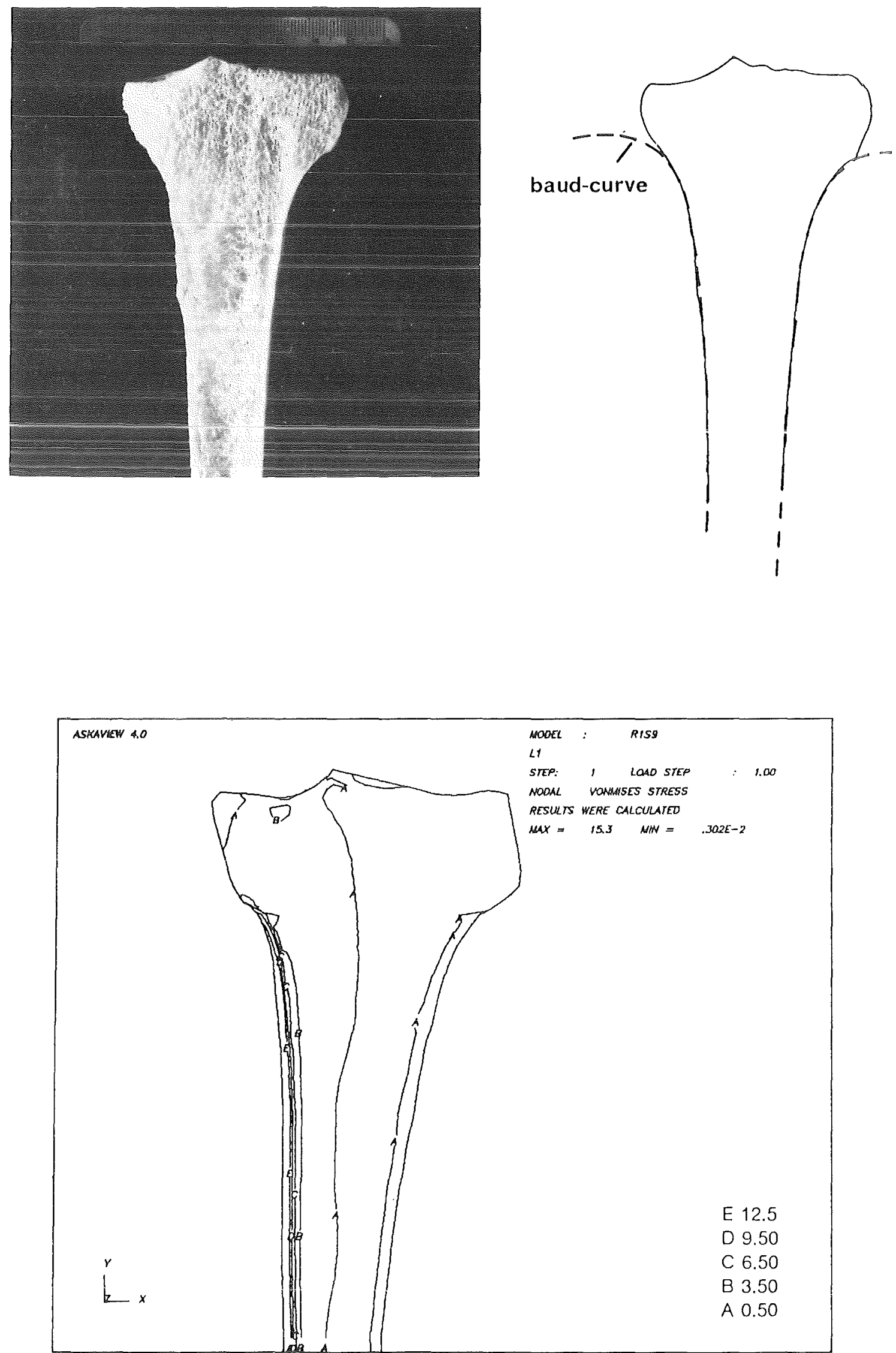

Fig.7 Front view of the human tibia showing excellent constant-stressbehaviour as a $2 \mathrm{D}-\mathrm{FEM}$ calculation shows 


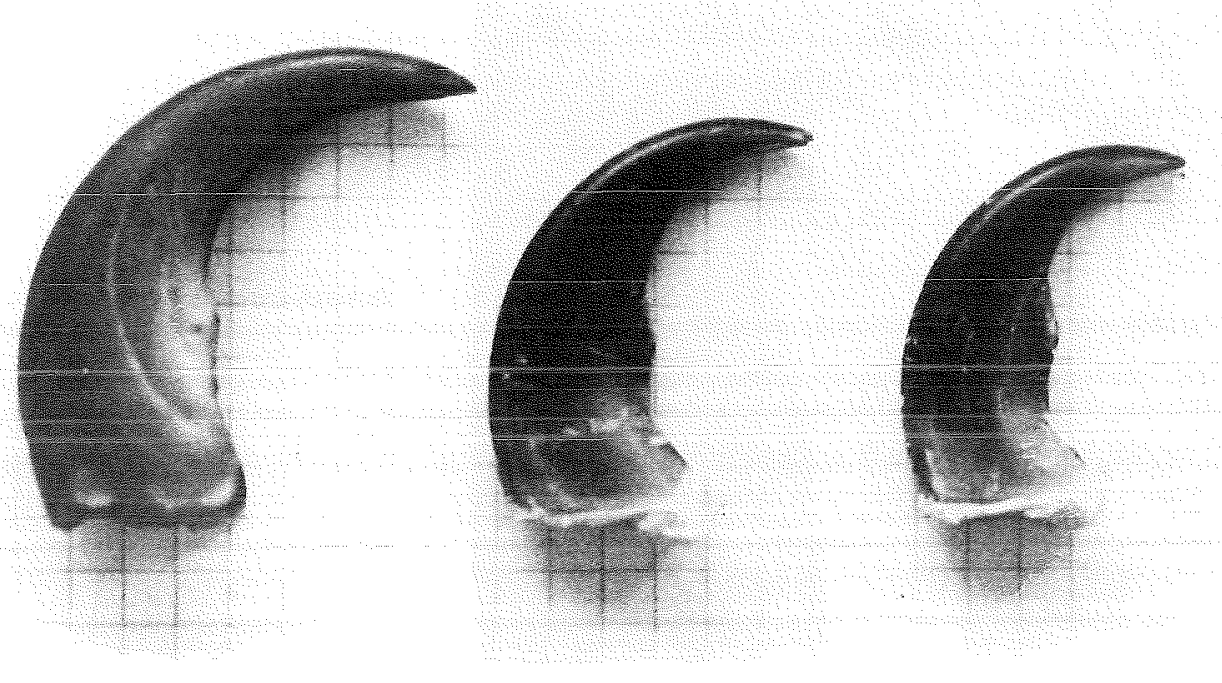

tiger

black bear

Fig.8 Some biological designs characterized by the contour line of the logarithmic spiral

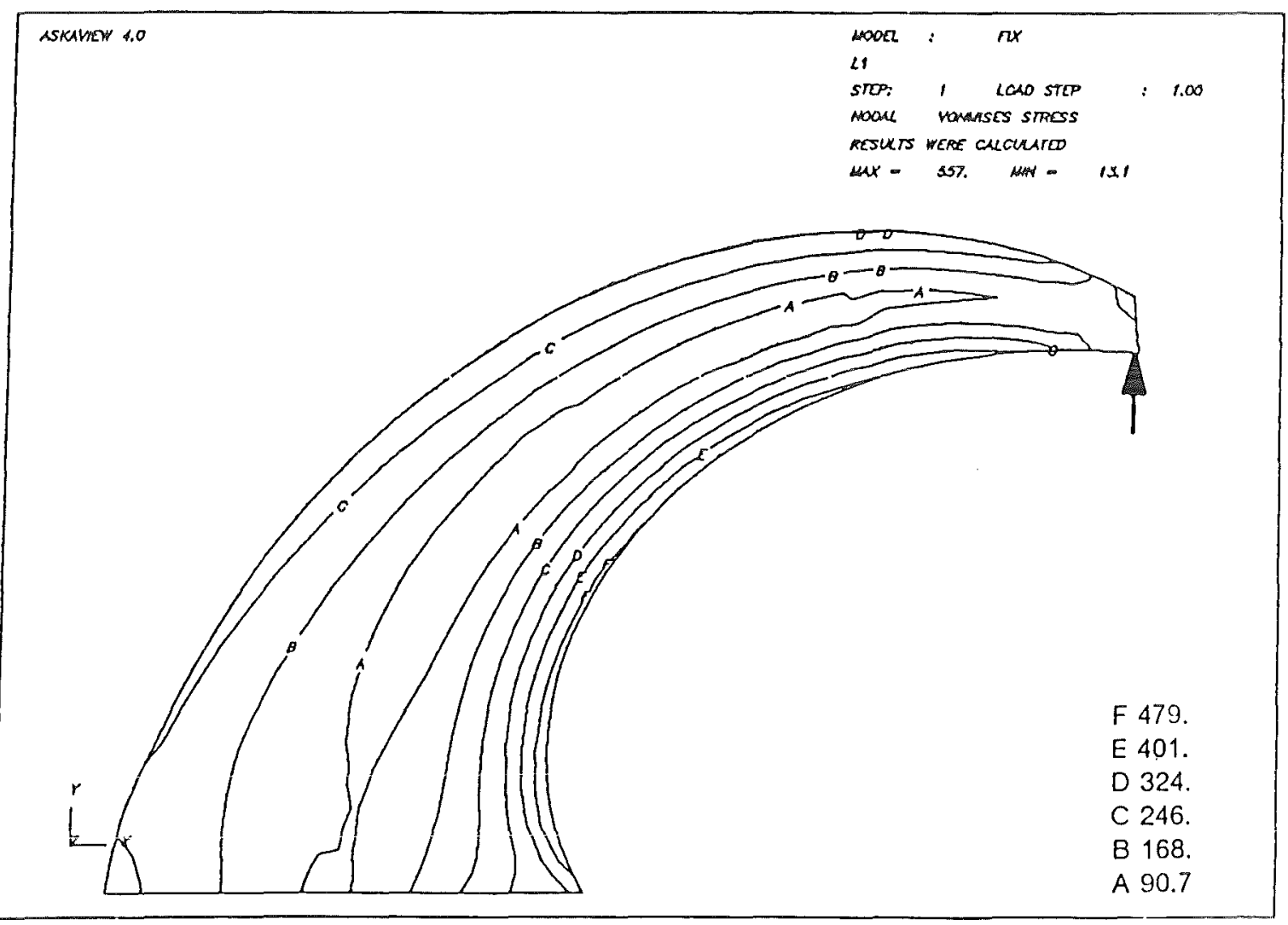

Fig.9 FEM-analysis of a tiger claw showing very good constant-stressbehaviour of von Mises stresses along the logarithmic spiral contour line 

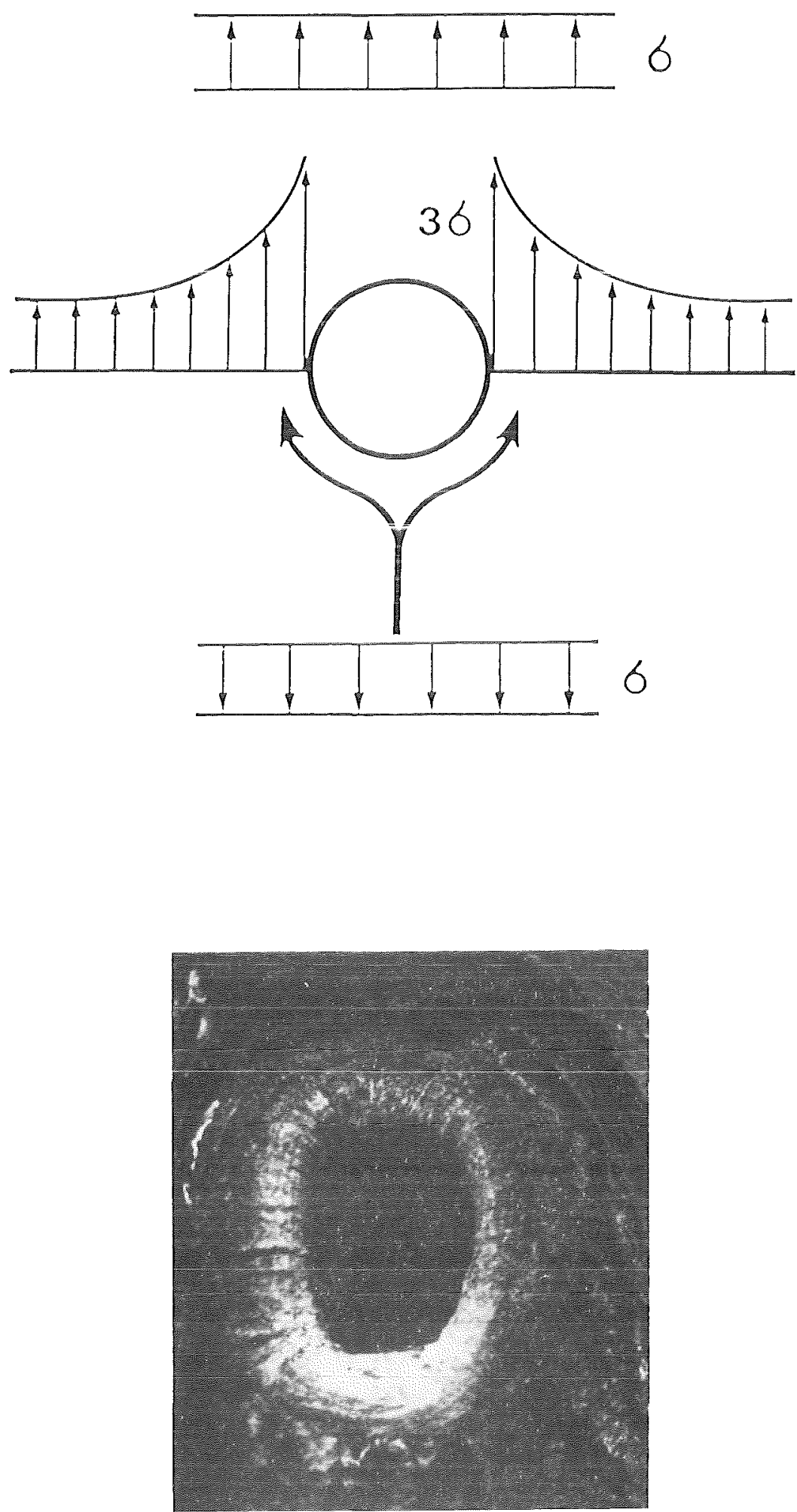

Fig.10 Normal wound healing of branch holes in trees is most active at places of highest notch stresses 


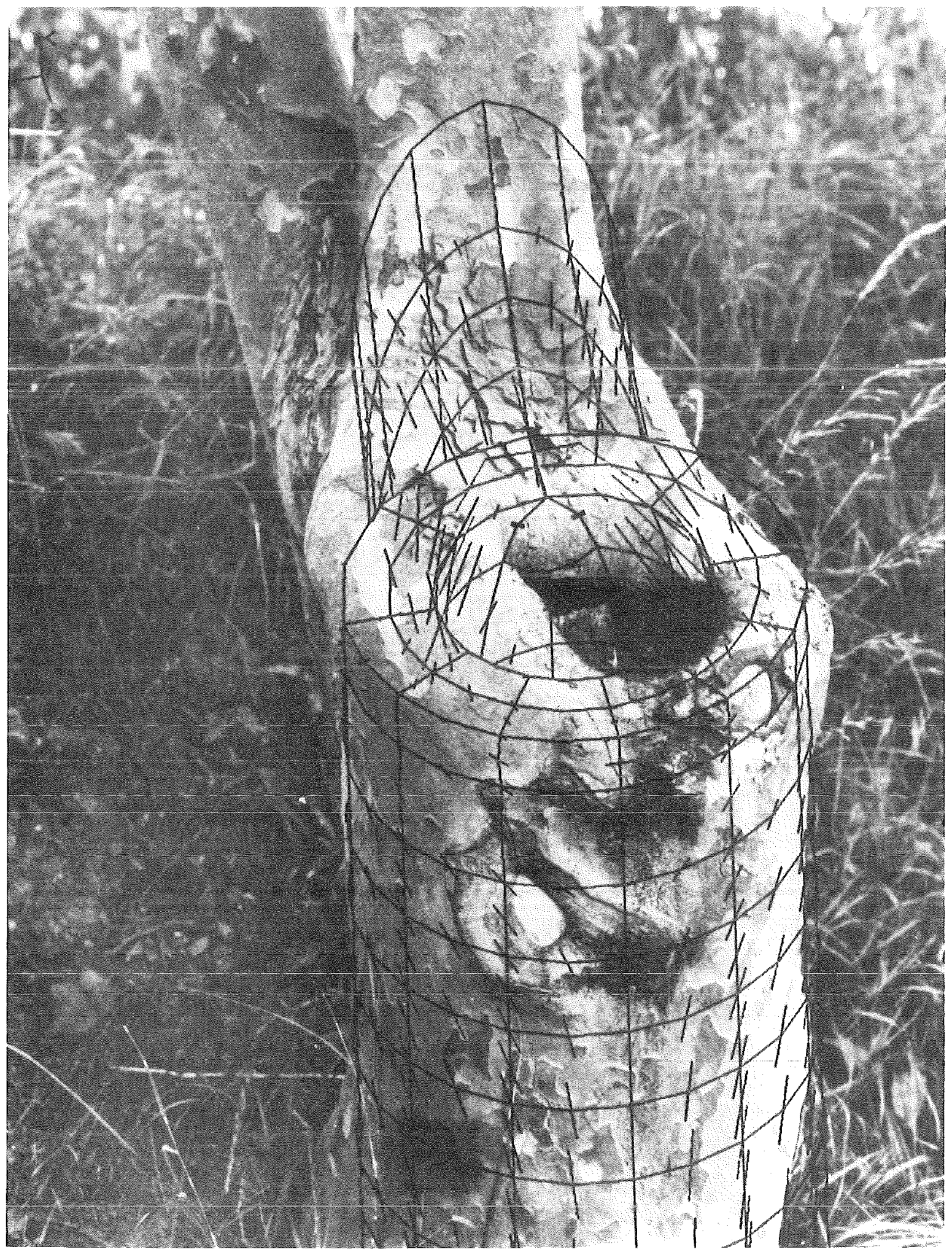

Fig.11 The long axis of partially healed wounds coincides well with main stress trajectories also slanted to the vertical axis (Photo: W. Eisele) 


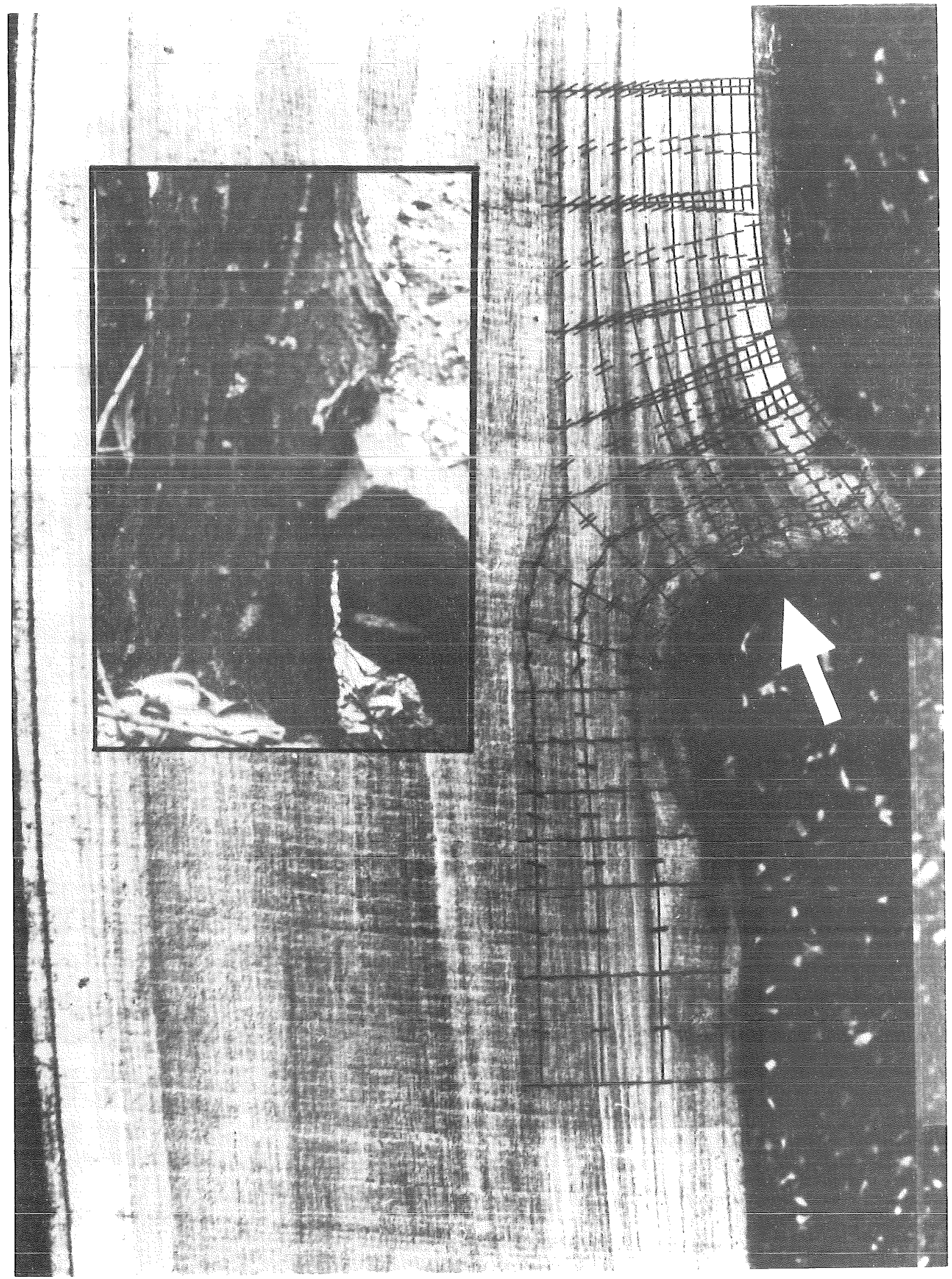

Fig.12a A heavy stone contacts a tree causing high localized contact stresses which are reduced by 'overgrowth', e.g. by increase of the contacting area. The main stress trajectories coincide with the axial direction of growth rings in order to avoid shear between them. 

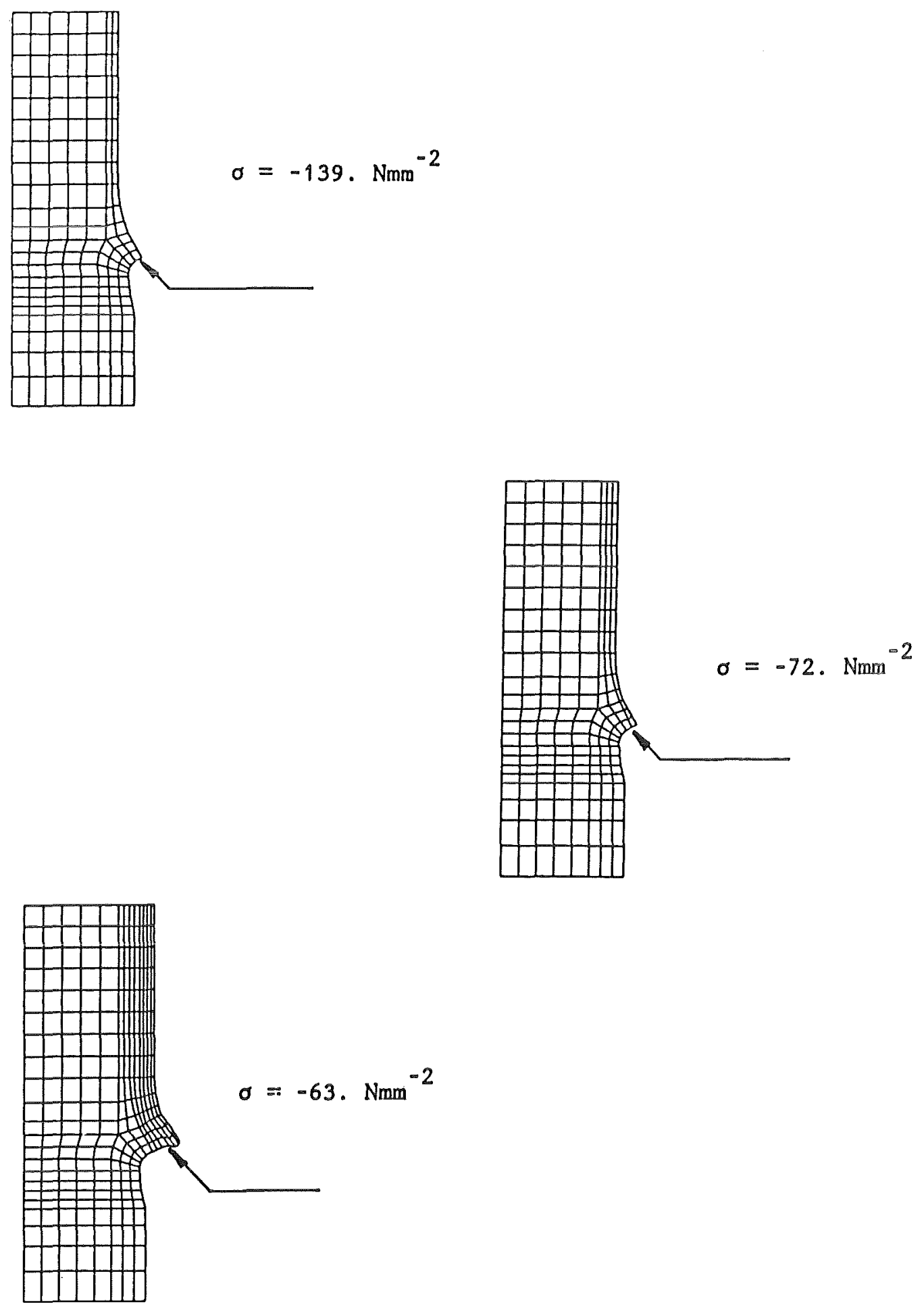

Fig.12b Reduction of maximum contact stresses. by increase of the contact area due to adaptive growth 


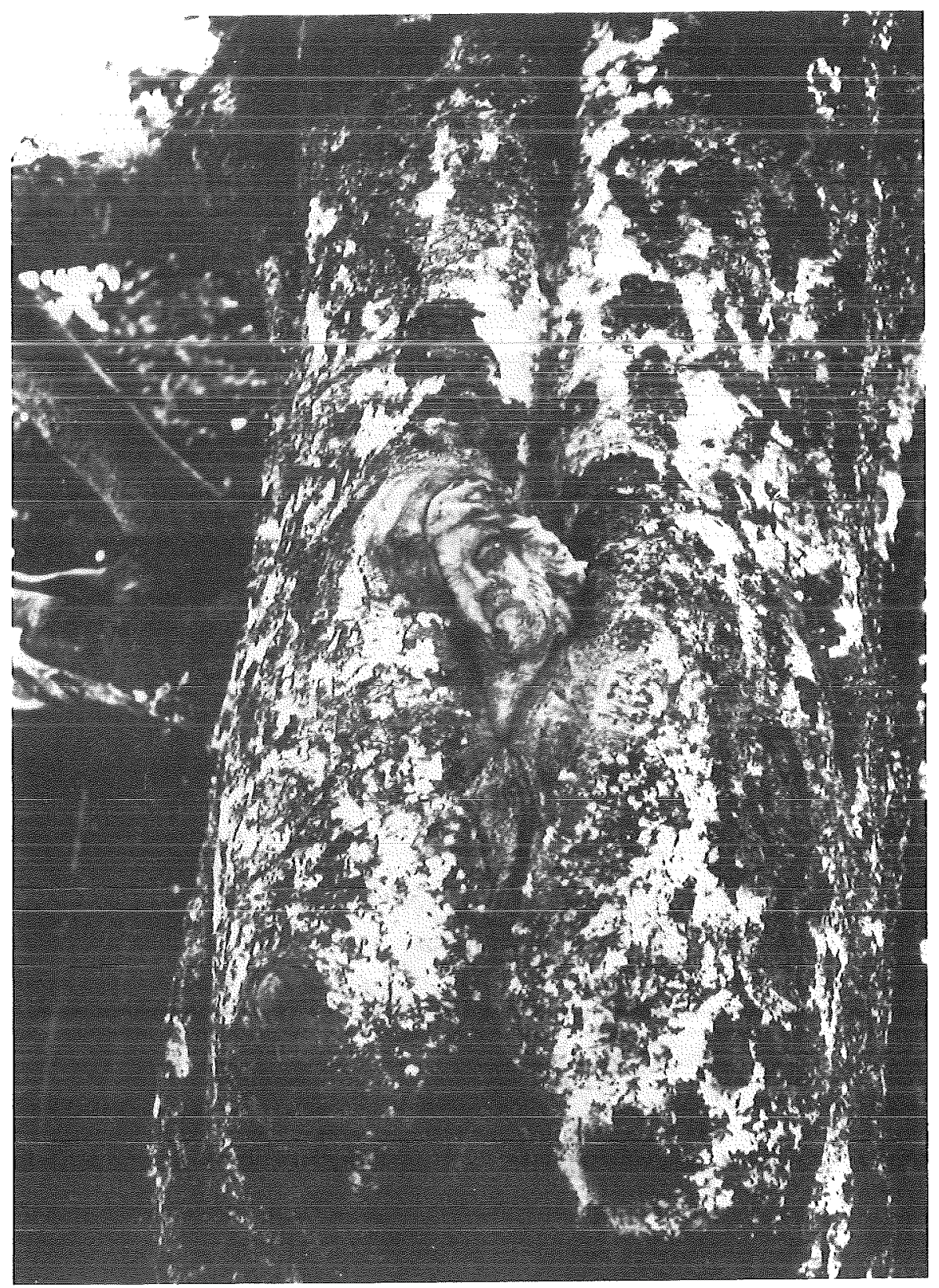

Fig.13 'The Balzer Lord' as a spectacular example of 'overgrowth' reducing contact stresses (Photo: Reinhard) 

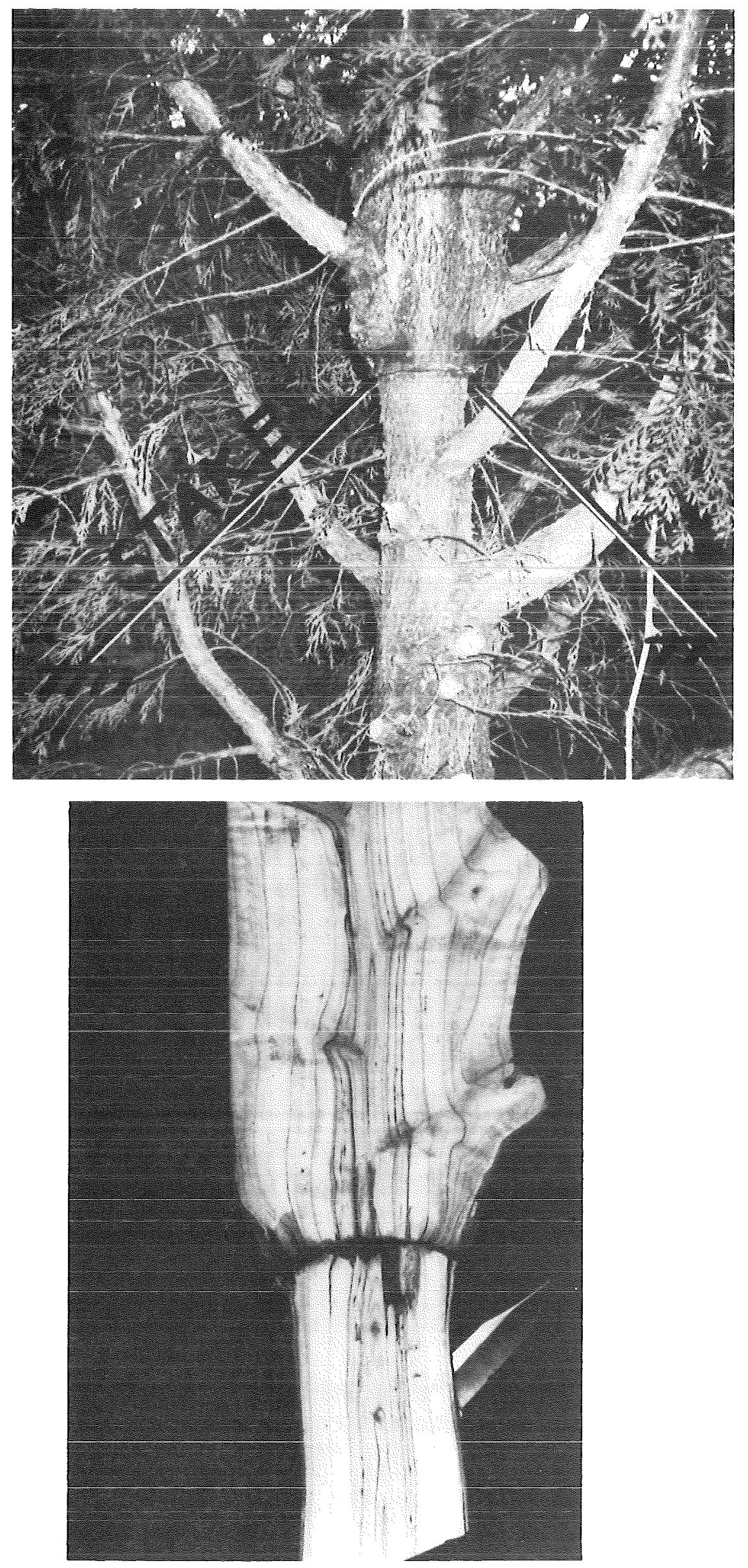

Fig.14 Adaptive growth of a tree tries to compensate increased stresses above 'forgotten' supporting stakes.

Note the increase in growth ring width above the notch! 


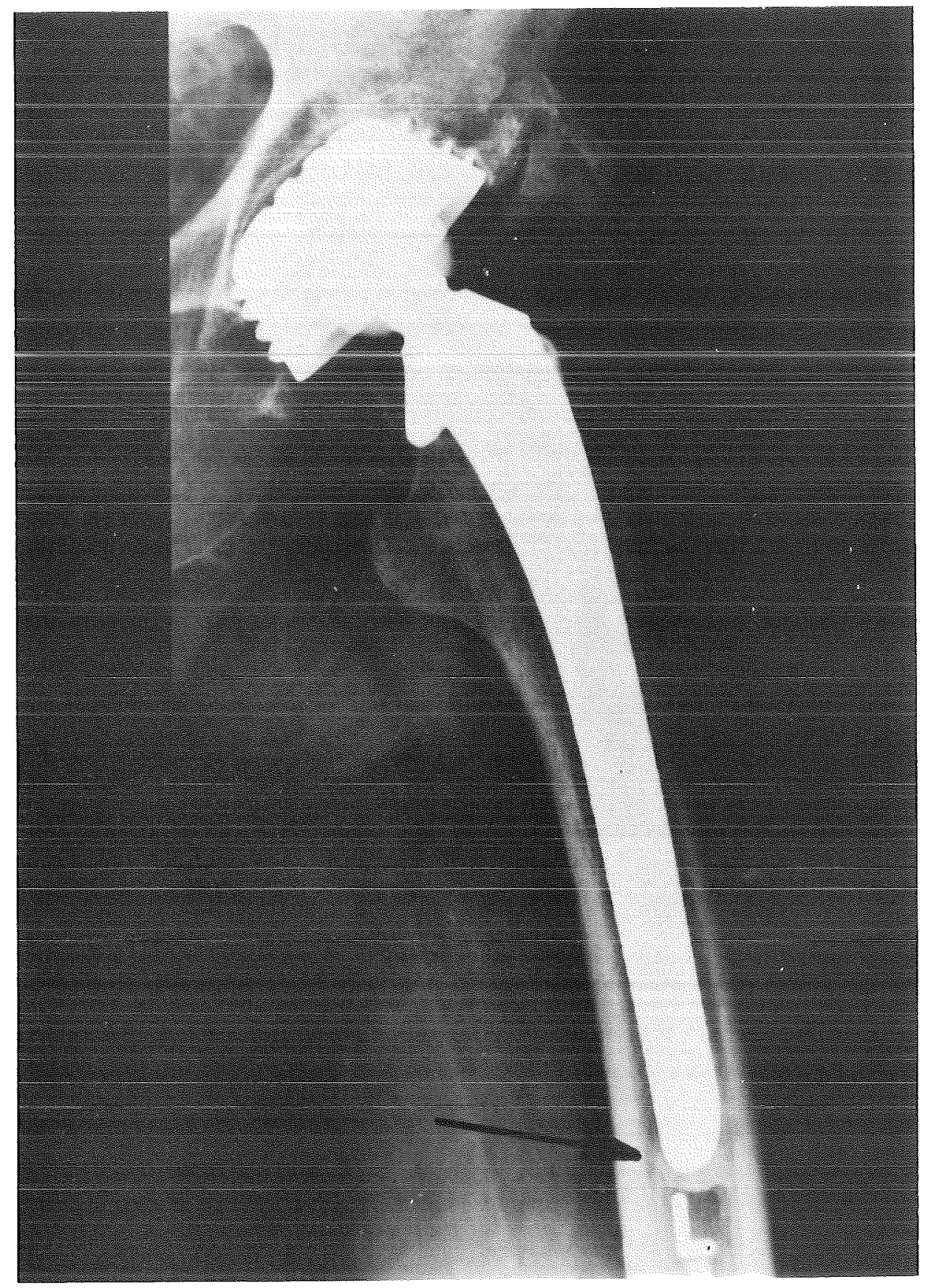

Fig. 15 Formation of a bony plug just below the stem of a hip endoprosthesis in order to compensate localiy increased stresses

a) Global view 

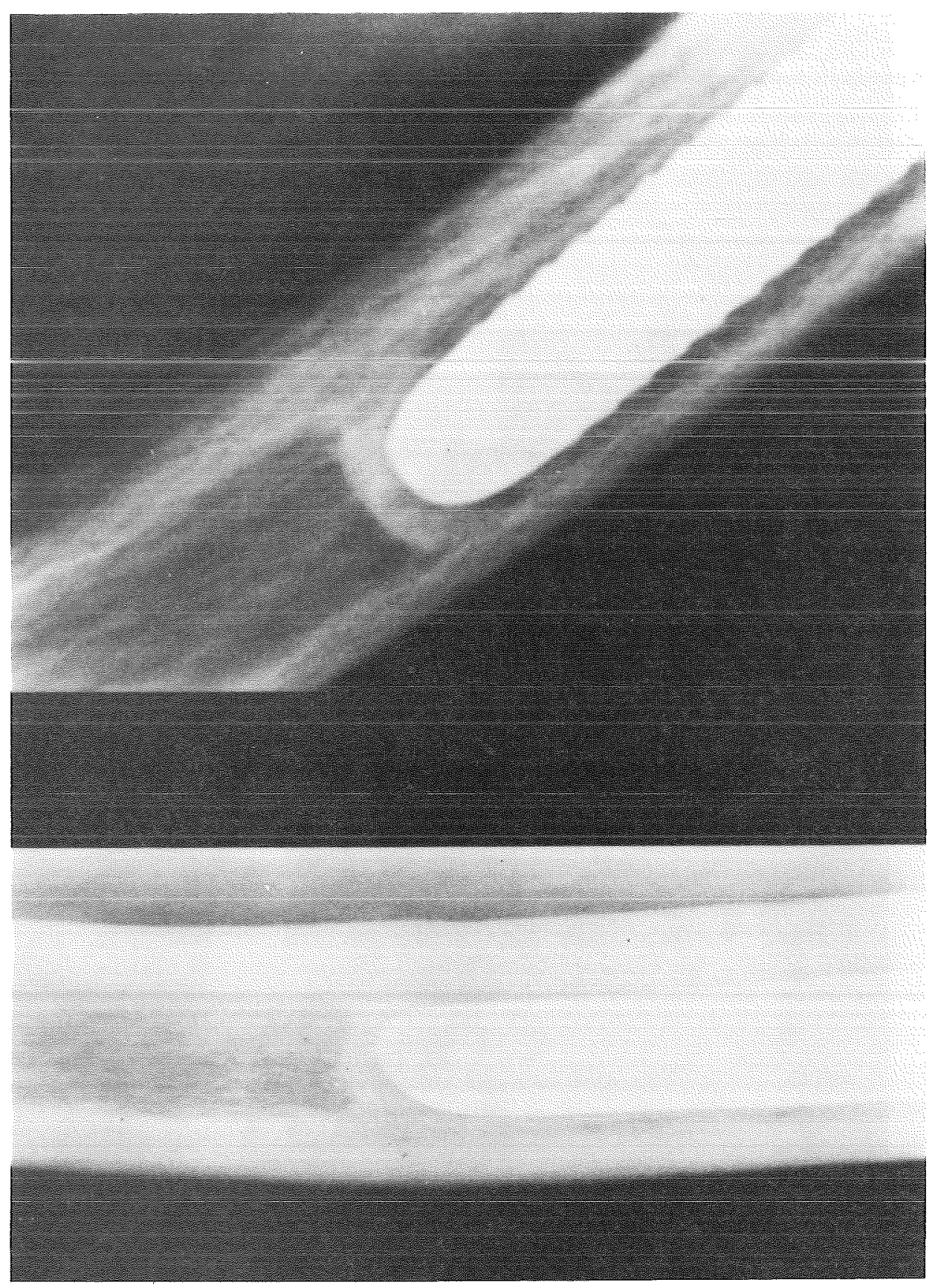

b) Details of other prosthesis tips surrounded by bony plugs 


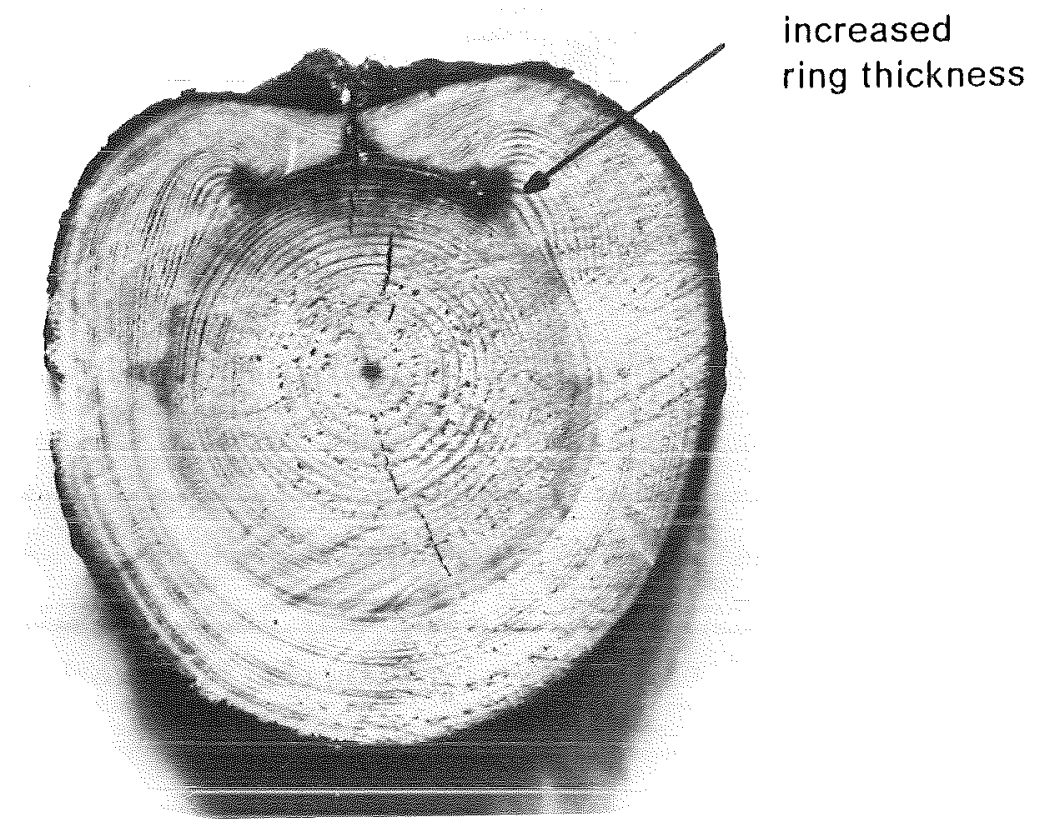

Fig.16 In trees only the outermost growth ring is active and only this ring is able to react to external loads.

This tree was wounded and the wound acts as a notch inducing notch stresses at its border. Only growth rings produced after the time of wounding react by adaptive growth.

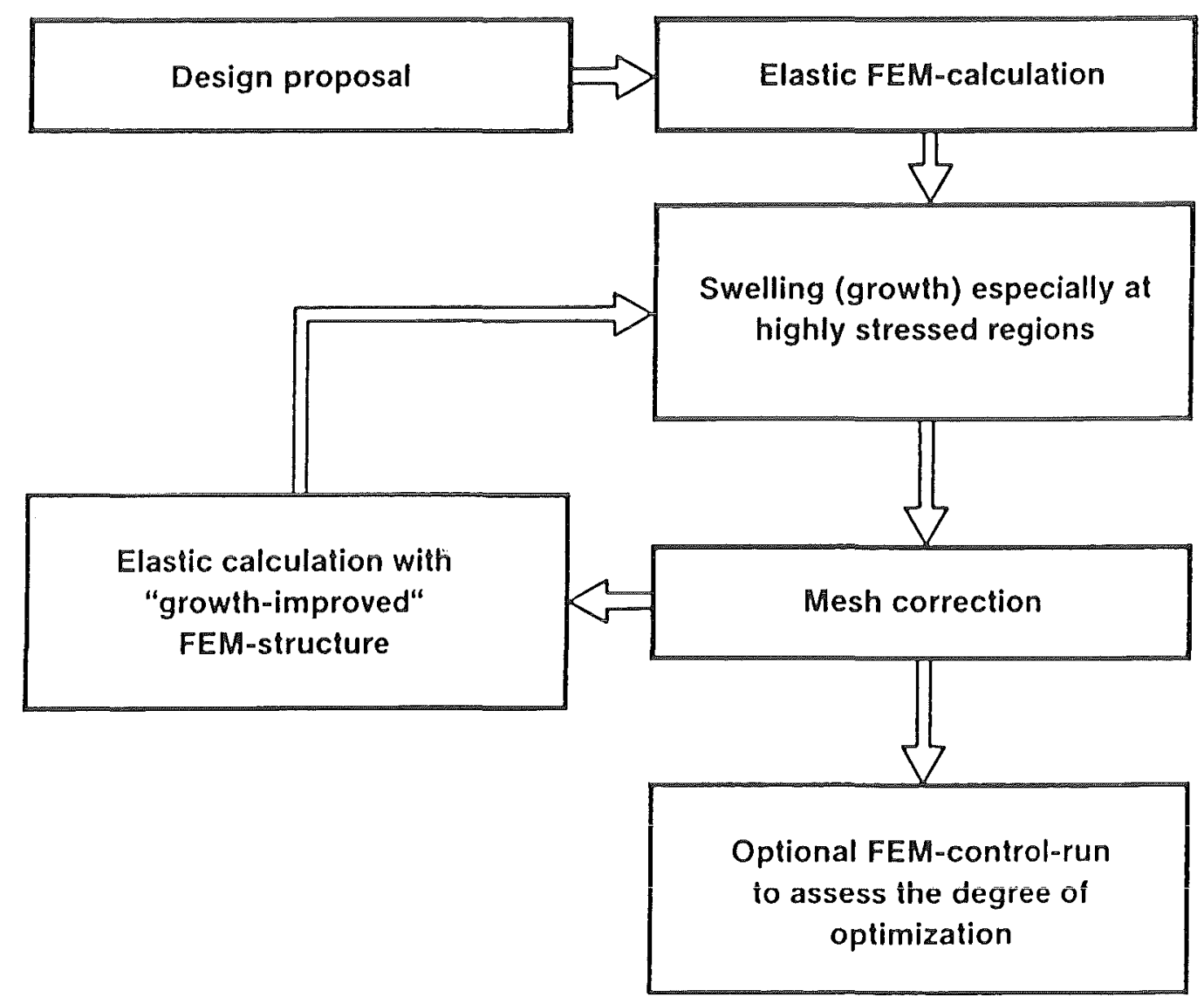

Fig.17 Flow chart of the CAO-procedure 
Fig. 18

\section{Framework tree}

This beech tree found near Lyon la Foret in France has formed a lateral bridge (framework) from one stem of a tree fork to the other. The branch that is forming the bridge was completely integrated in the other stem. The edges (notches) of the joint are smoothed by adaptive growth. Most impressive at first sight is that the left stem only increases its girth above the bridge. No further growth can be seen within the framework below the lateral joint, because there are reduced stresses which do not stimulate further growth. 


\section{Framework tree}

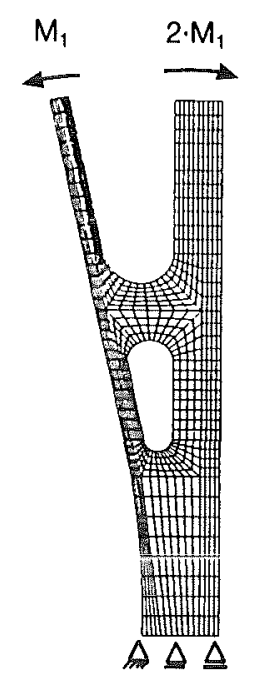

non-optimized
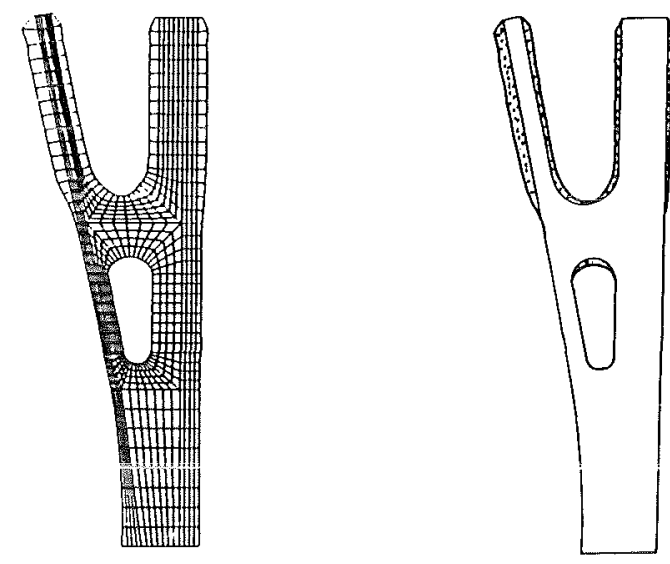

optimized

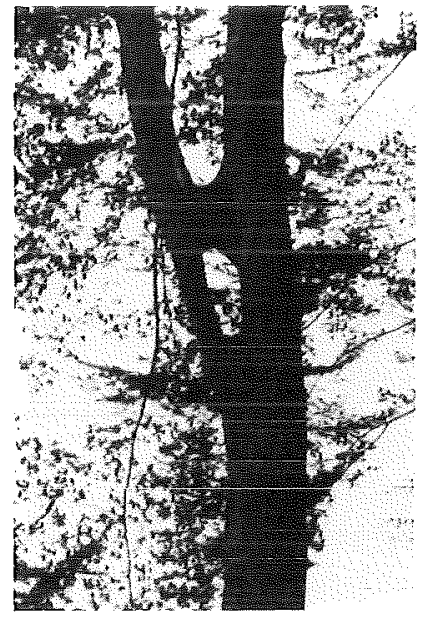

Reduction of maximum stresses $68 \%$

v. Mises-stress distribution

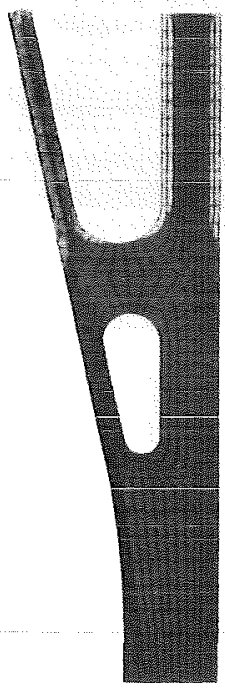

non-optimized

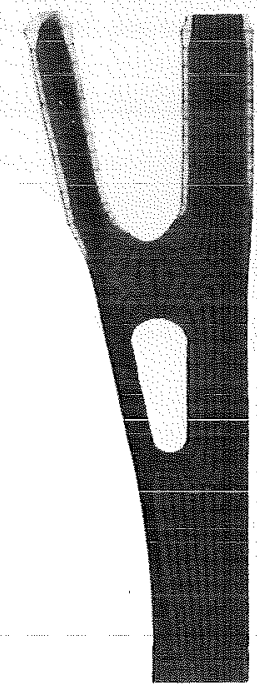

400.

350.

300.

250.

200.

150.

100.

50.0
0

optimized

FEM: Susanne Burkhardt 
Fig. 19

\section{H-shaped tree}

This tree had a fate similar to that of the framework tree described before. The left internal notch, however, has also healed into a 'rounded' contour (photo) which could not be computer simulated. Looking at the saw cut (photo) the reason becomes clear. At first the tree in reality also healed into a narrow peak-like notch (see growth rings!) whose surfaces then touched each other, came into contact, were 'welded' together and made the contour smoother. This could be simulated only by use of interface elements which have not heen used here. Iooling at the tree growth rings rolated to the carly stage of integration of the bridging branch the agreement between theory and real growth is found to be satisfactory, also at that critical point [21].
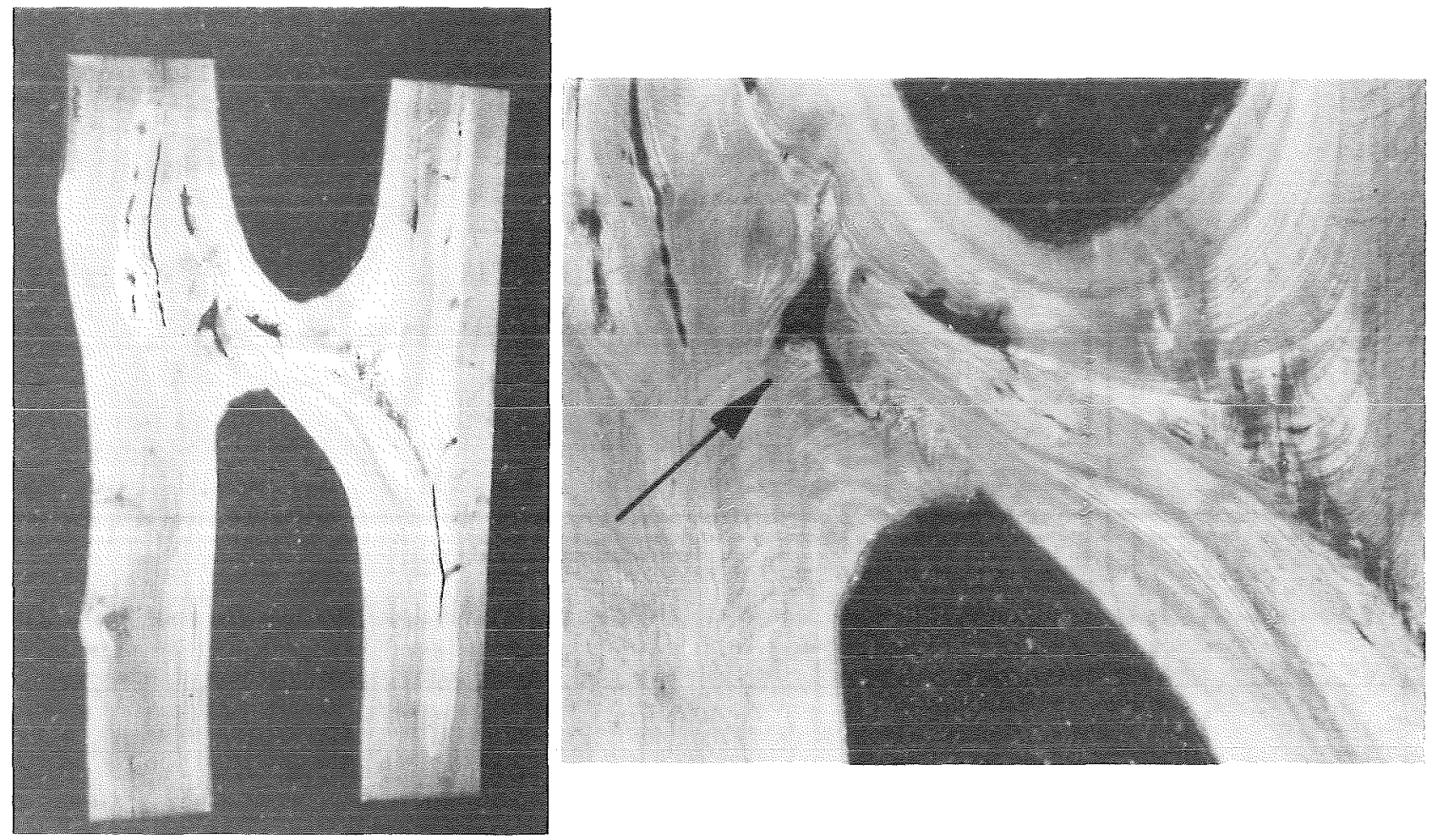


\section{Framework tree}

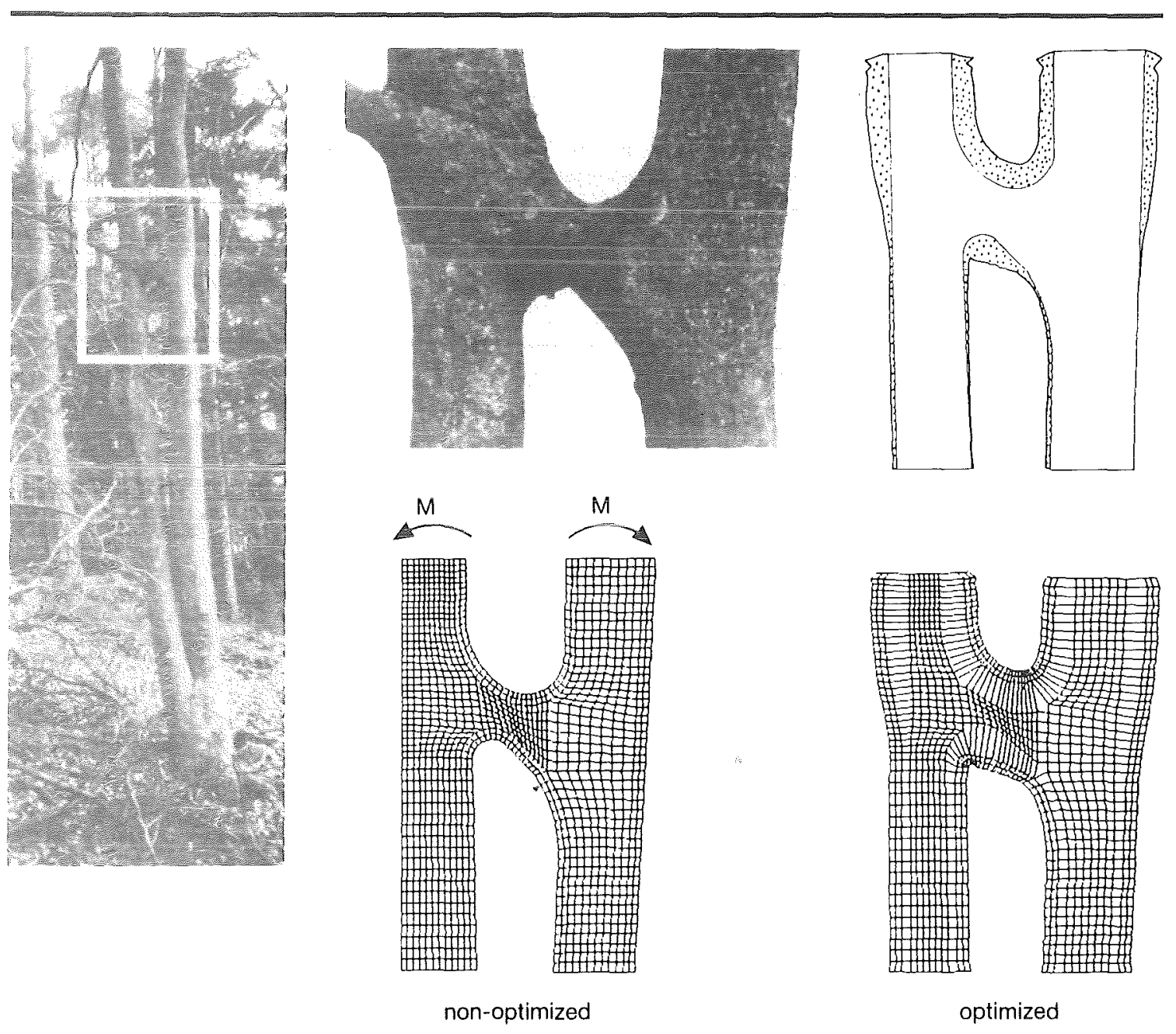

Reduction of maximum stresses $56 \%$

v. Mises-stress distribution

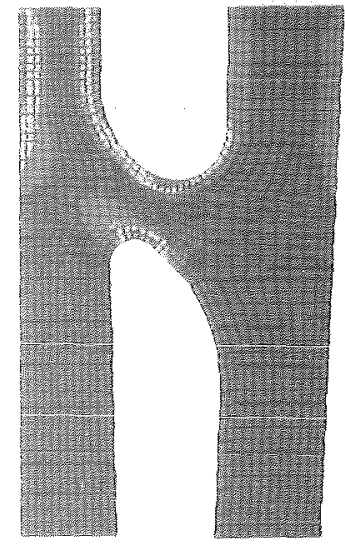

non-optimized

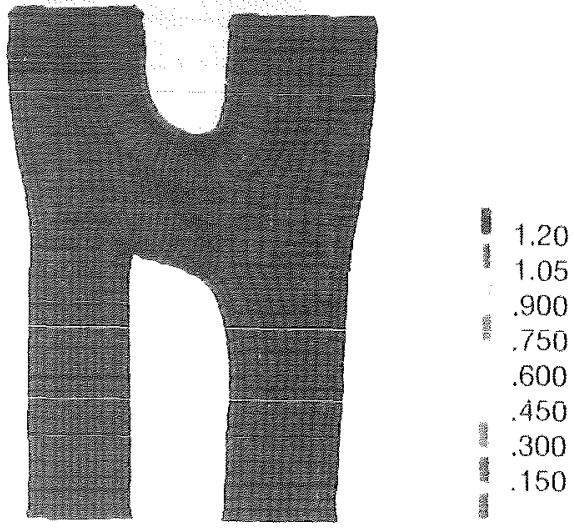

optimized 
Fig. 20

\section{Healing of branch holes}

When a branch is pruned at its base it will dry or be destroyed by decay. Beside the wound notch stresses will occur even if the branch 'hole' is filled with the stump of the branch. Tensile stresses are acting at the periphery of a tree. The tree tries to restorate a state of constant stress which had been disturbed by the wound. Therefore, wound healing is fastest at places of highest stresses, leading to the vertical spindle shape which can be seen on the photo.

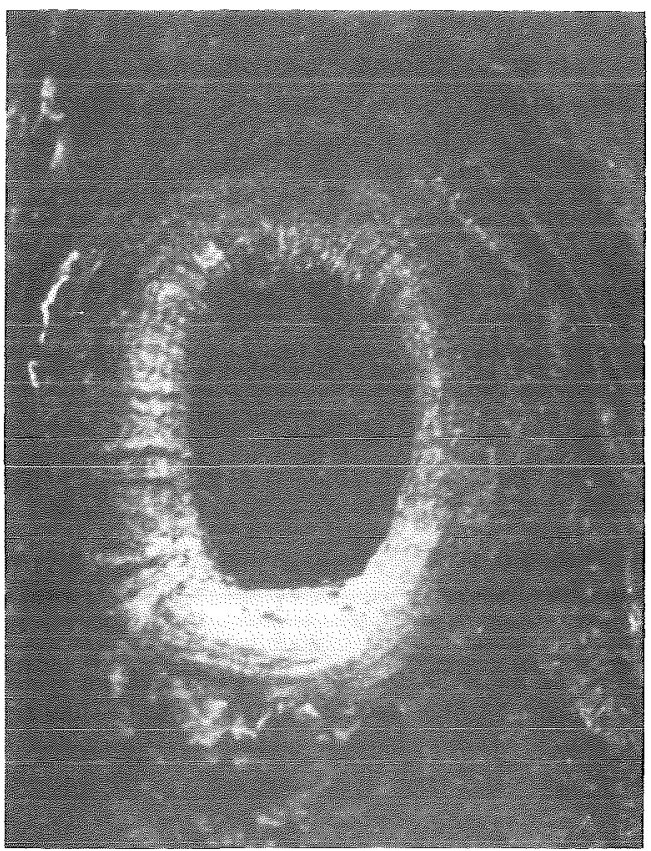




\section{Circular hole in tensile plate growing into a spindle shape}

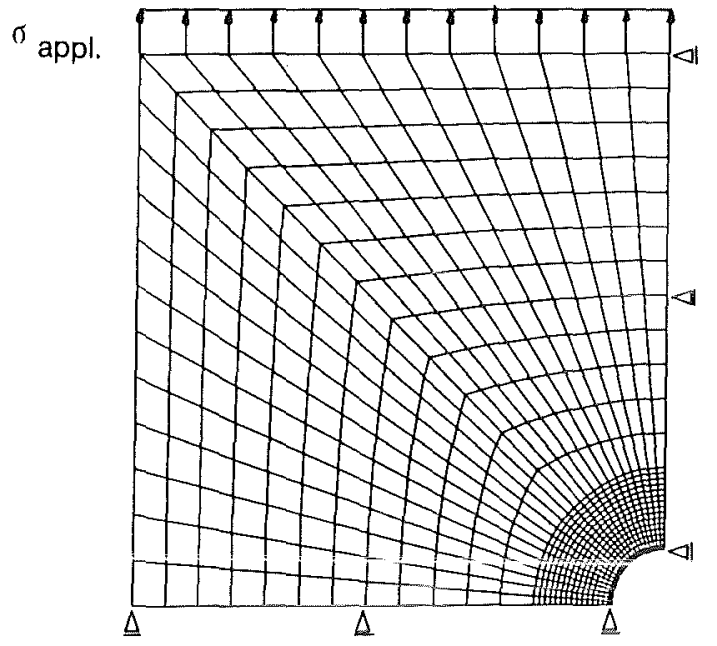

non-optimized
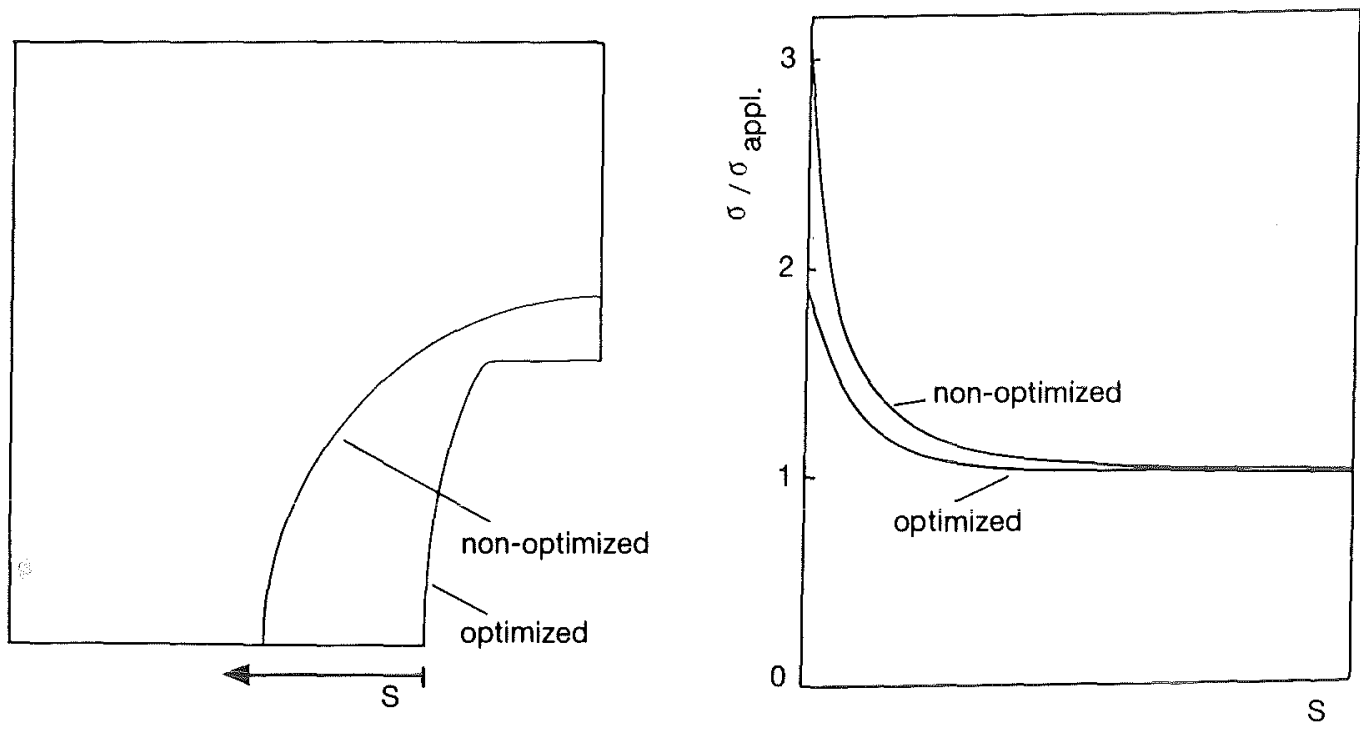

v. Mises-stress distribution
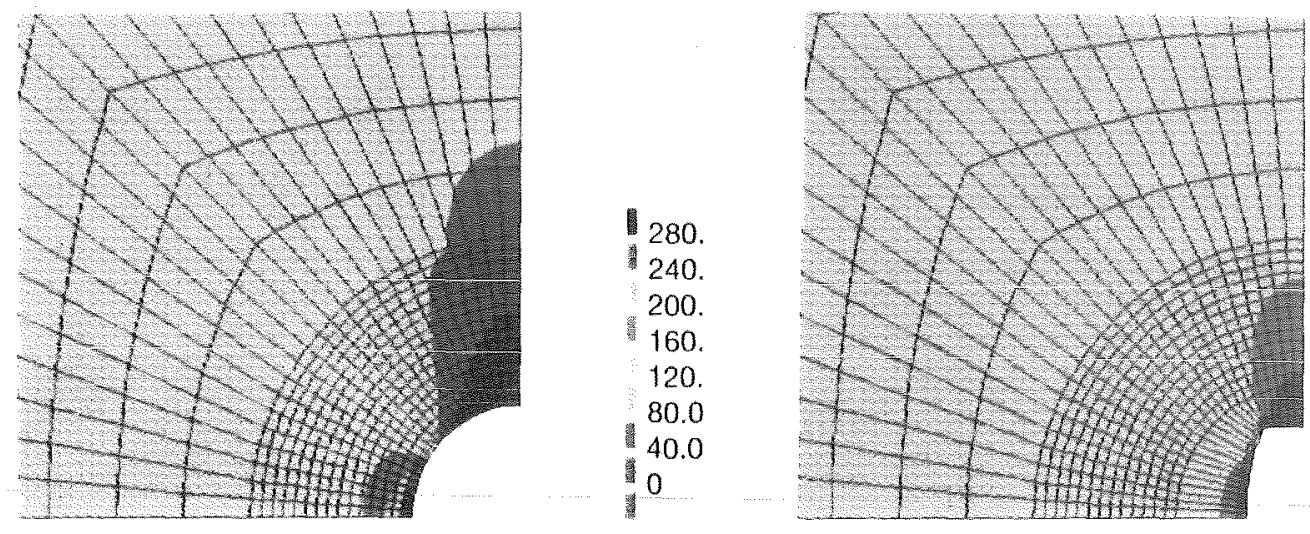

FEM: Susanne Burkhardt 
Fig. 21

\section{Hole in tensile plate kept in circular shape}

If a hole is not allowed to heal into a spindle shape as discussed earlier for branch holes, the solution is to allow growth out-of-plane. This will lead to the formation of some ridges directed parallel to the externally applied tension. The force flow stopped at the upper and lower borders of the hole is now redirected into the ridges where lower or no notch stresses are caused because of the increased volume. The photo shows that this phenomenon can be seen also at branch holes with old branch stumps situated low at the stem. The optimization has been done in a very cost-effective way by a one-cycle run.

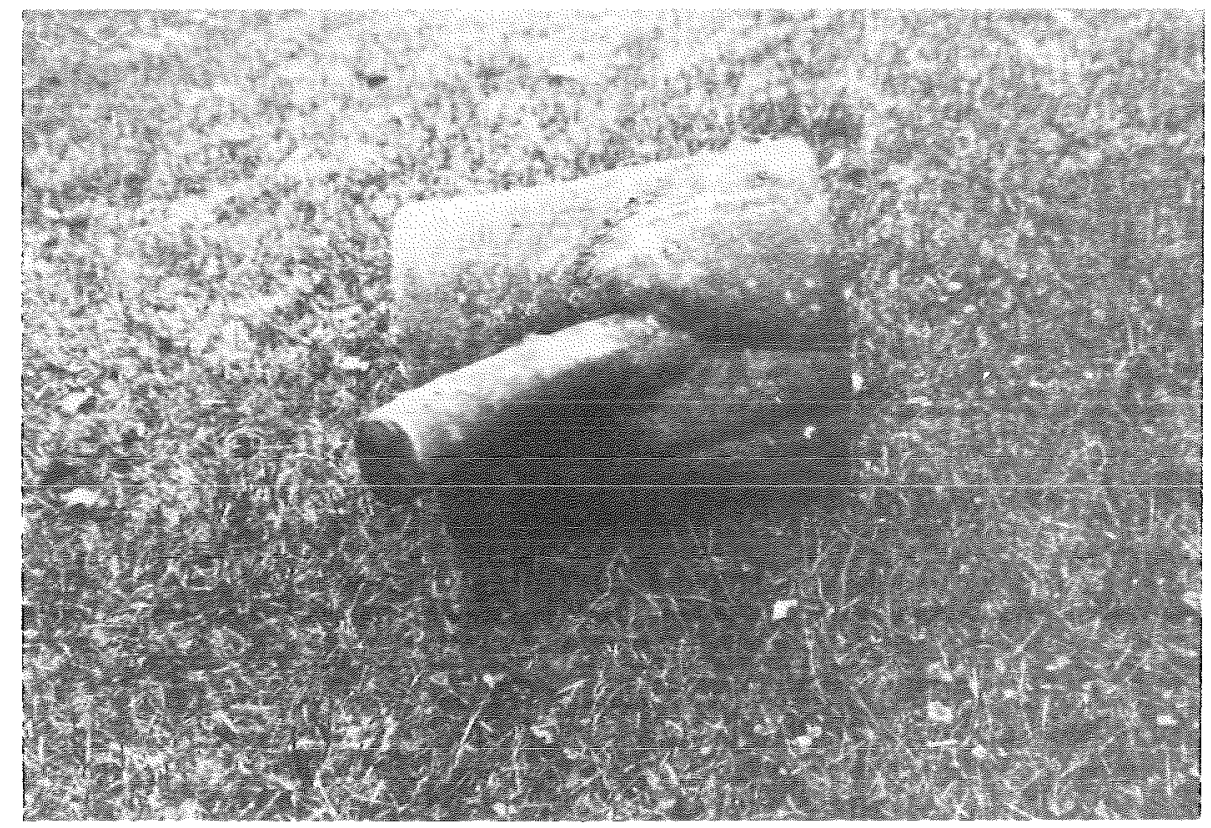




\section{Tensile plate with circular hole}
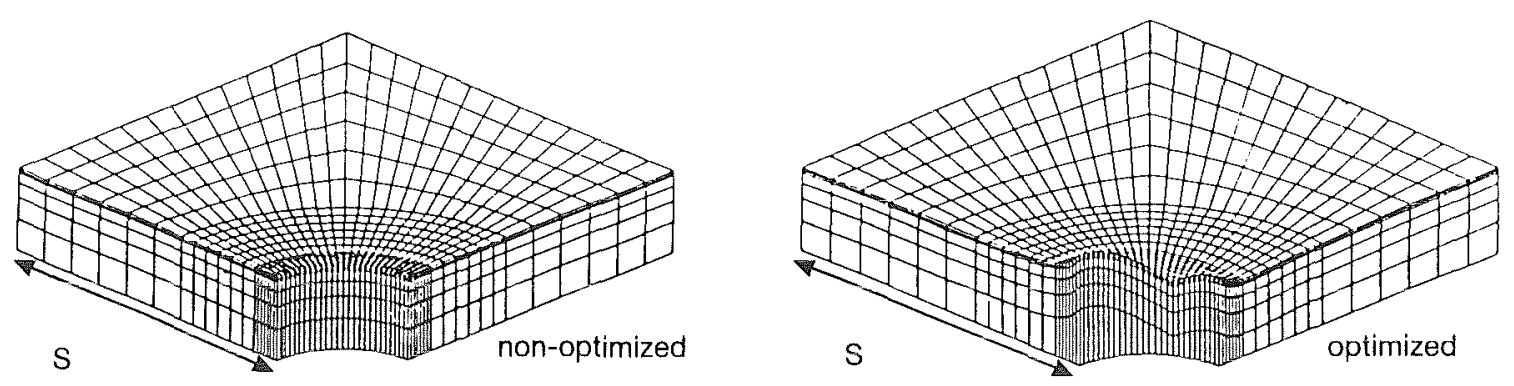

$1 / 8$ structure

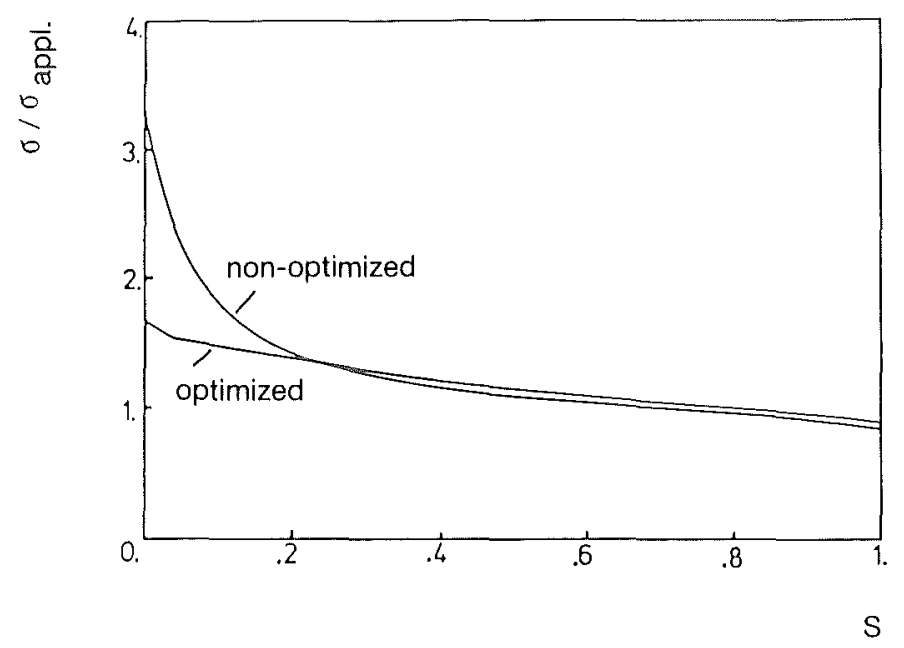

v. Mises-stress distribution

320

280.

240.

200.

160

120

80.0

non-optimized

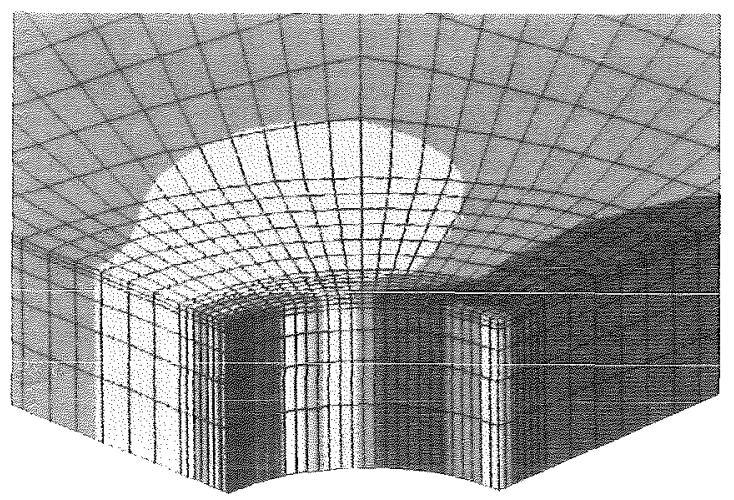

optimized

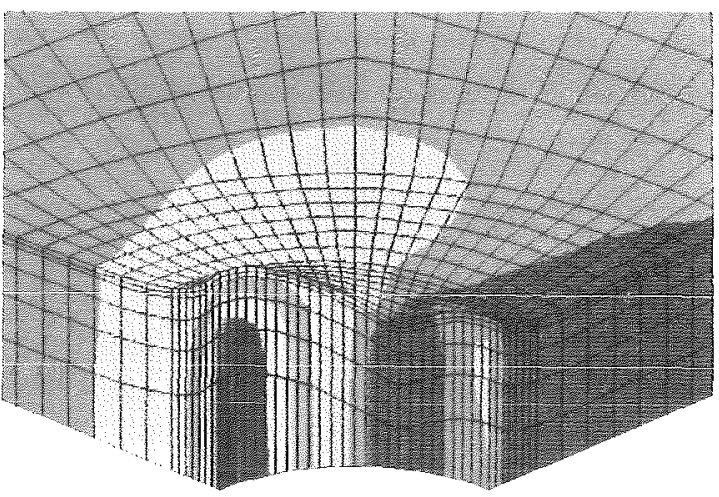


Fig. 22

\section{Claw of a tiger}

The tiger claw has the shape of a logarithmic spiral. In order to check its degree of shape optimization a design proposal was made with two intersecting circular contours, which lead to high notch stresses. After application of CAO the claw contours are logarithmic spirals as expected having a much more homogeneous distribution of Mises-stresses along the contour lines. 


\section{Claw of a tiger}
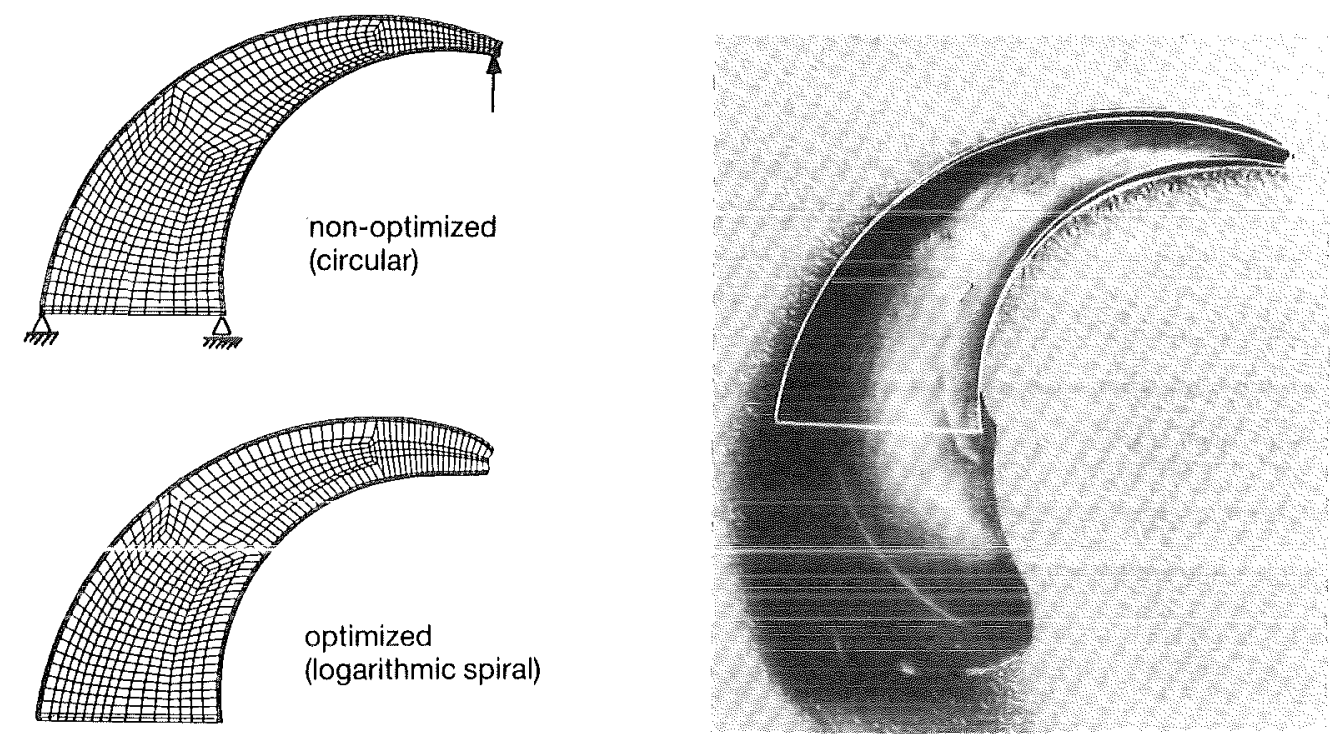

v. Mises-stress along contour
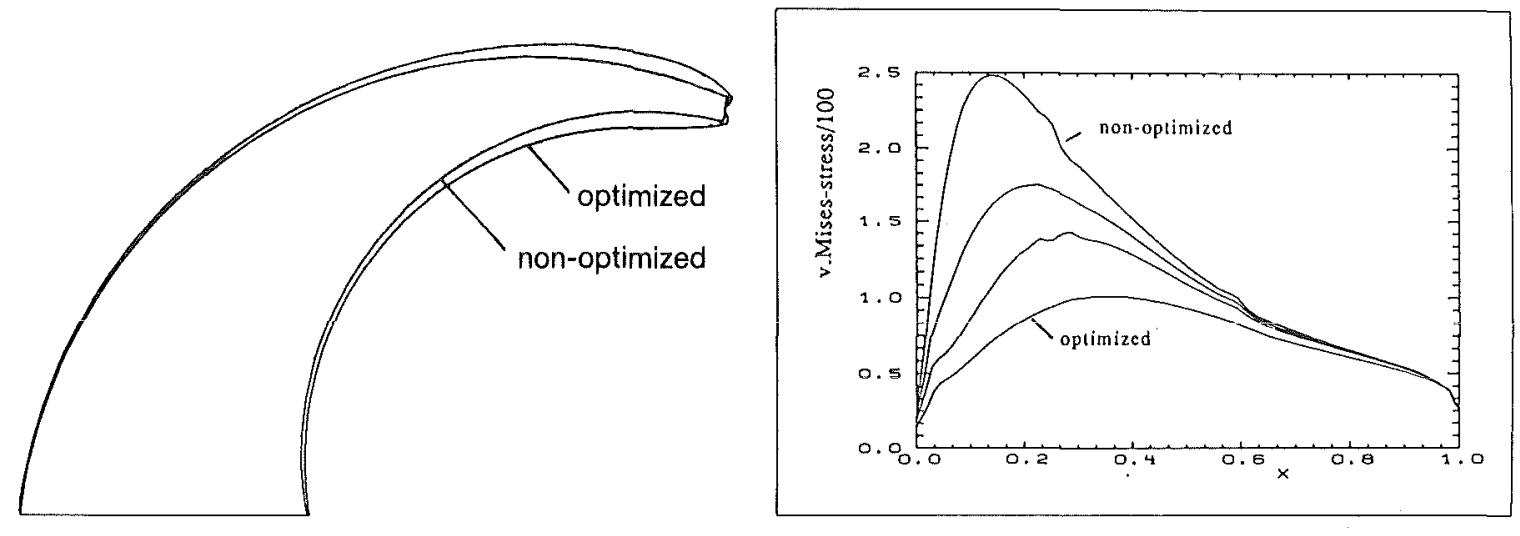

v. Mises-stress distribution

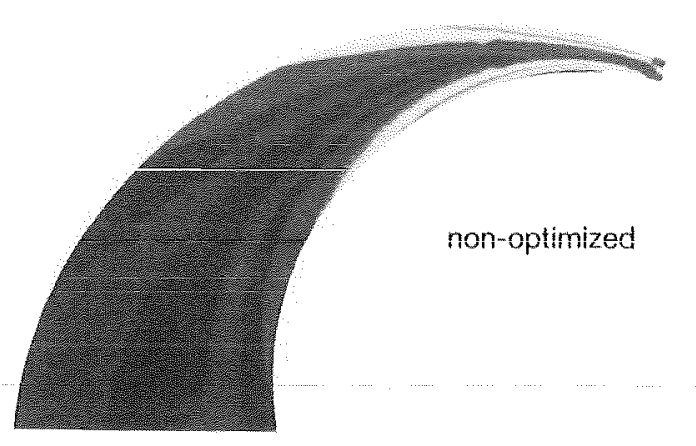

231.
215.
198.
182.
149.
132.
116.
99.2
82.7
49.6
33.1
16.5
10

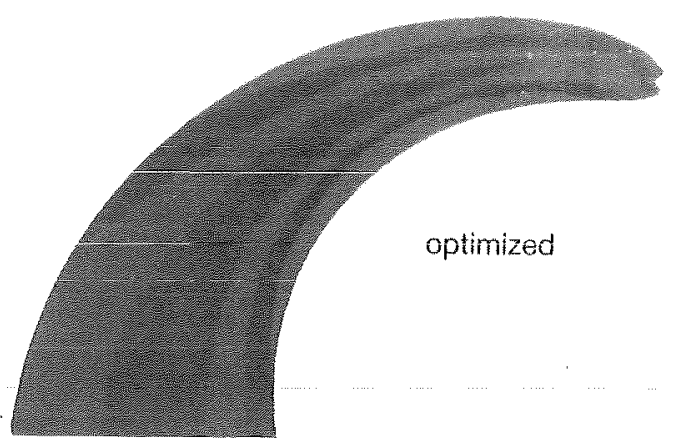

FEM: Stefan Reuss 
Fig. 23

\section{Bending bar with narrowing cross-section}

The design proposal again has a narrowing cross-section described by a circular contour line which leads to a stress magnification factor of 1.8. Shape optimization successfully reduces the notch stresses. The notch con-

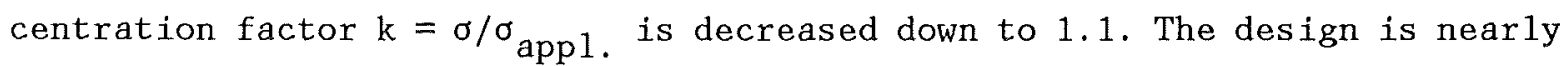
identical to the Baud curve [7] which may be found frequently in nature in both the original and the modified versions (Figures $4,5,6$ ). 


\section{Bending bar with narrowing cross-section}
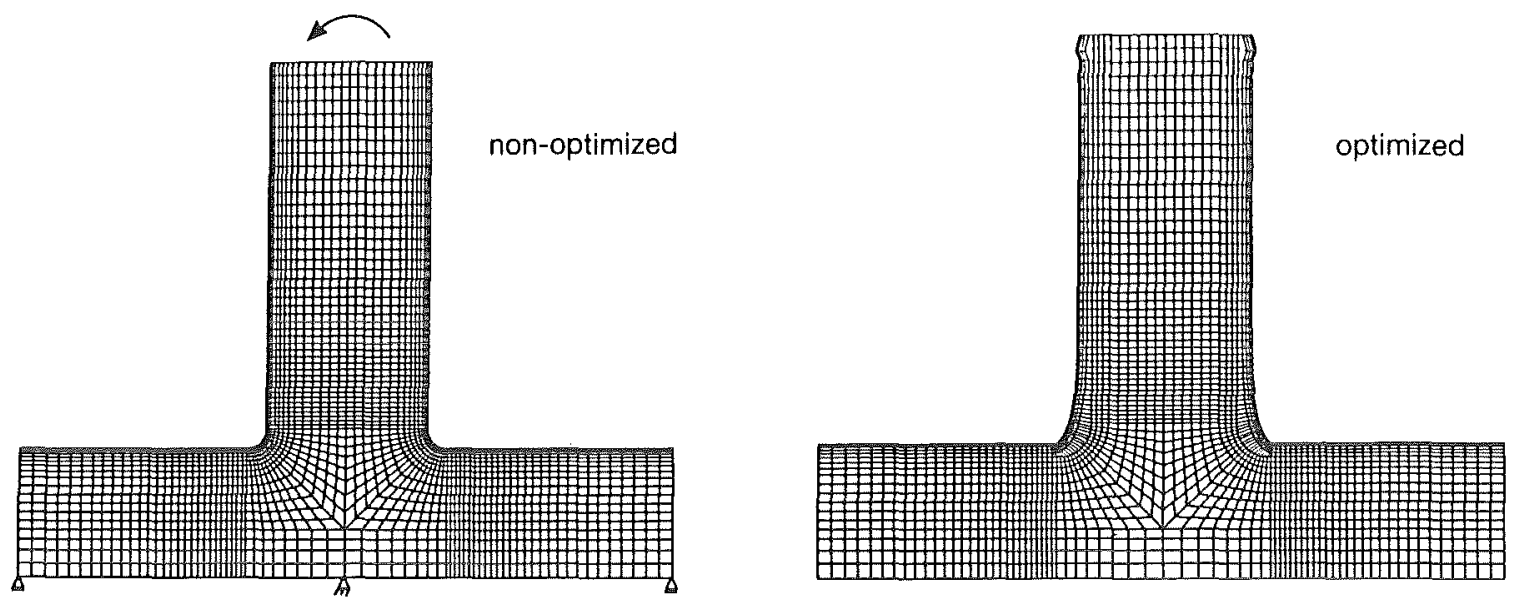

tangential stresses along contour
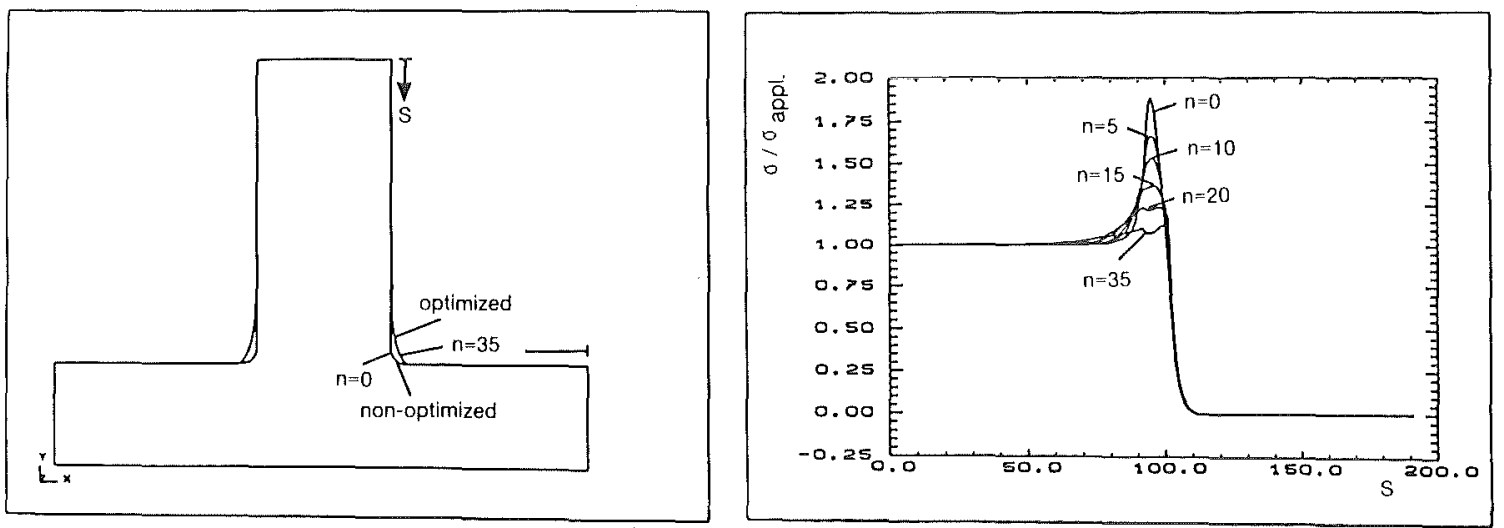

v. Mises-stress distribution

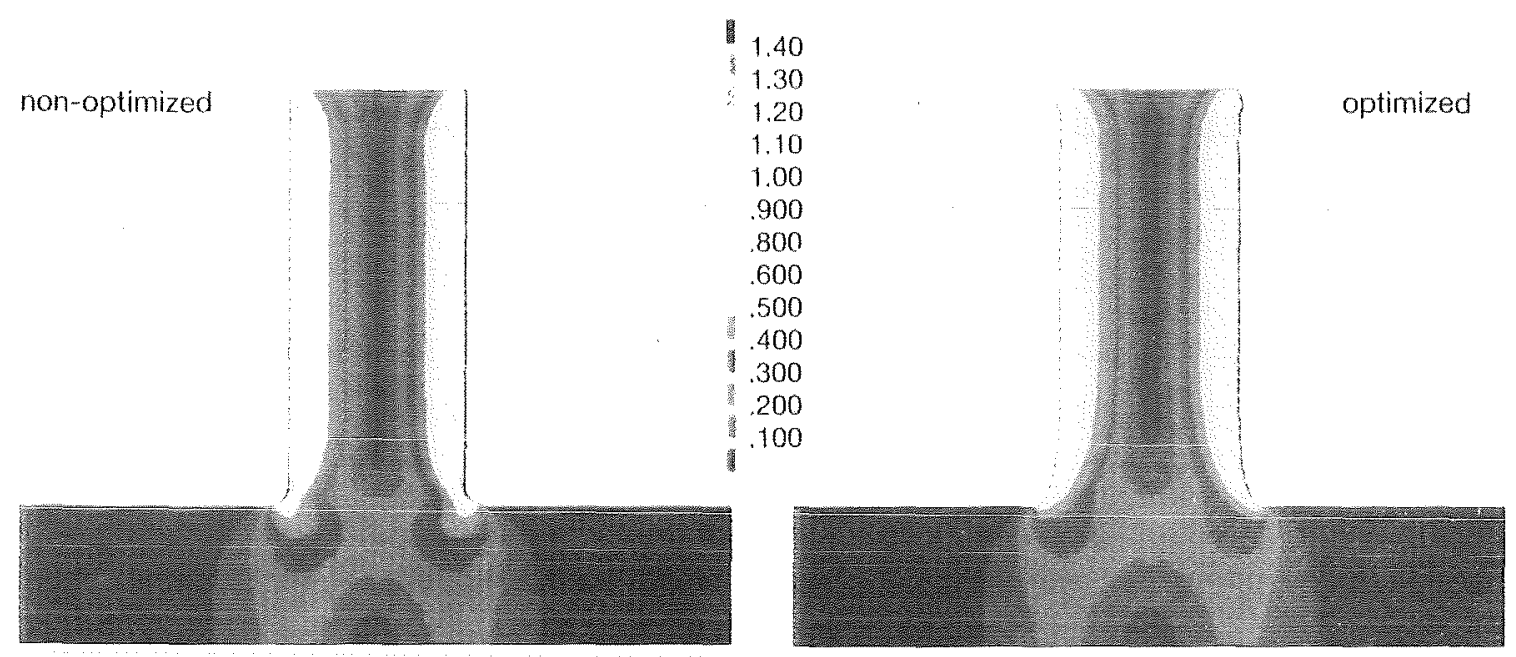

FEM: Dagmar Erb 
Fig. 24

\section{Tensile bar with narrowing cross-section}

The FEM-structure is only half of the real structure because of symmetry. The design proposal has a quarter circle as transition contour line leading to a magnification of applied stress by the factor 1.7. This is reduced to 1.1 by shape optimization. 


\section{Tension bar with narrowing cross-section}
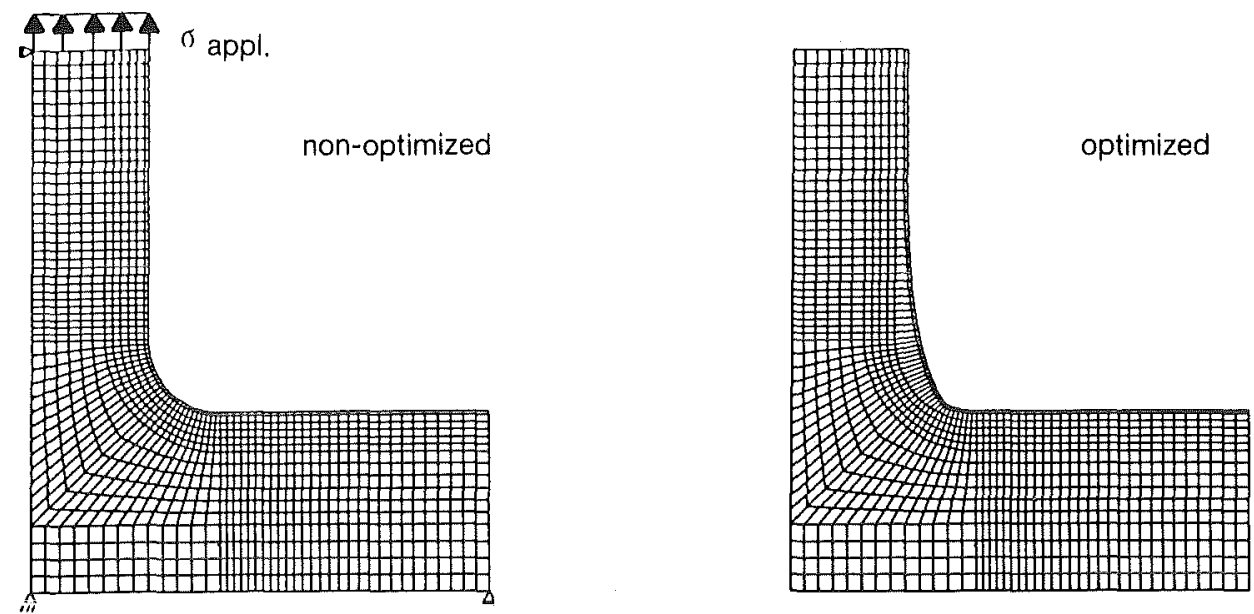

tangential stresses along contour
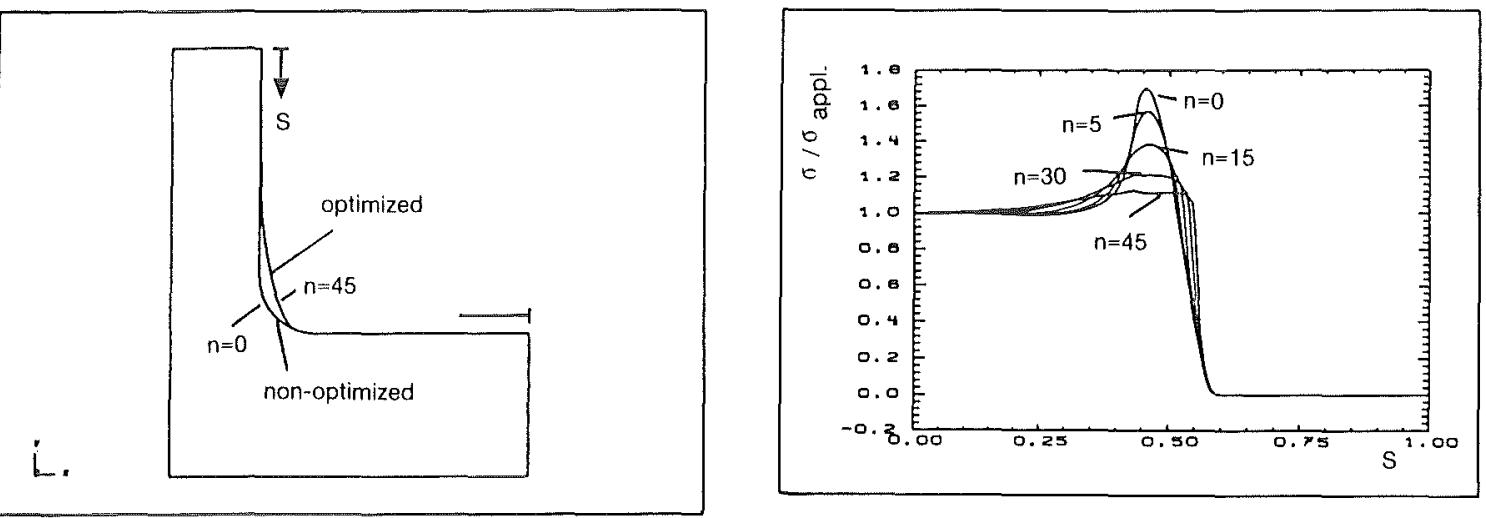

v. Mises-stress distribution

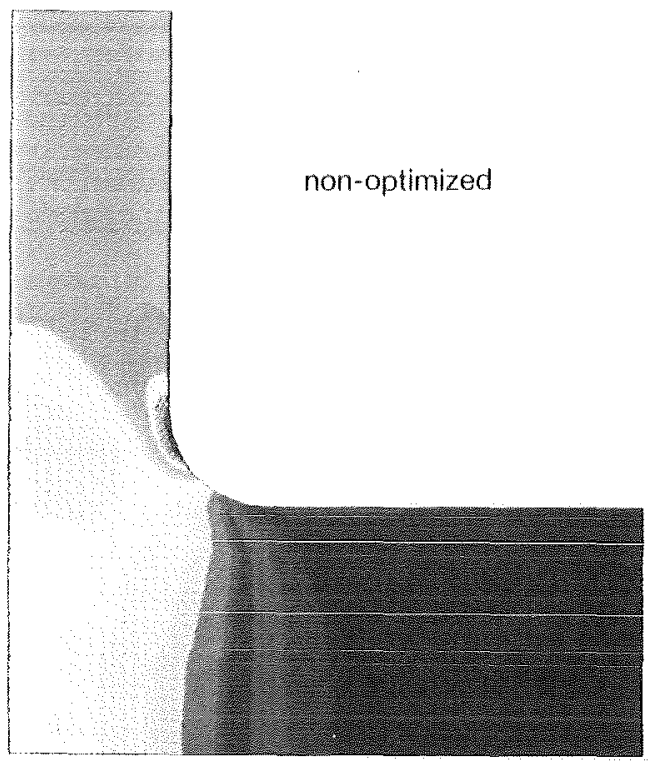

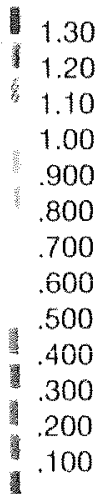

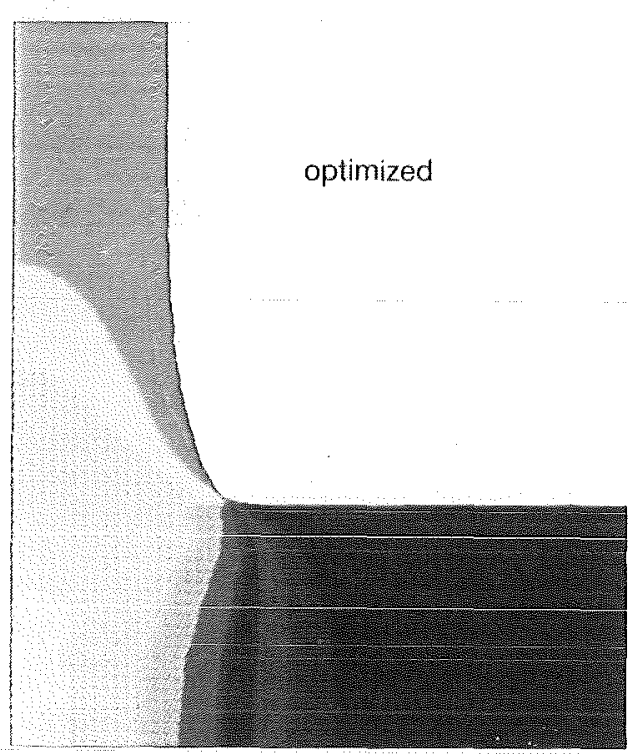

FEM: Dagmar Erb 
Fig. 25

\section{Tensile strip with a knee}

The upper part of the design proposal is homogeneously stressed by the axially applied tensile stress. The lower part is subjected to the same axial force superimposed to some bending stresses caused by the lateral lever arm. It is plausible that the lower half of the structure increases by growth, where especially the initially circular-shaped lower notch is smoothed where the highest stress acts in the design proposal. 
Tensile strip with knee

non-optimized
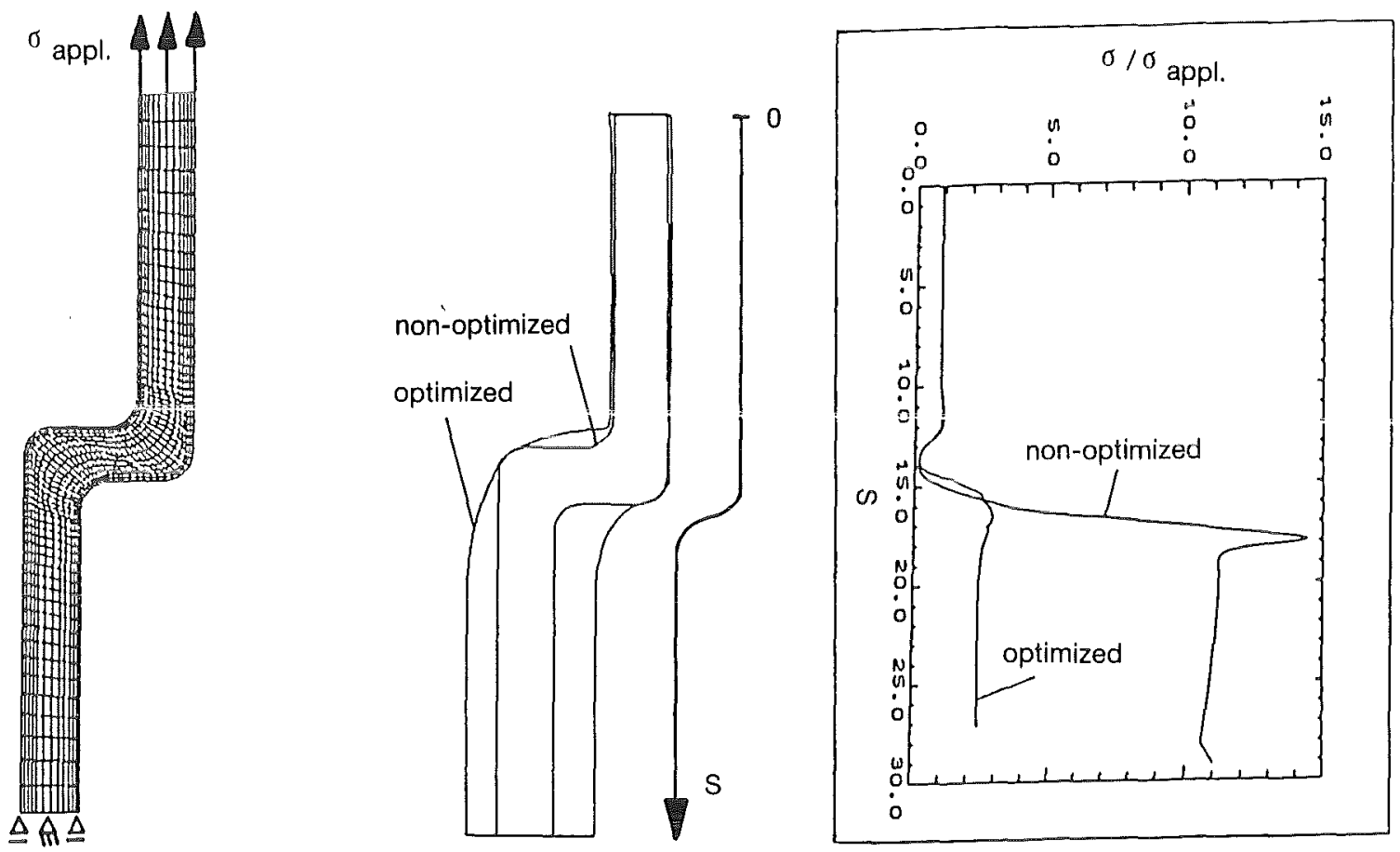

v. Mises-stress distribution 
Fig. 26

\section{Bending bar with a knee}

The same design proposal as used for the tensile strip before has been loaded by a constant bending moment at the upper end. Because in this case the bending moment is constant over the entire length, the width of the optimized design is the same everywhere. The outermost parts of the knee are nearly unloaded and, therefore, they shrink leading to this smoothly curved design with constant axial stresses at the surface. 


\section{Bending bar with knee}

non-optimized
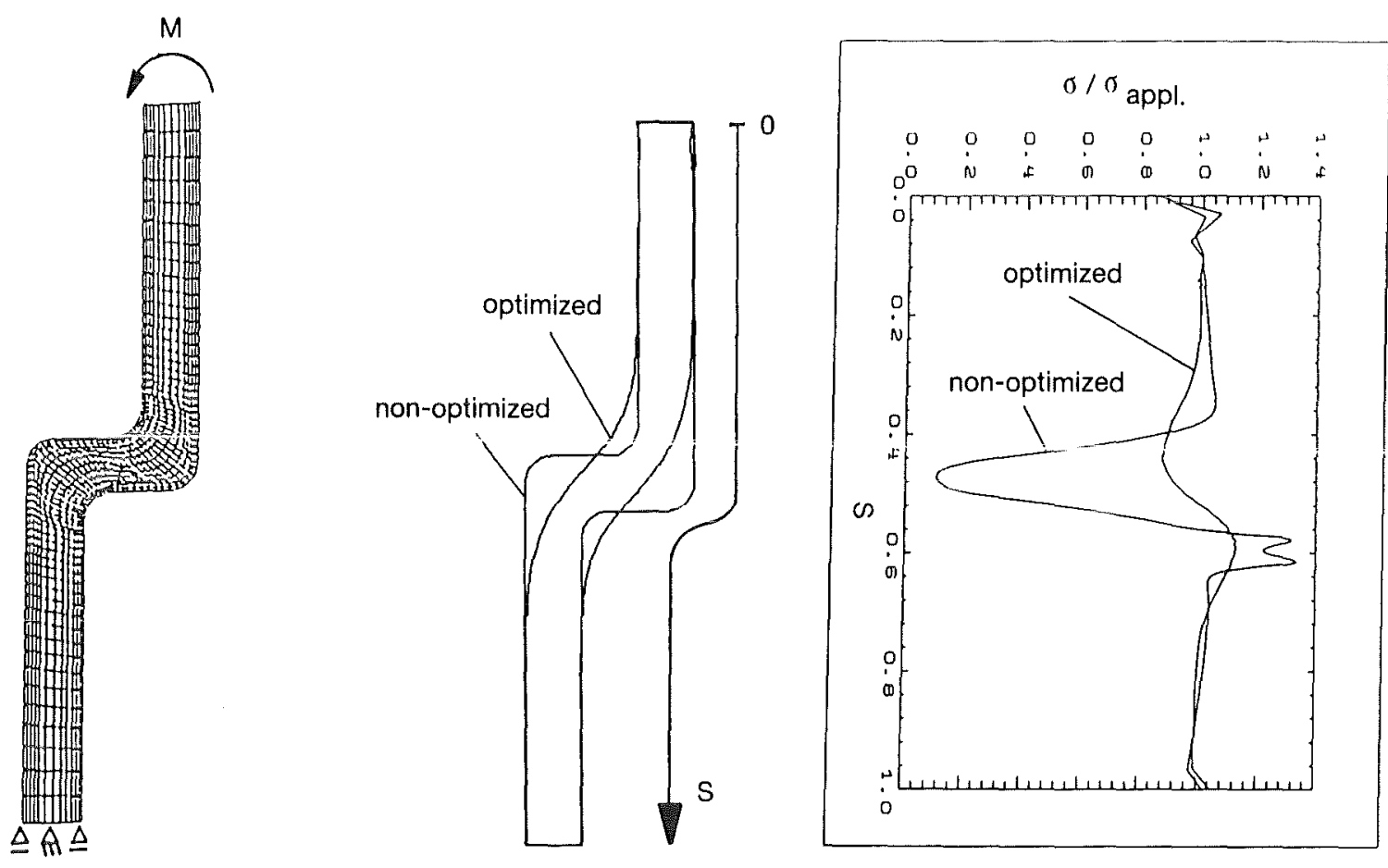

v. Mises-stress distribution
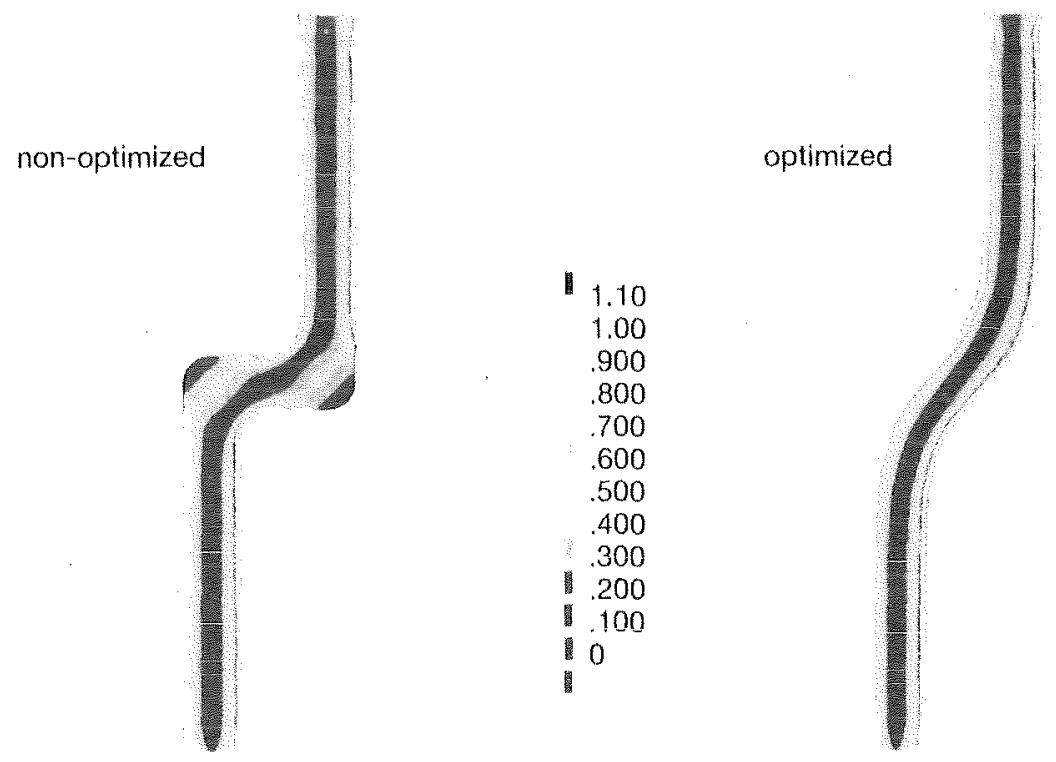

FEM: Lothar Harzheim 
Fig. 27

Bending bar with a knee loaded by a lateral end force

The design proposal was defined to be thinner at the top because of the vertical gradient of the bending moment. Again, the outermost parts of the knee shrinked leading to a smoothly curved upward narrowing optimized design of nearly constant surface stresses. 


\section{Laterally loaded strip with knee}

non-optimized
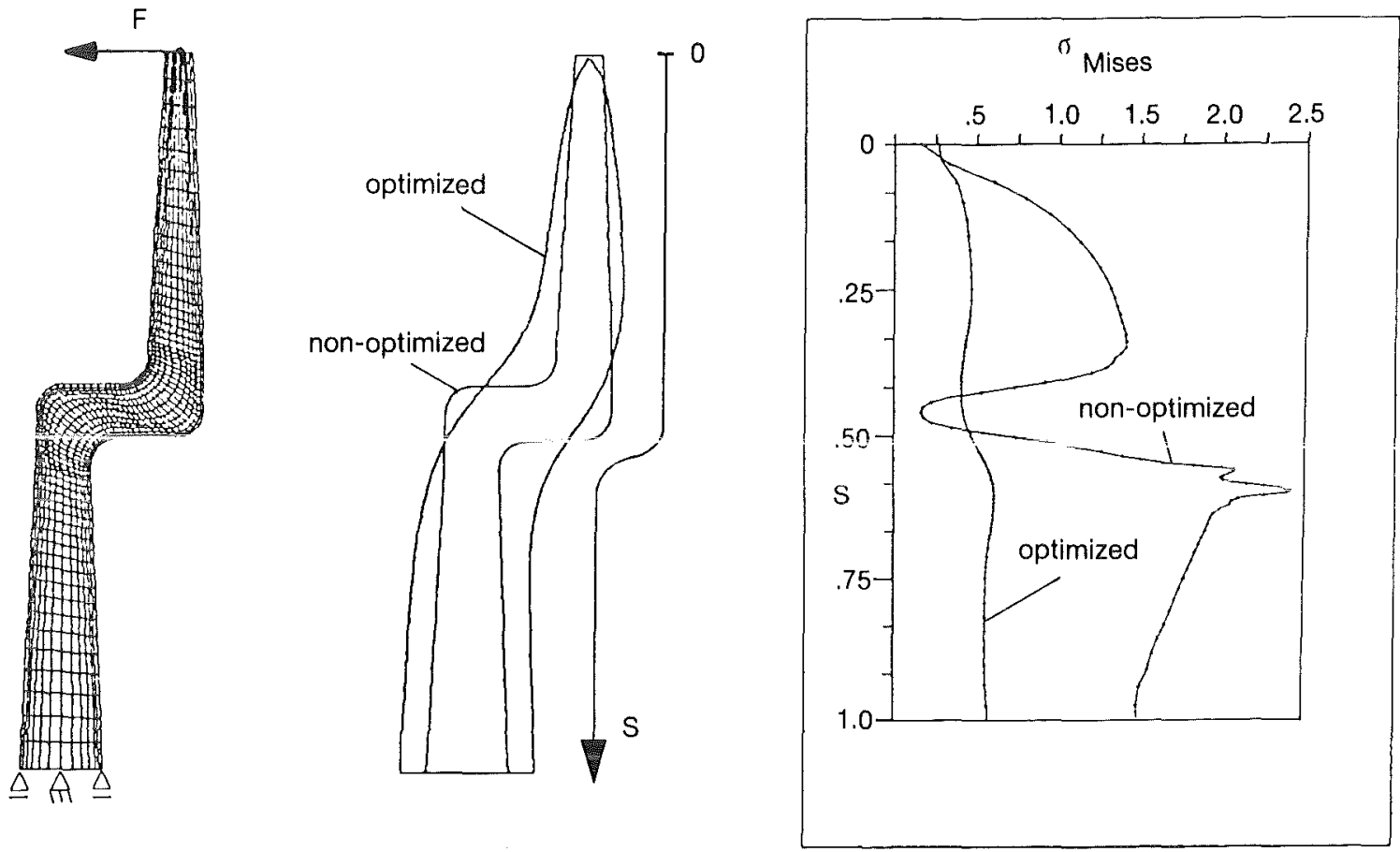

v. Mises-stress distribution
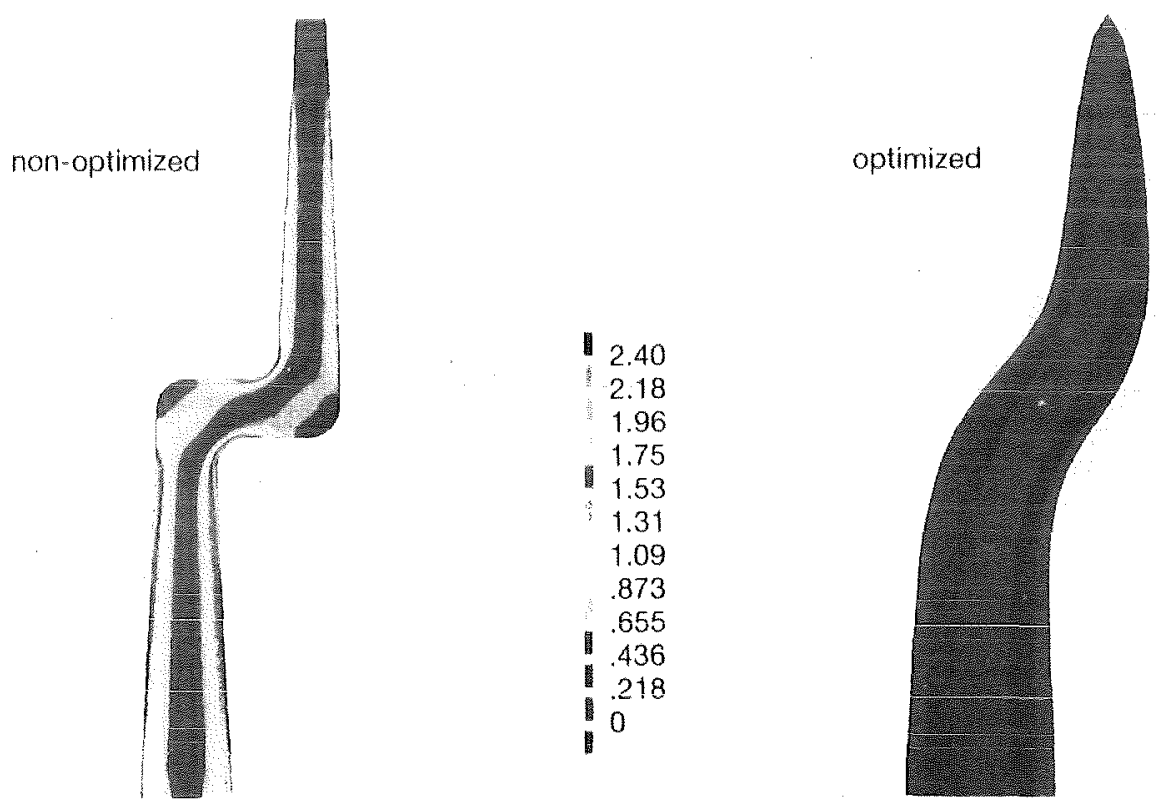

FEM: Lothar Harzheim 
Fig. 28

\section{Frame}

The quarter structure of a frame, which was designed for an autoclave, had sharp notch stresses at the circularly designed notch. The frame is partially loaded by internal pressure. In a first shape optimization the shape of the corner was improved which led to a significant notch stress reduction down to nearly 50\%. In a second step, the right part of the design was removed partially in order to reduce weight, because it was obviously not load bearing. The stress distribution remained practically unchanged by weight

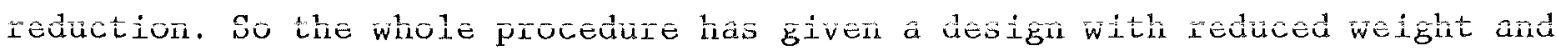
reduced notch stresses. 


\section{Frame}
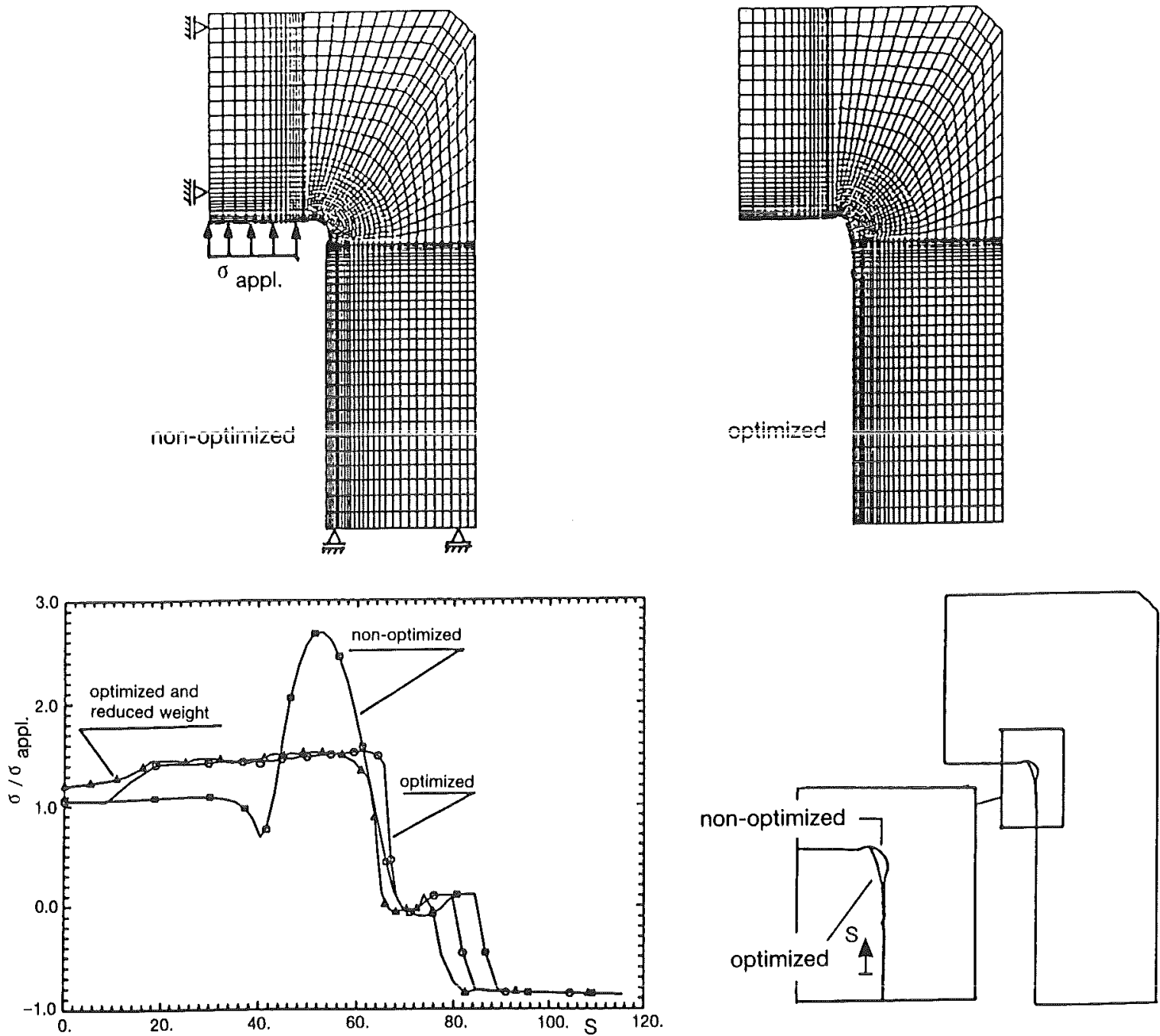

Mises-stress distribution

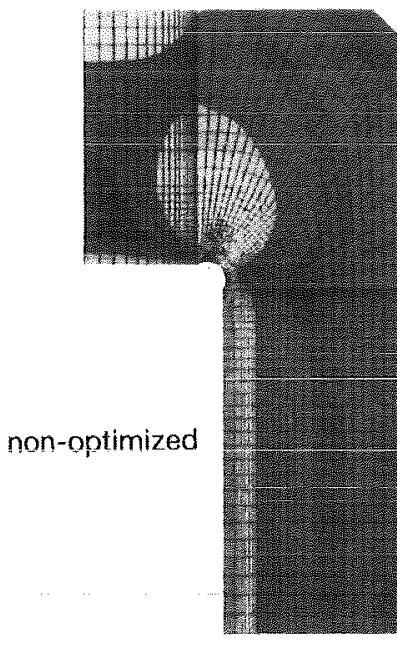

492.

459 .

427.

394.

329.

296.

264.

231

198.

optimized
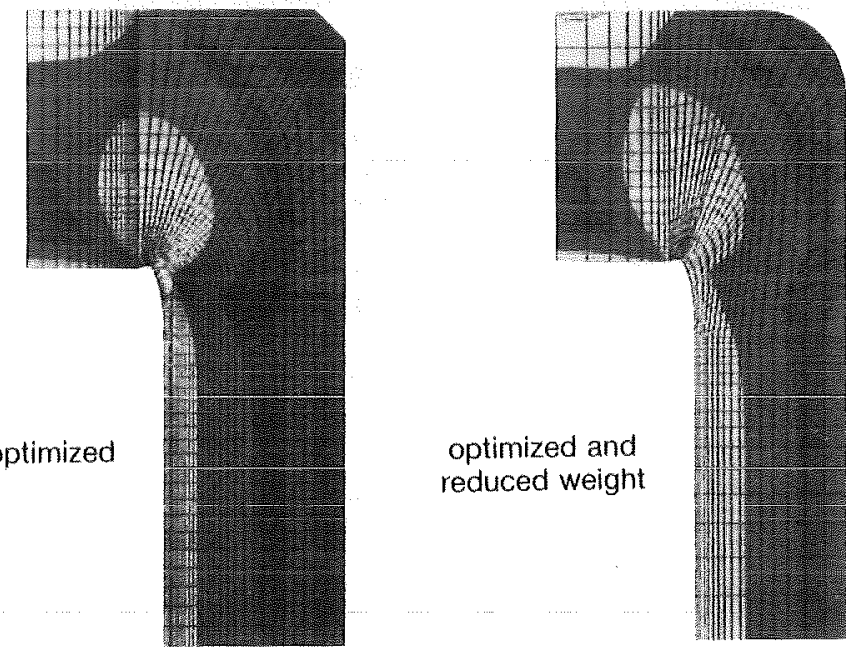

FEM: Gabriele Korseska 
Fig. 29

\section{Prosthesis surface with spikes}

Cemented prosthesis designs are being replaced at present by cementless prosthesis designs which call for a certain roughness to improve bone ingrowth in order to minimize micro-movements and loosening. However, nonoptimized roughness may be accompanied by high notch stresses. The goal was the design of well-defined roughness, where spikes are separated from each other by grooves. But, of course, grooves are notches. However, these notches have been shape optimized here to become notches not causing notch stresses which aliow good bone ingrowih and, at hile same lime avoid fátigue fáliure, because al1 notch stresses are reduced by shape optimization based on biological growth, e.g. application of CAO. 


\section{Prosthesis surface with spikes}
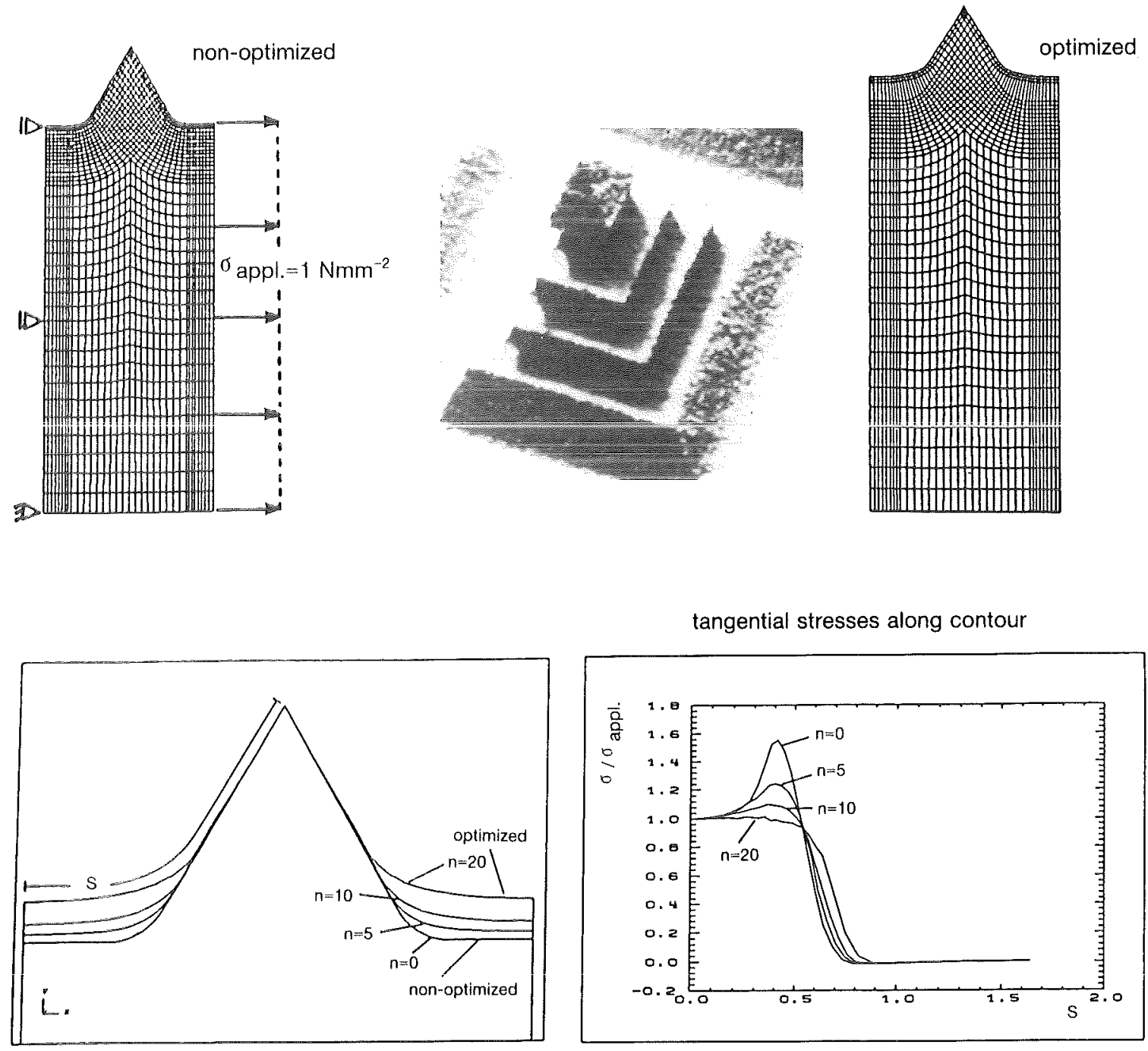

v. Mises-stress distribution
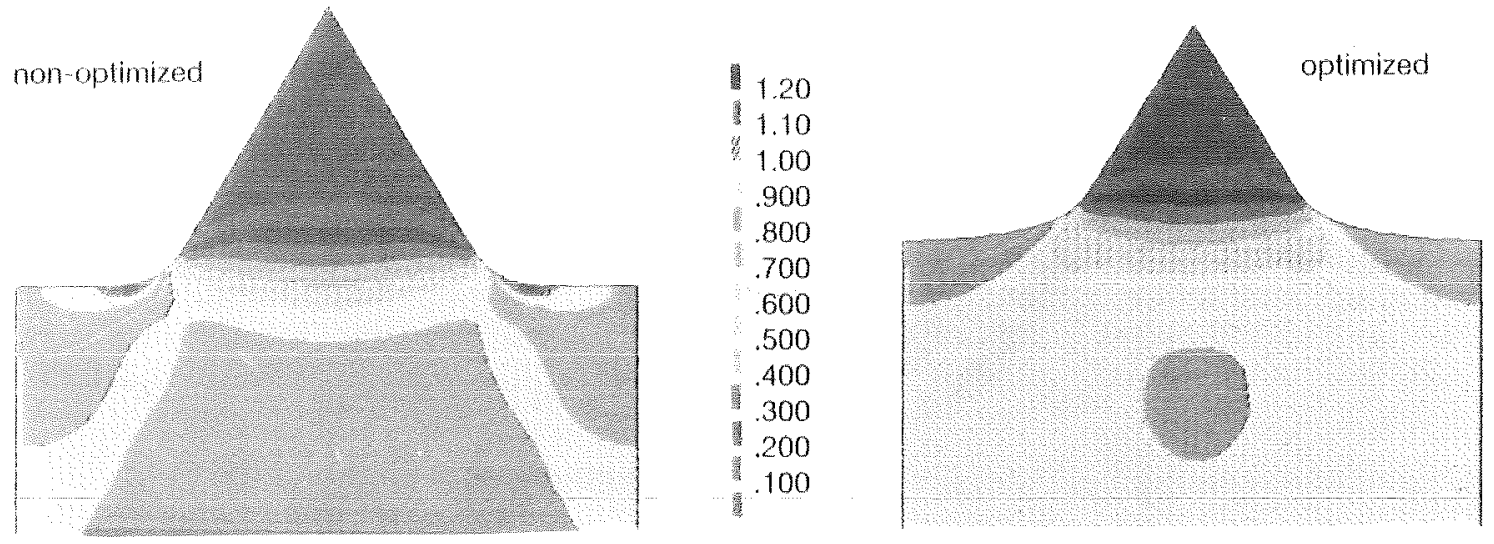

FEM: Dagmar Erb 
Fig. 30

\section{Chain link}

The traditional chain link (1) is as old as it is disadvantageous because of the magnification of wear acting, unfortunately, just at the place where the highest notch stresses are active (sketch below!). In a first approach the CAO was not used. Just the notch was separated from the wear zone giving an intermediate design (2) still having notch stresses, but they are well separated from the action of the wear zone. Afterwards, this design (2) has been improved by growth. By the way, the notch stress completely disappeared leading to design ( 3 ).

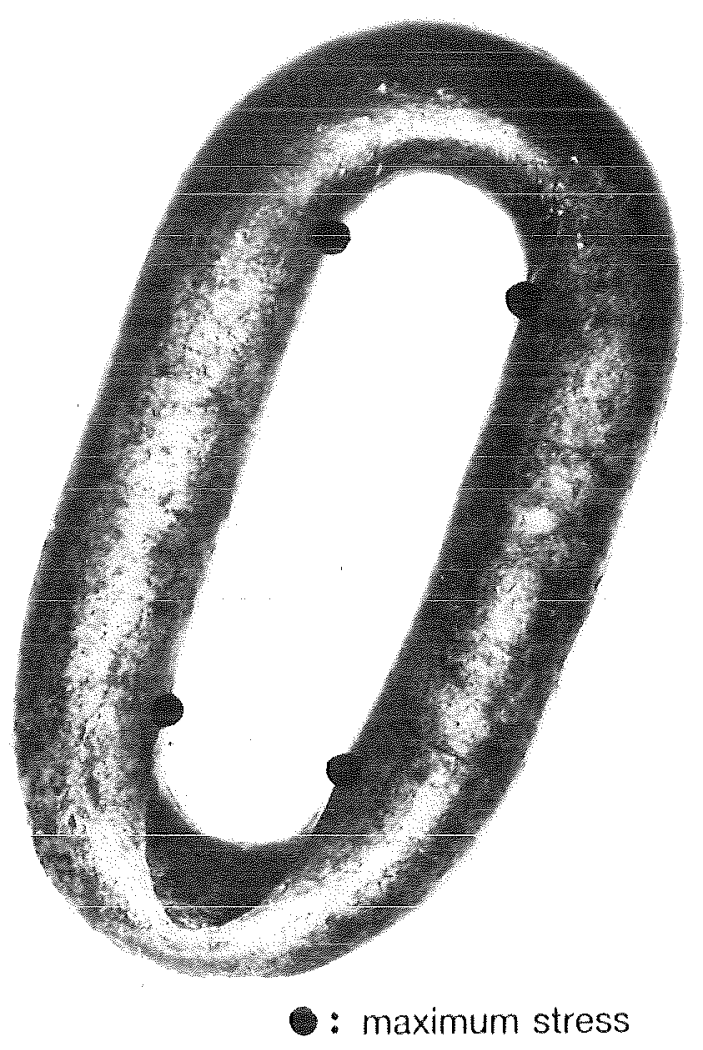




\section{Wear resistant chain link}
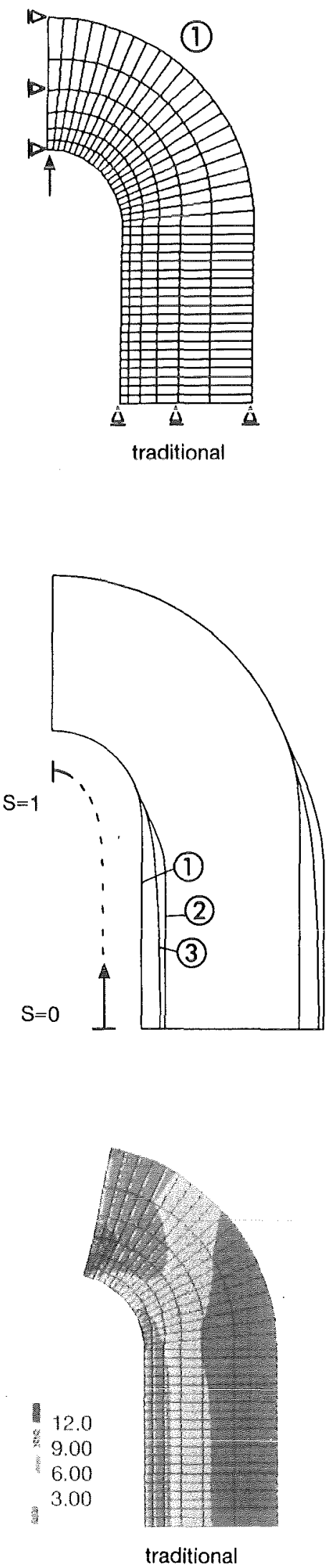

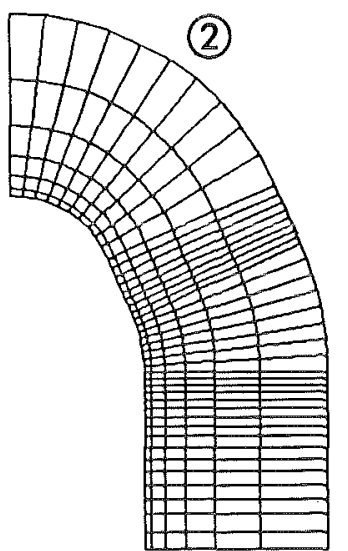

new non-optimized (notch separated from wear zone)

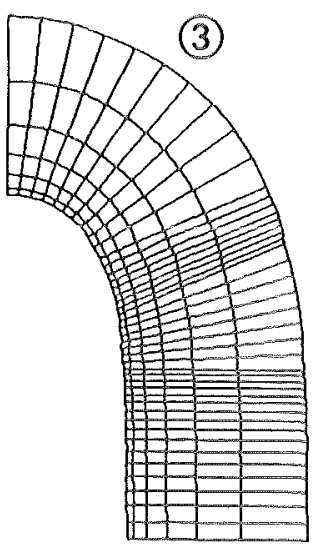

new opimized

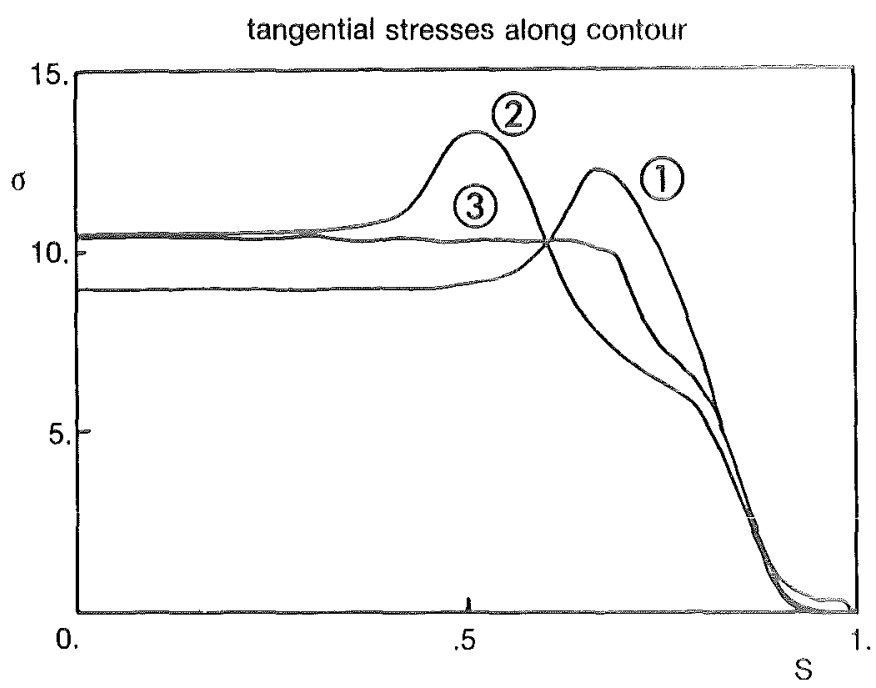

v. Mises-stress distribution

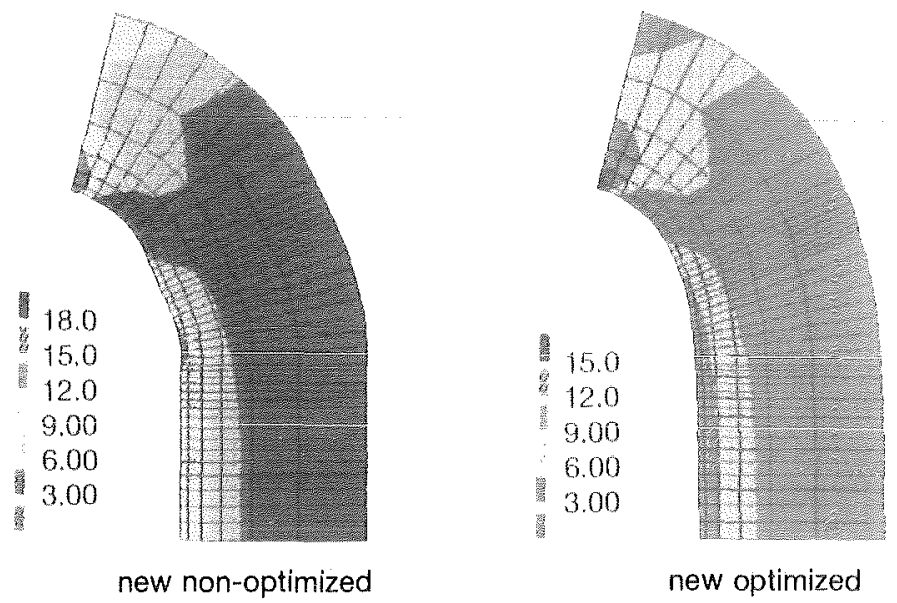

FEM: Susanne Burkhardt 
Fig. 31

\section{Crane hook}

This crane hook is loaded by hole bearing, e.g. Hertz' contact stresses inside. The increase by growth is very much limited from functional reasons, because the hook has to bear the 'shadded' cylinder. However, even this small amount of well-defined attachment of more material at the very right places reduced the notch stresses. For further improvements growth out of plane is recommened. 


\section{Crane hook (2D-model)}
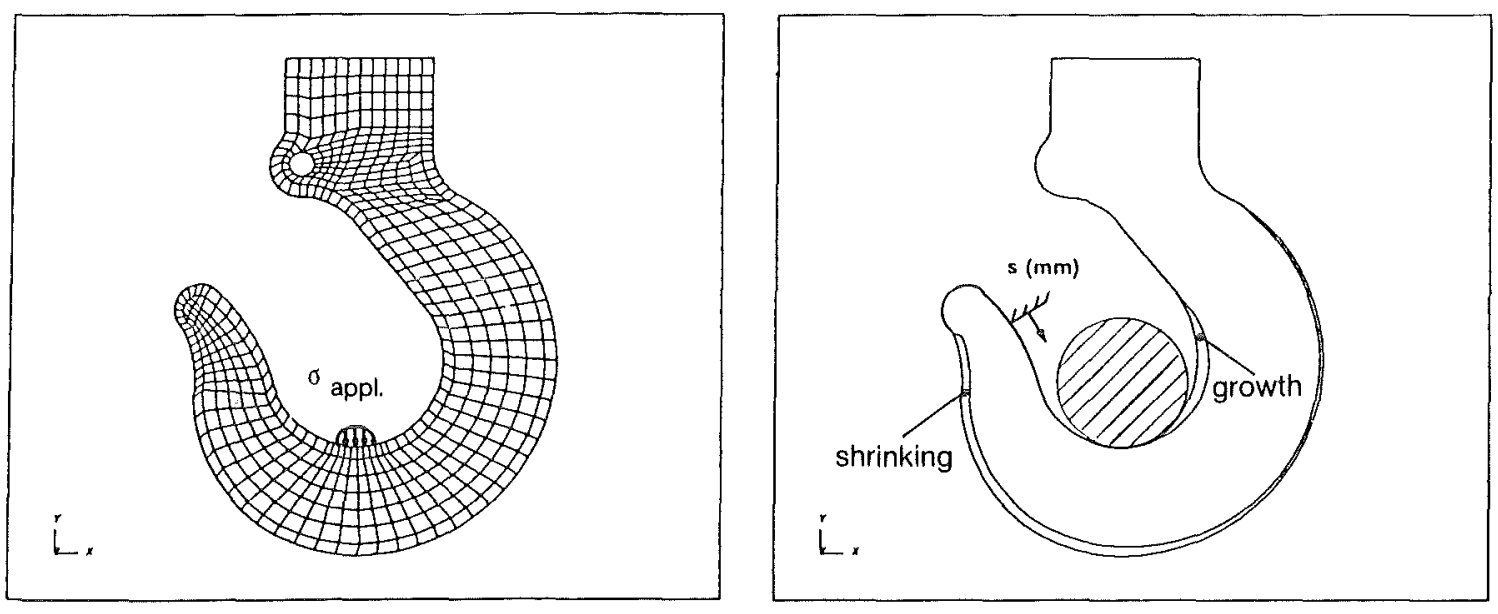

FE-structure

tangential stresses along contour

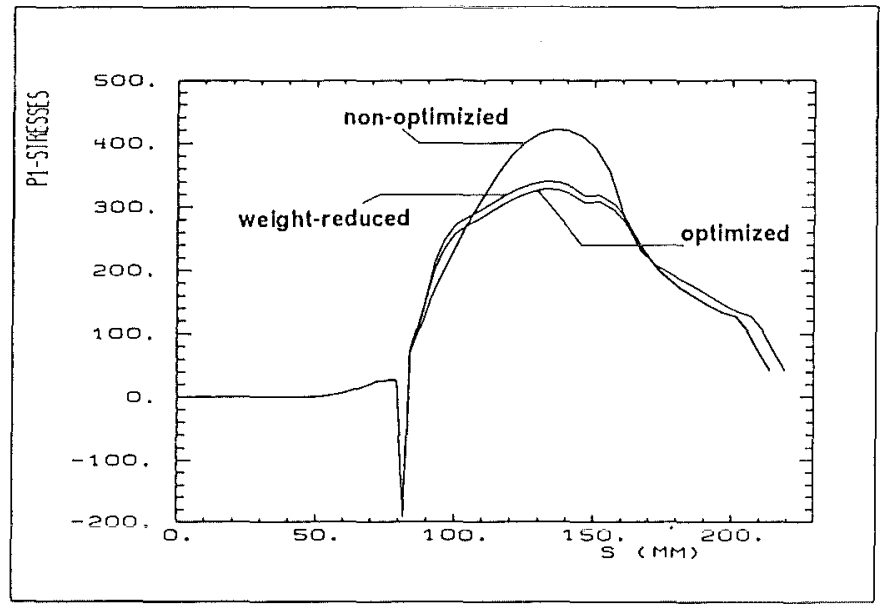

Principal stress distribution

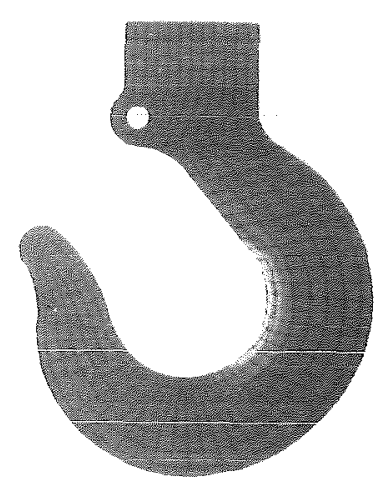

non-optimized

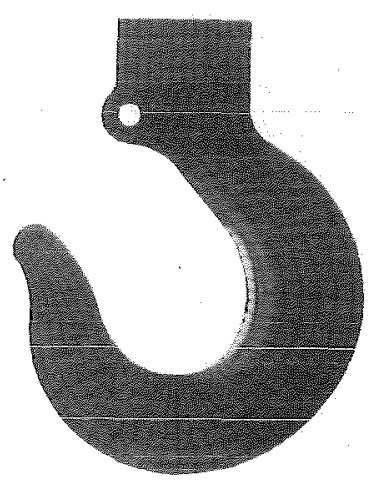

optimized

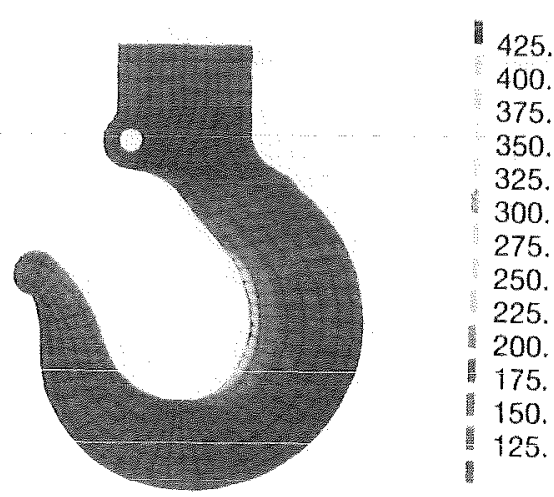

weight-reduced

FEM: Heidemarie Huber-Betzer 
Fig. 32

\section{Rubber bearing}

A rubber bearing is compressed between two conical stee1 tubes.

Due to the large deflections localized squeezing causes a folding notch which may lead to failure during the service. It is no accident that this folding notch is formed just at that place where even for small deformations a localized stress peak occurs. Therefore a linear elastic optimization was carried out to reduce this stress peak which was successful after four cycles of optimization. In a following test run with rubber elements and large displacoments no squeezing fold did occur furthormore. This shows that the squeezing fold was a consequency of the localized notch stresses which occured even for small displacements. 
non-optimized

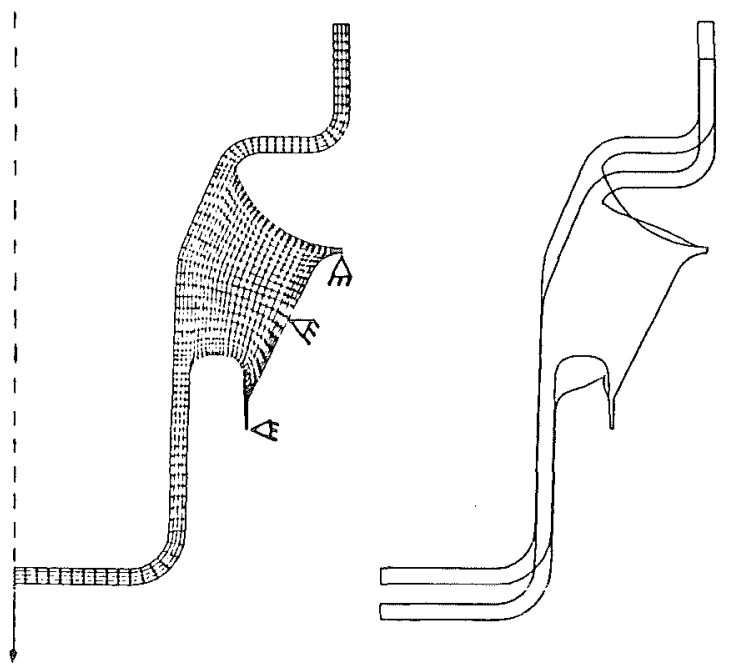

optimized

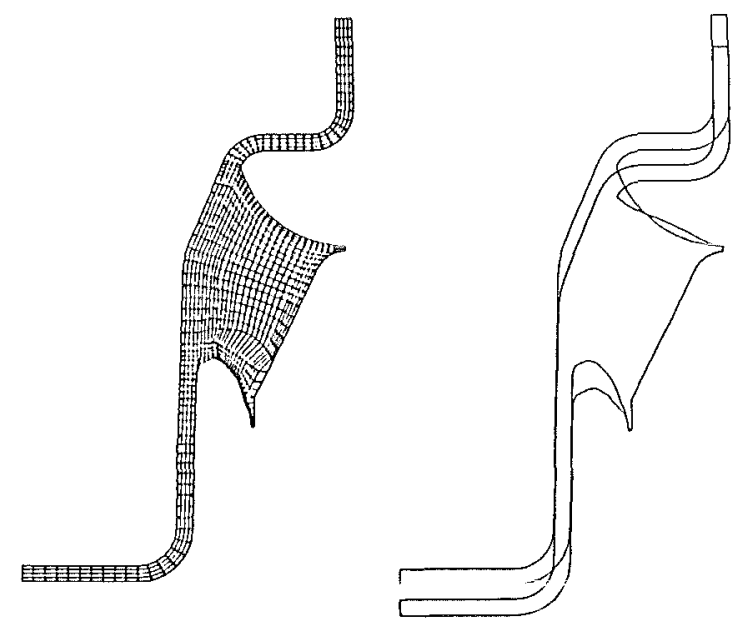

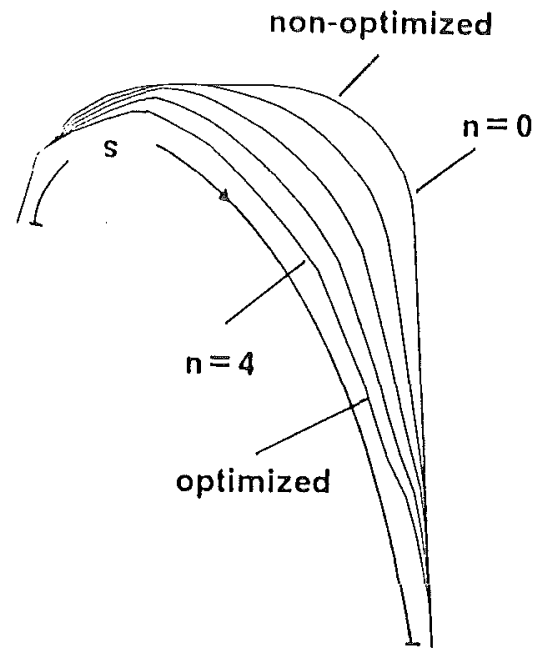

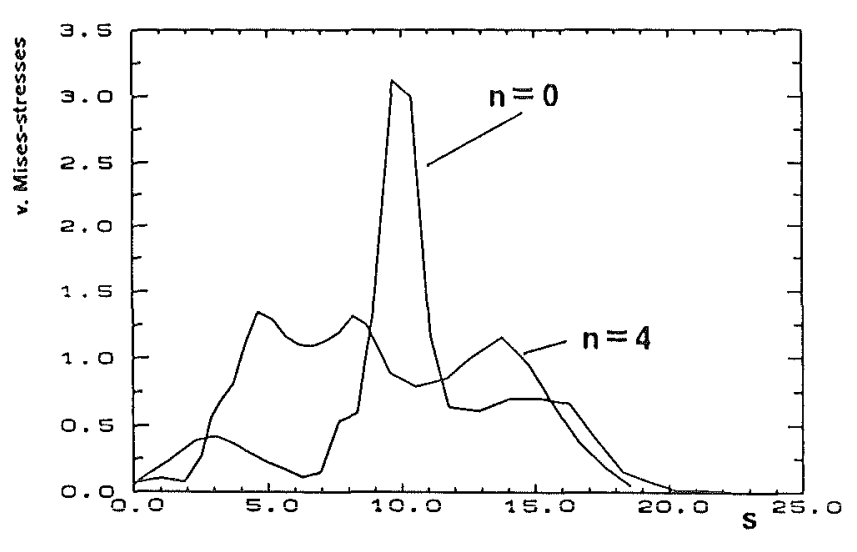

v. Mises-stress distribution
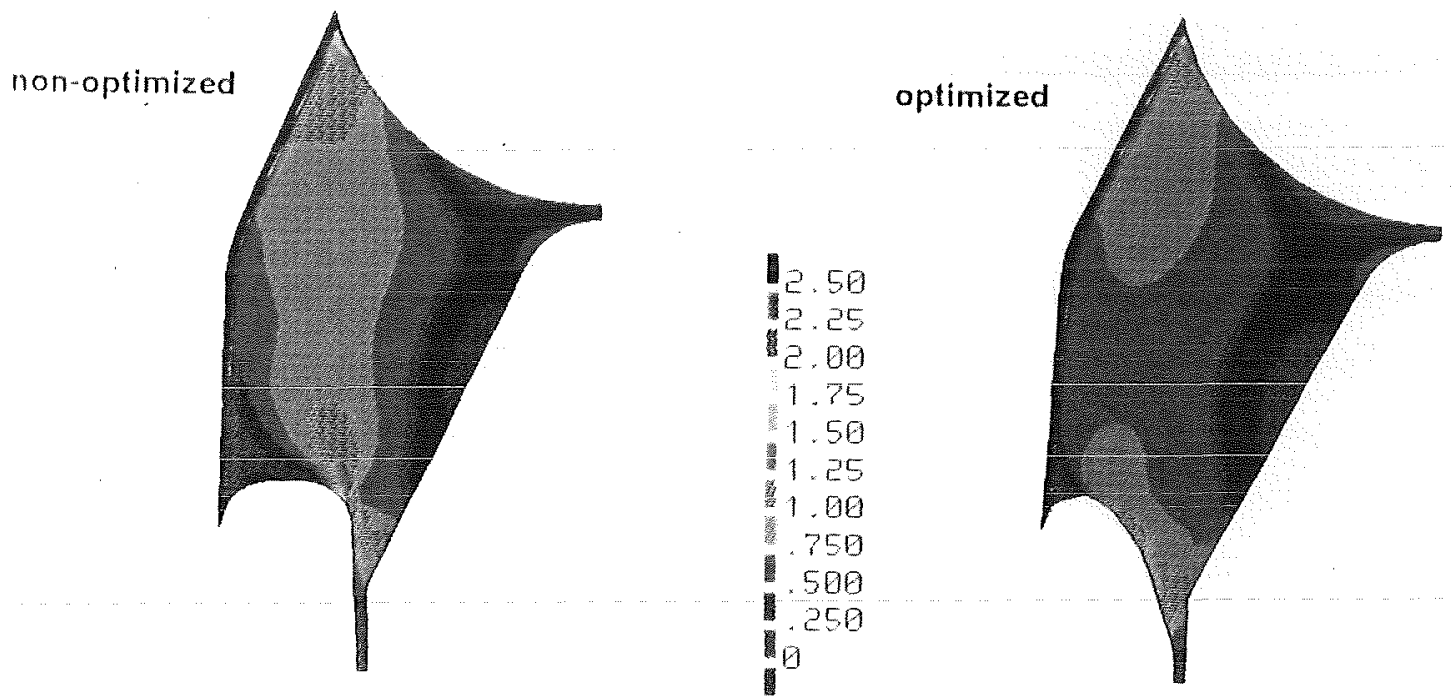

FEM: Dagmar Erb 
Fig. 33

\section{Pipe with narrowing wall thickness}

A pipe has a wall thickness which changes locally in a flat circular manner. Although the transition radius was very large there is a notch stress in this area which could be potential dangerous under service conditions.

After optimization the notch stress peak is nearly completely reduced. The example shows that even circular notches which seem to be smooth are worth the effort of structural shape optimization. 
PIPE WITH NARROWING WALL-THICKNESS
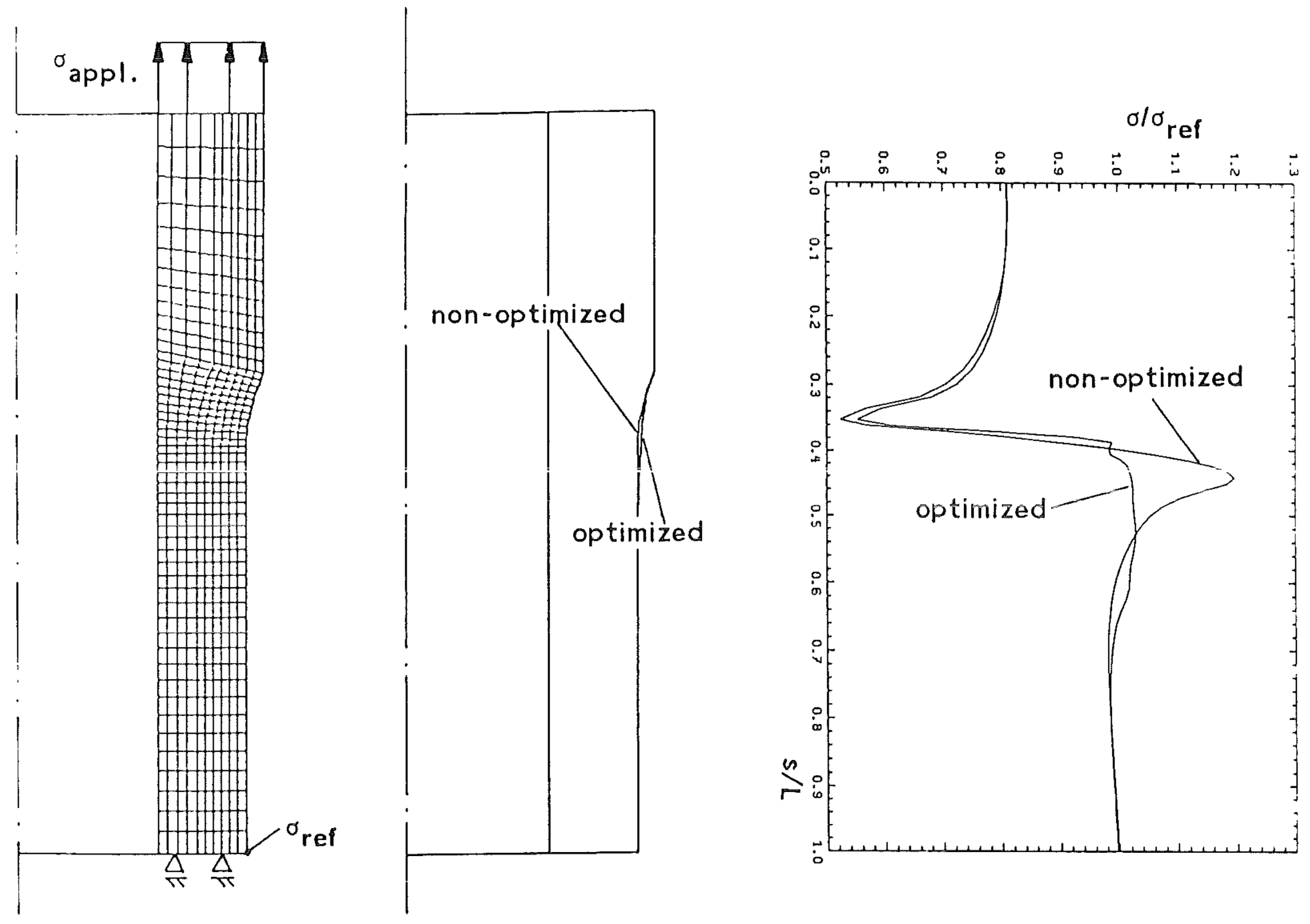

von Mises-stress distribution

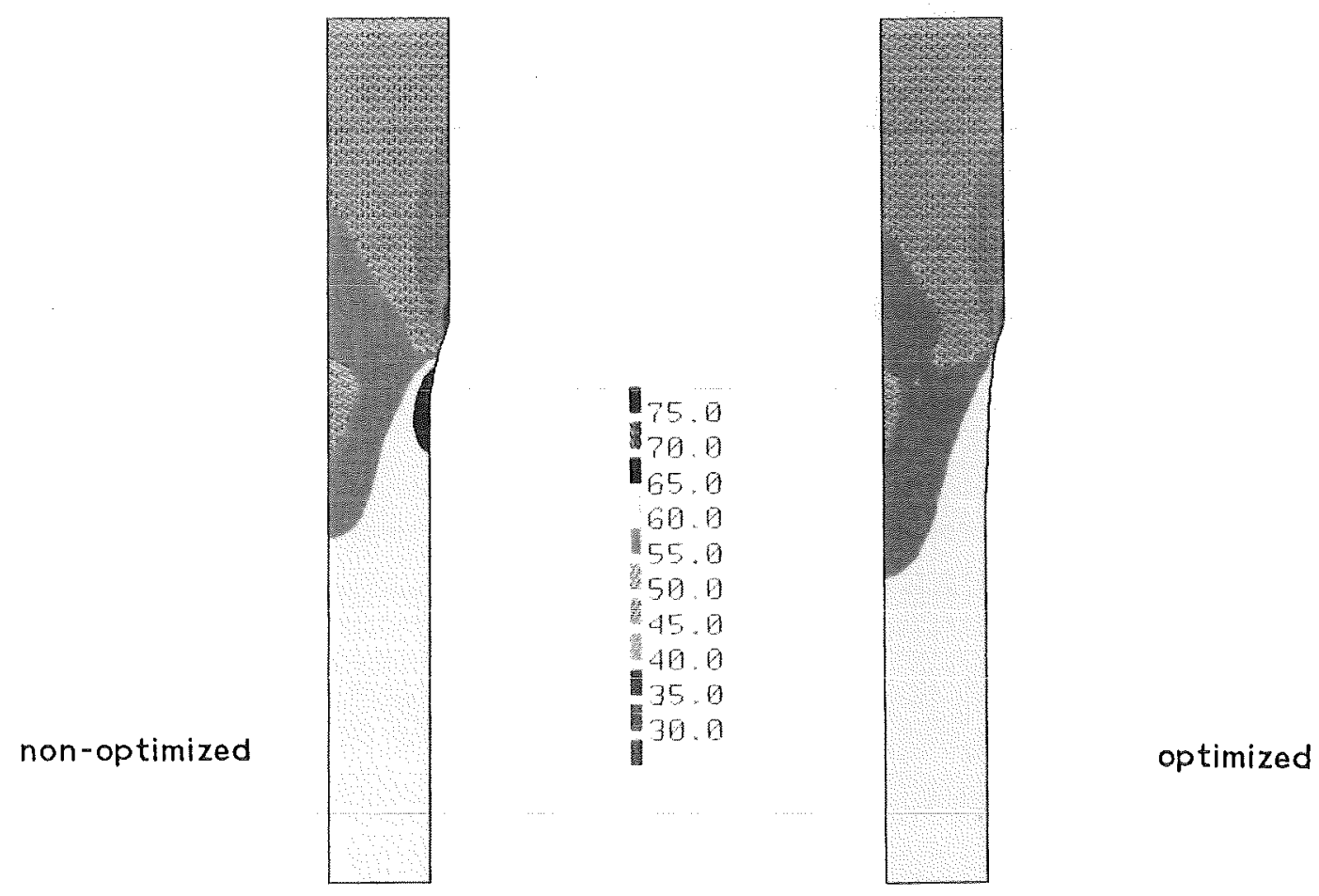

FEM: Manfred Prinz 
Fig. 34

\section{Vertebral arch}

The vertebral arch is a gate necessary for the nerves leaving the spine at this place. However, such a deep notch at a highly loaded element of the spine looks like sabotage in a first impression. Therefore it was checked how the nature has fine-tuned the shape of the notch in order to reduce notch stresses. Even a rough 2D-FEM-mode1 shows that the non-symmetric optimized shape of the vertebral arch agrees well with a photo of the real design. This illustrates that not only tree structures but a1so bony constructions can be prodicted and assessed by uso of tho CAO-method. 


\section{VERTEBRAL ARCH}

non-optimized
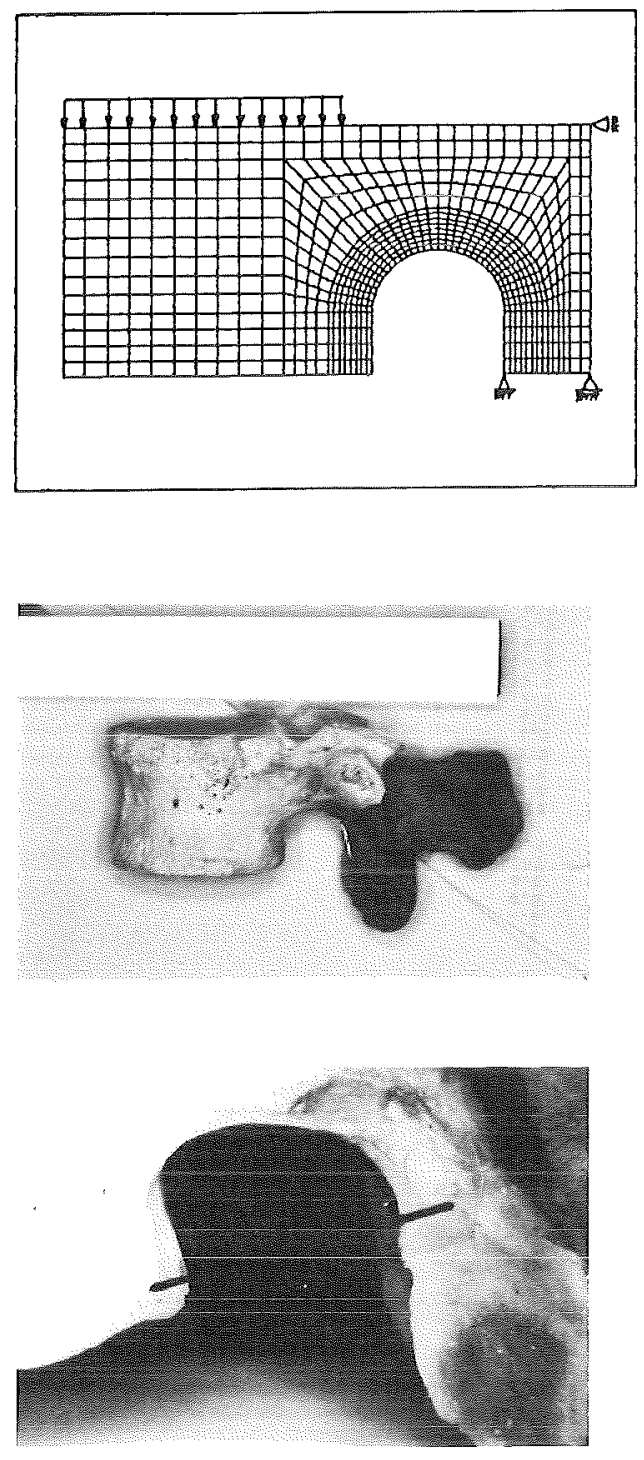

optimized

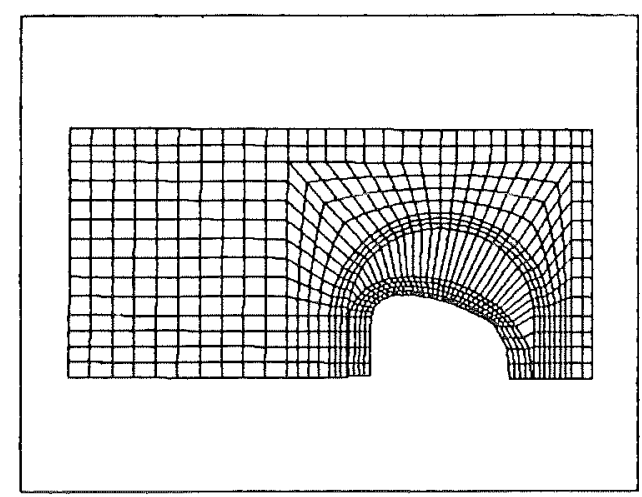

von Mises-stresses along contour

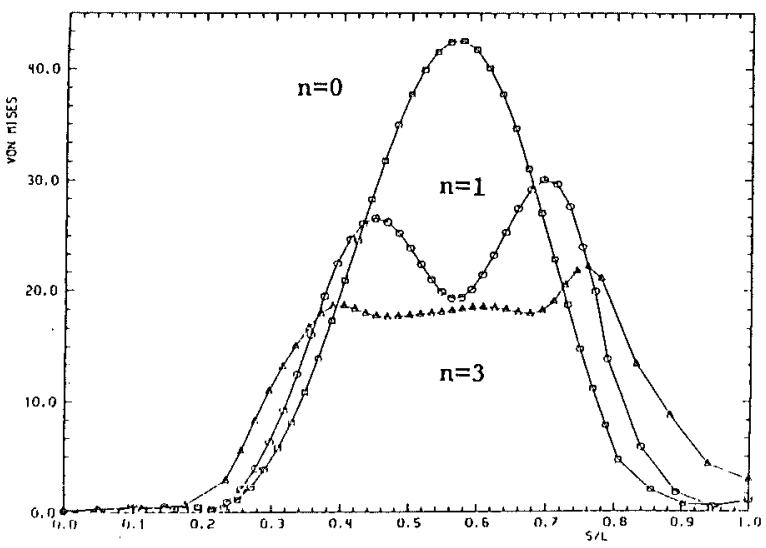

von Mises-stress distribution

non-optimized

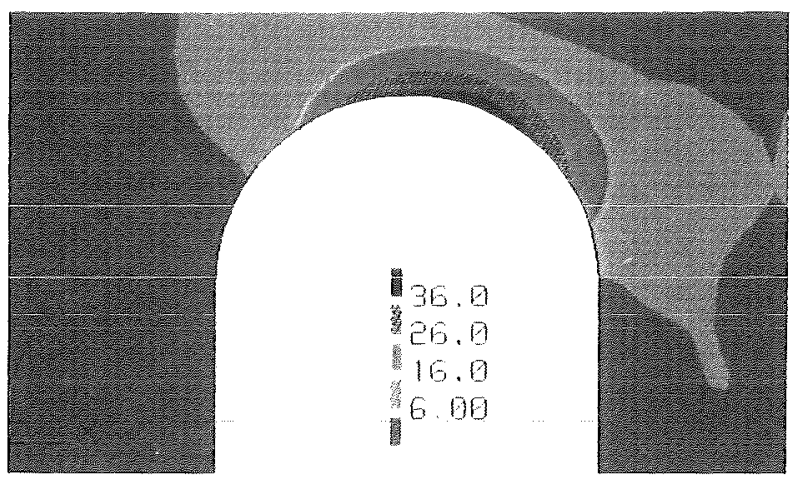

optimized

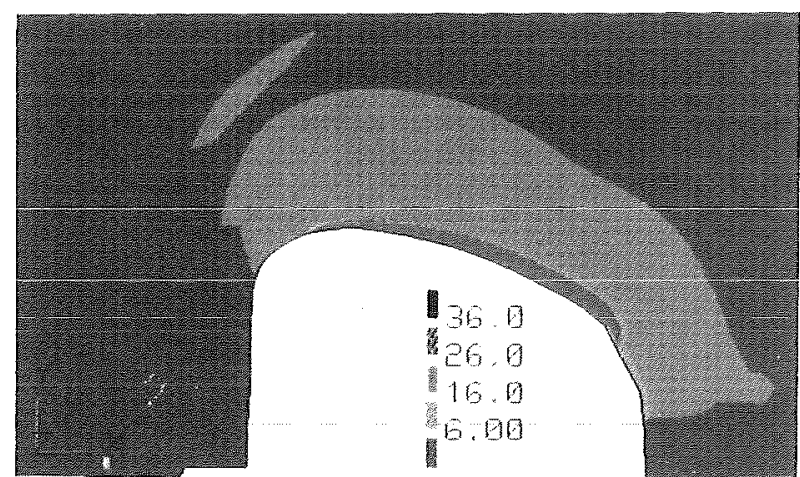


Fig. 35

\section{Triangular window cut into a tree}

Trees restorate the optimum state of homogeneous surface stress fastest at places with maximum stress peaks disturbing the optimum. This triangular wound was cut into a tree and has the highest stress peak at the left corner where fästest wound healing can be seen in both the photo and the CAO-prediction showing good agreement. 


\section{Windows cut into trees}

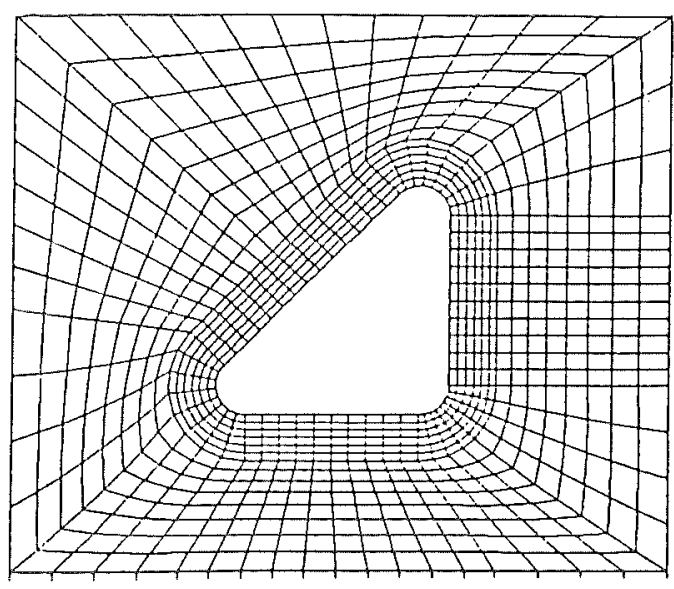

non-optimized

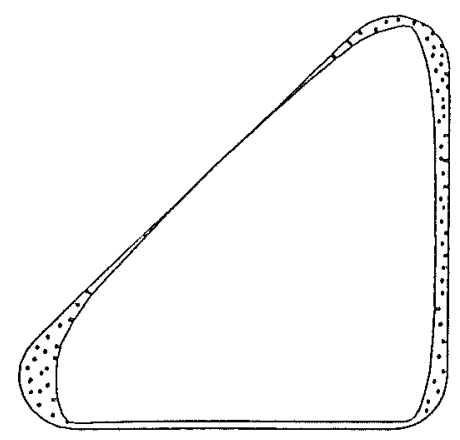

Reduction of maximum stresses $25.5 \%$

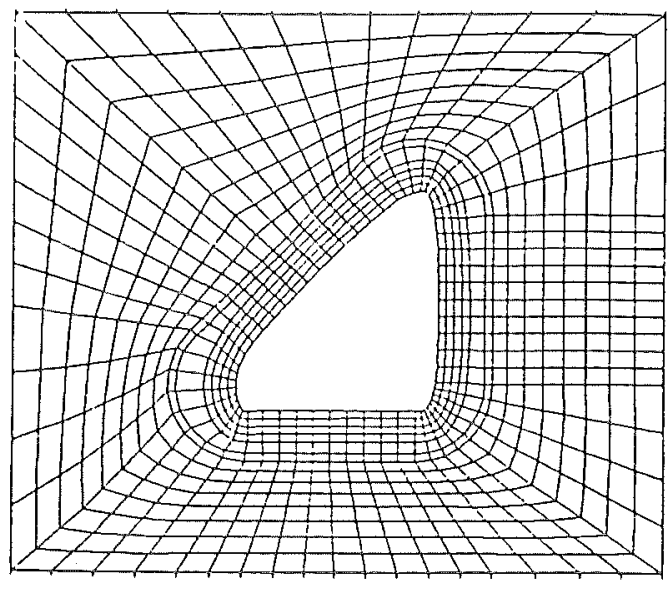

optimized

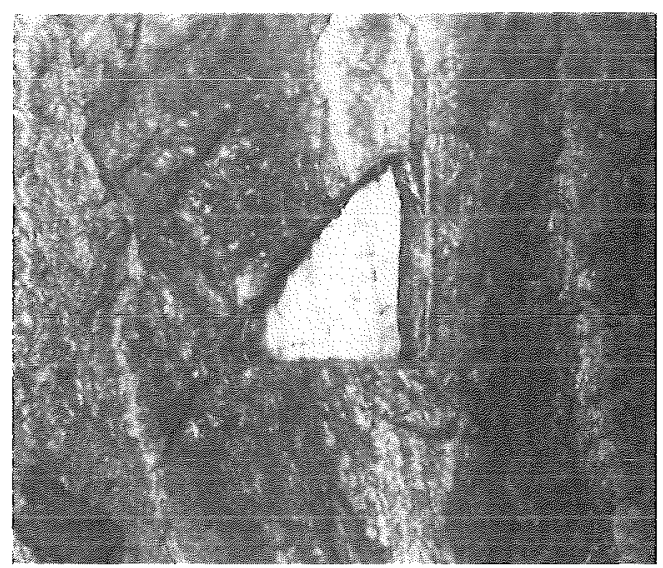

\section{v. Mises-stress distribution}

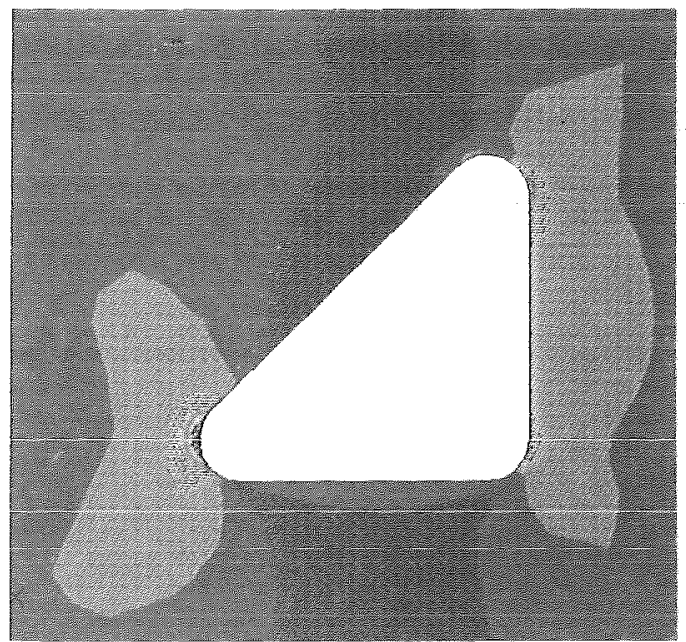

non-optimized

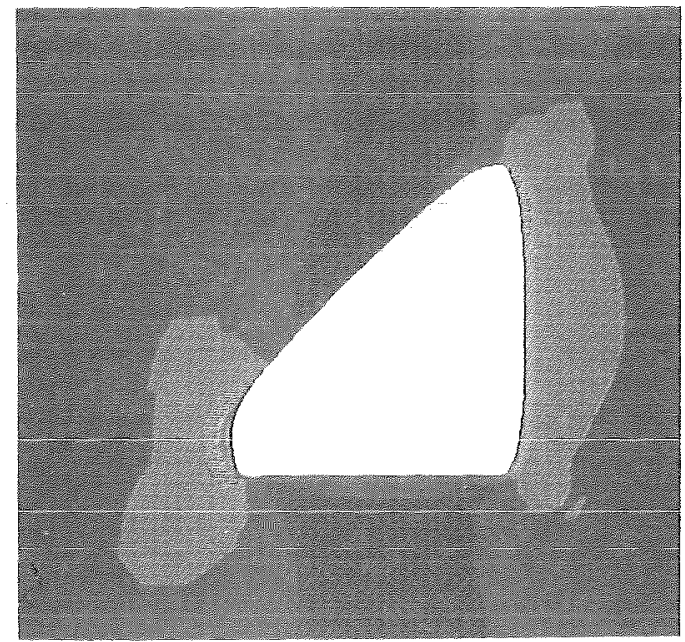

optimized 
Fig. 36

Fish-shaped window cut into a tree

Here the highest stresses are again at the left narrow notch which hea1s fastest as it can be seen as we11 at the photo as at the CA0-prediction. The main difference to the triangular window shown before is that the maximum callus formation is on the symmetry axis also at the right side of the window, whilst the triangular notch heals faster at the very top and the bottom of the right border of the wound and it heals more slowly at the middle of the right wound edge according to the stress distribution different from the fish type notch showin heie. 


\section{Windows cut into trees}

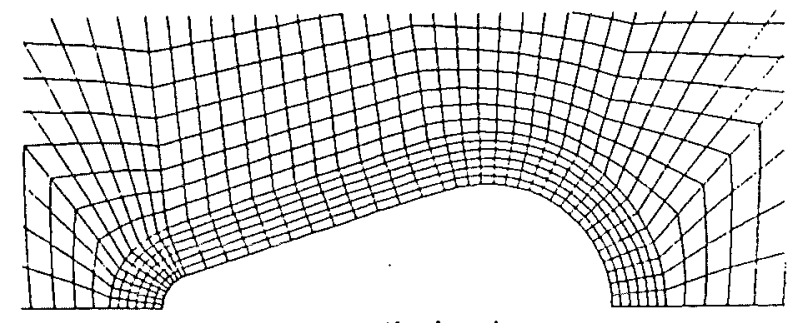

non-optimized

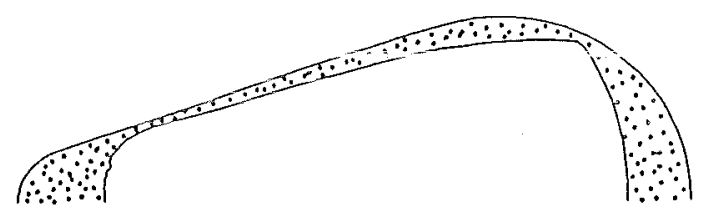

Reduction of maximum stresses $29.6 \%$

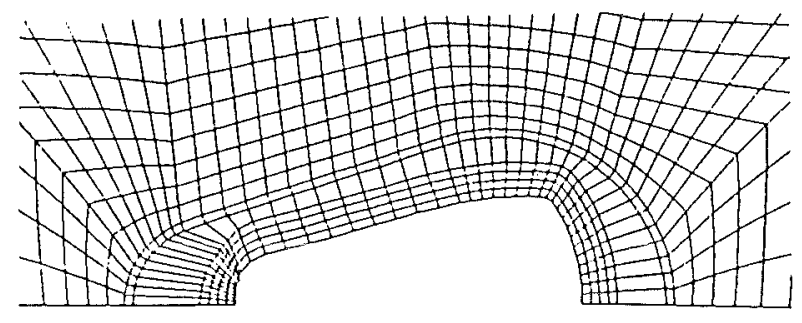

optimized

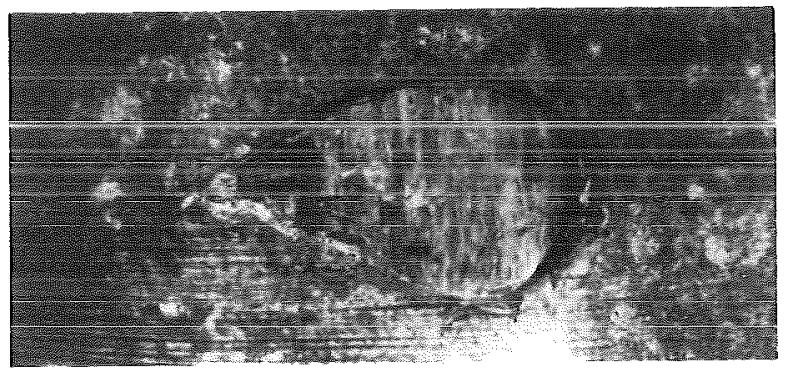

v. Mises-stress distribution

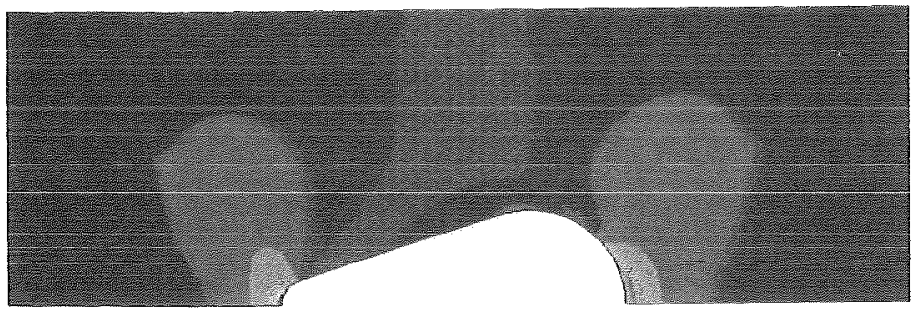

non-optimized

750

675

600

525

450

300

2ac

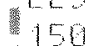

留 75

$\mathrm{a}$

optimized 